\title{
The costs and benefits of sociality in semi-free ranging Barbary macaques (Macaca sylvanus)
}

\author{
Dissertation \\ for the award of the degree \\ "Doctor of Philosophy" (Ph.D.) \\ Division of Mathematics and Natural Sciences \\ of the Georg-August-Universität Göttingen
}

within the doctoral program Behaviour and Cognition (BeCog) of the Georg-August University School of Science (GAUSS)

\author{
Submitted by \\ Nadine Müller \\ from Roth, Germany
}





\section{Thesis Committee}

Prof. Dr. Julia Ostner

Behavioural Ecology, Georg-August-Universität, Göttingen \& Primate Social

Evolution, German Primate Centre, Leibniz Institute for Primate Research, Göttingen

PD. Dr. Oliver Schülke

Georg-August-Universität, Göttingen \& Primate Social Evolution, German Primate Centre, Leibniz Institute for Primate Research, Göttingen

Prof. Dr. Lars Penke

Biological Personality Psychology, Georg-August-Universität, Göttingen

\section{Members of the Examination Board}

Reviewer:

Prof. Dr. Julia Ostner

Second Reviewer:

PD. Dr. Oliver Schülke

\section{Further members of the Examination Board}

Prof. Dr. Lars Penke, Biological Personality Psychology, Georg-AugustUniversität, Göttingen

Prof. Dr. Peter Kappeler, Behavioural Ecology and Sociobiology Unit, German Primate Centre, Leibniz Institute for Primate Research, Göttingen

Prof. Dr. Eckhard W. Heymann, Behavioural Ecology and Sociobiology Unit, German Primate Centre, Leibniz Institute for Primate Research, Göttingen

Dr. Christian Roos, Primate Genetics Laboratory, German Primate Centre, Leibniz Institute for Primate Research, Göttingen 



\section{Dedication}

To my family, who gave me roots to grow.

To my friends who, helped me reach out to the skies.

To the wind beneath my wings.

To this wonderful earth for all its wonders, who gave me dreams, and made me start chasing them.

To all the companions, fellow follower of monkeys and kindred spirits, to wings we grew, learning and understanding and growing together.

To all those amazing moments and memories.

To making the world a little better every day, and those who inspire me to try! And most of all: To the future and all the wonderful things yet to come! 



\section{Table of contents}

Summary.......

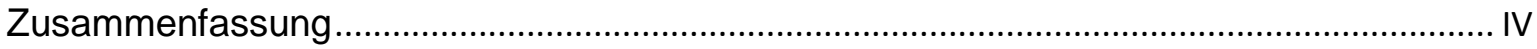

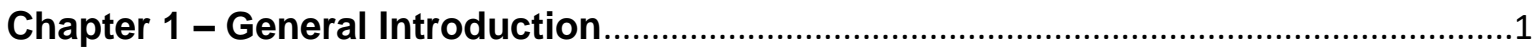

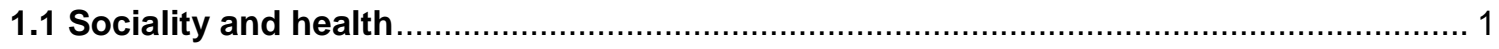

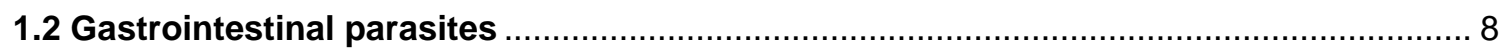

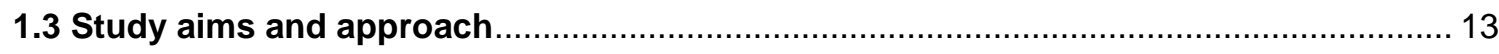

Chapter 2 - Age, but not anthelmintic treatment, is associated with ........................ 20 urinary neopterin levels in semi-free ranging Barbary macaques.

Nadine Müller, Michael Heistermann, Christina Strube, Oliver Schülke \& Julia Ostner

Chapter 3 - Physiological and social consequences

of gastrointestinal nematode infection in a nonhuman primate

Nadine Müller-Klein, Michael Heistermann, Christina Strube, Zina Morbach, Navina Lilie,

Mathias Franz, Oliver Schülke \& Julia Ostner

Chapter 4 - Exposure and susceptibility drive reinfection

with gastrointestinal parasites in a social primate

Nadine Müller-Klein, Michael Heistermann, Christina Strube, Mathias Franz,

Oliver Schülke \& Julia Ostner.

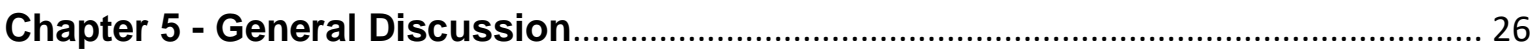

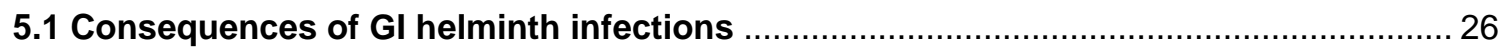

5.2 GI helminth transmission: Determinants of exposure ….......................................... 32

5.3 GI helminth transmission: Determinants of susceptibility …….................................. 33

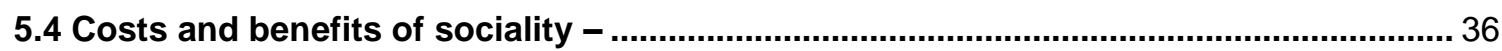

or: how to not get cut by sociality's double-edged sword

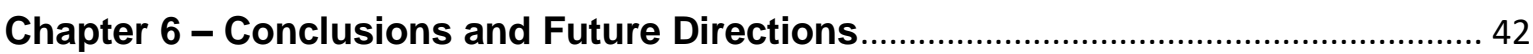

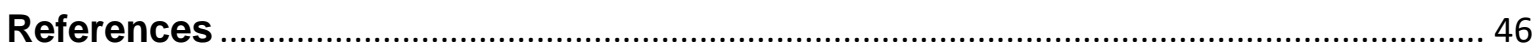

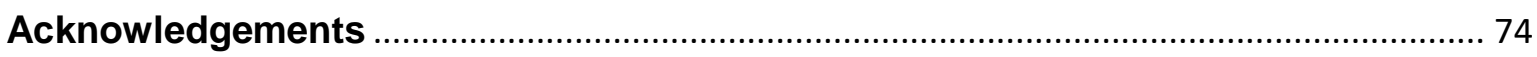

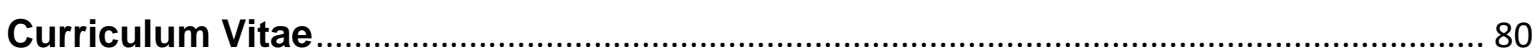

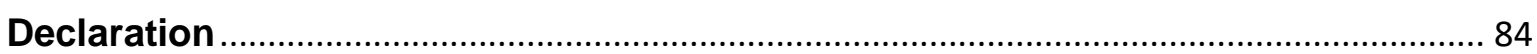




\section{Summary}

Parasite infections are ubiquitous throughout the animal kingdom, and increased risk of parasite transmission has been suggested as one of the major costs of group living. With bigger group size and higher interaction frequencies, transmission is expected to increase due to higher pathogen exposure. In contrast, social integration and close affiliative relationships are known predictors of increased health, longevity and reproductive success in social animals. Sociality is thus hypothesized to offer fitness benefits by improving health, including reduced susceptibility to infectious diseases. The underlying mechanisms mediating the health benefits of social interactions are still largely unclear, particularly in wildlife. Recent methodological and theoretical advances in the fields of disease ecology and eco-immunology make studying the links between host sociality and parasites more feasible. Consequently, understanding host-parasite dynamics and the role of sociality for health has received increasing attention in behavioural ecology and evolutionary biology.

Gastrointestinal (GI) helminths are a powerful tool to study the links between sociality and health, as they can be assessed noninvasively. However, host-parasite interactions are complex and can function as feedback loops: parasites alter their host's physiology and behaviour, which in turn predict exposure and susceptibility to parasite infection. Often the directionality of the links between host behaviour, sociality and physiology and infection isn't clear due to the correlational nature of conducted studies. Additionally, host behaviour can contribute to both exposure and susceptibility simultaneously and both factors can be intertwined, so understanding the role of sociality for parasite transmission is challenging.

In this thesis I investigate the host-parasite dynamic between GI helminth infections and a social primate, the Barbary macaque (Macaca sylvanus), aiming at understanding the causes and consequences of GI helminth infection. Capitalizing on strongyle nematode clearance by routine anthelmintic treatment in a semi-free ranging population, I can take a step beyond correlational studies and draw more causal inferences about the direction of host-parasite interactions, placing a special focus on social behaviour. I combine behavioural observation data ( 3500 hours) with analyses of molecular markers of immune regulation (urinary neopterin, uNEO), physical condition (urinary C-peptide, $\mathrm{uCP}$ ) and hypothalamic-pituitary-adrenal (HPA) axis activation and parasite status assessment. This enables me to assess the consequences of parasite clearance and investigate the predictors of reinfection with GI helminths. To account for uncertainty of noninvasively assessed parasite status, I use patch occupancy modelling to estimate infection probabilities and individual reinfection risk. I test whether infection-related behavioural changes are attributable to sickness behaviour or avoidance of infected conspecifics to extrapolate the impact of GI helminth infections on social behaviour and potentially evolution. With regard to parasite transmission, I test whether grooming predicts reinfection risk, indicating transmission due to social contact. 
Strongyle nematode infections, mostly caused by Oesophagostomum spp., were ubiquitous within the study population, with generally low egg shedding and large inter-individual variation in reinfection risk. Infections did not cause overt symptoms or affect physical condition. They nonetheless elicited sickness behaviour responses, namely increased HPA axis activation in combination with reduced activity. Anthelmintic treatment did not alter uNEO levels, but uNEO increased with age, implying immunosenescence. As coinfections with further GI helminths occurred mostly in old individuals, immunosenescence might influence an individual's ability to cope with GI helminth infections in general. Individual frequency to initiate proximity to others was not predicted by an individual's, but by the potential partner's infection status, indicating avoidance of infected individuals.

Reinfection was predicted by measures of both susceptibility and exposure. The strongest predictor of earlier reinfection was coinfection with further GI helminth taxa. I found no evidence for HPA axis activation and immune function as strong predictors of reinfection. Being in good physical condition tended to increase reinfection risk, indicating the presence of parasite tolerance strategies in Barbary macaques. Time spent in areas likely contaminated with faeces, a measure of exposure to infective parasite stages, emerged as a predictor of increased infection risk, confirming the direct environmental transmission route of strongyle nematodes. High social bond strength with opposite sex partners decreased reinfection probability, probably due to reduced susceptibility resulting from immunomodulatory effects of affiliative interactions. In contrast, grooming a high number of partners and strong bonds with same sex partners emerged as predictors of increased infection probability, implying a social component of transmission. Social interactions can thus have an ambivalent effect, contributing to both protection from and increased risk of GI helminth infections. The discrepancy between same and opposite sex bond effects is likely attributable to differences in interaction patterns, resulting in different relative contributions of same and opposite sex bonds to exposure and susceptibility.

In conclusion, the results suggest that GI parasite infections can influence social behaviour in nonhuman primates. Given the dual role of social interactions for GI helminth transmission, a possible strategy to maximize benefits while limiting costs of sociality could be selective formation of strong bonds with a small number of partners, with the caveat that particular interaction patterns might be more beneficial than others. My results lead to a range of questions which need to be addressed by future research, particularly whether primates mitigate costs of infection by employing tolerance strategies. Causally linking components of social behaviour to exposure and susceptibility will be important for understanding individual variation in infection risk and contribution to transmission through a population. Investigating whether variation in responses to GI helminth infections predict long-term health and fitness outcomes will be vital to assess the impact of hostparasite dynamics on behaviour and potentially host social evolution. 


\section{Zusammenfassung}

Infektionen mit Parasiten sind im Tierreich allgegenwärtig, und ein erhöhtes Risiko für Parasitenübertragung gilt als einer der größten Nachteile des Gruppenlebens. Mit zunehmender Gruppengröße und Anzahl an Interaktionen sollte es zu häufigeren Kontakten mit Krankheitserregern und damit zu vermehrter Krankheitsübertragung kommen. Im Gegensatz dazu tragen soziale Integration und enge affiliative Beziehungen bei sozial lebenden Tierarten zu besserem Gesundheitszustand, höherer Lebenserwartung und höherem Reproduktionserfolg bei. Es wird daher angenommen, dass durch soziale Interaktionen positive Einflüsse auf die Gesundheit, unter anderem niedrigere Anfälligkeit für Krankheiten, entstehen, die zu Fitnessvorteilen führen. Besonders bei wildlebenden Tieren sind die Mechanismen, über die Sozialverhalten zu Gesundheitsvorteilen führt, noch weitestgehend unbekannt. Jüngste methodologische und theoretische Fortschritte auf den Gebieten der Krankheitsökologie und Öko-Immunologie erleichtern die Erforschung der Verbindungen zwischen Parasiten und dem Sozialverhalten des Wirts. Somit rückt die Erforschung der Dynamik zwischen Wirtstieren und Parasiten und die verbindung zwischen Sozialverhalten und Gesundheit zunehmend auch in den Fokus der Verhaltensökologie und Evolutionsbiologie.

Gastrointestinale Parasiten sind ein vielversprechendes System, um die Zusammenhänge zwischen Sozialverhalten und Gesundheit zu untersuchen, da sie nicht-invasiv analysiert werden können. Allerdings sind Wirt-Parasitenbeziehungen komplex und beinhalten oft Rückkopplungsschleifen: Während Infektionen mit Parasiten das Verhalten des Wirtes beeinflussen, bestimmen Verhalten und Physiologie des Wirtes Kontaktraten mit Krankheitserregern und Anfälligkeit für Infektionen. Da zumeist Korrelationsstudien vorliegen, sind die kausalen Zusammenhänge zwischen den Interaktionen von Wirtsverhalten, Physiologie und Parasiteninfektionen weitestgehend unbekannt. Zusätzlich kann das Verhalten des Wirtes gleichzeitig zum Kontakt mit Krankheitserregern und der Infektionsanfälligkeit beitragen und beide Komponenten können miteinander verwoben sein, so dass es schwierig ist, die Rolle von sozialen Interaktionen für Parasitenübetragung zu entschlüsseln.

Um die Ursachen und Konsequenzen von Infektionen mit gastrointestinalen Helminthen zu verstehen, werden in dieser Dissertation die Zusammenhänge zwischen gastrointestinalen Parasiten, Physiologie, Verhalten und sozialen Interaktionen bei sozialen Primaten, den Berberaffen (Macaca sylvanus) untersucht. Dabei mache ich mir die routinemäßige Entwurmung einer halbwilden Population zu Nutze, die zur Freiheit von Infektionen mit Strongiliden führt. Durch die experimentelle Veränderung des Parasitenstatuses können eher Schlüsse über Kausalzusammenhänge der Interaktionen zwischen Wirt und Parasiten, insbesondere im Bezug auf das Sozialverhalten, gezogen werden, als es in Korrelationsstudien möglich ist. Hierzu werden 
Verhaltensdaten (ca. 3500 Stunden) mit Analysen von molekularen Marker der Immunregulation (Neopterin im Urin), der körperlichen Verfassung (C-Peptide im Urin) und der Aktivität der Hypothalamus-Hypophysen-Nebennieren-(HPA)-Achse und die Bestimmung des Infektionsstatuses verbunden. Um die methodische Ungenauigkeit der nicht-invasiver Parasitenanalysen zu berücksichtigen, werden Patch-Occupancy-Modelle zur Abschätzung der Infektionswahrscheinlichkeiten und des Risikos der Wiederansteckung genutzt. Zusätzlich wird analysiert, ob infektionsbezogene Verhaltensänderungen eine Folge von Krankheitsverhalten oder der Vermeidung infizierter Artgenossen sind. Dies lässt Rückschlüsse auf den Einfluss von Parasiteninfektionen auf das Sozialverhalten zu, die möglicherweise auf die soziale Evolution der Tiere übertragen werden können. Ich überprüfe auch, ob soziale Fellpflege als möglicher direkter Übertragungsweg das Risiko einer Ansteckung mit Darmparasiten vorhersagt.

Infektionen mit Strongiliden, zumeist Oesophagostomum spp., waren in der Studiengruppe allgegenwärtig und zeigten meist geringe Ei-Ausscheidungsraten, aber große interindividuelle Unterschiede in der Wiederansteckungswahrscheinlichkeit. Diese Infektionen verursachten keine offensichtlichen Symptome oder eine Veränderung der körperlichen Verfassung. Sie riefen dennoch Anzeichen für Krankheitsverhalten hervor, messbar als stärkere Aktivität der HPA-Achse und geringere Aktivität infizierter Tiere. Die Entwurmung rief keine Veränderungen der Neopterinlevel hervor. Diese stiegen jedoch im Alter an, was auf Immunoseneszenz hindeutet. Da Infektionen mit weiteren Helminthen vorwiegend in älteren Individuen vorkommen, könnte dies darauf hindeuten, dass Immunoseneszenz die Fähigkeit der Tiere, Parasiteninfektionen einzudämmen, beeinflusst. Die Rate, mit der die Tiere sich Artgenossen annäherten, hing nicht mit dem eigenen Parasitenstatus, sondern dem des Partners zusammen, was auf eine Vermeidung infizierter Artgenossen hindeutet.

Wiederansteckung wurde durch Marker für Parasitenanfälligkeit und -kontakt bestimmt. Der stärkste Prädiktor für eine schnellere Wiederansteckung war eine Ko-Infektion mit weiteren gastrointestinalen Helminthen. Es gab keine Hinweise darauf, dass HPA-Achsenaktivität oder Immunfunktion starke Prädiktoren für eine Wiederansteckung sind. Eine gute körperliche Verfassung führte zu einer tendenziellen Erhöhung des Ansteckungsrisikos, was wahrscheinlich ein Zeichen für Toleranz gegenüber Darmparasiteninfektionen in Berberaffen ist. Der Übertragunsweg von Strongyliden über die Umwelt wurde bestätigt: Tiere, die viel Zeit in Gebieten mit hoher Kotkontamination verbrachten, d.h. wahrscheinlich häufig Kontakt mit infektiösen Parasitenstadien hatten, hatten auch ein erhöhtes Ansteckungsrisiko. Starke soziale Bindungen zu Partnern des anderen Geschlechts verringerten das Infektionsrisiko, wahrscheinlich auf Grund positiver Effekte sozialer Interaktionen auf die Funktion des Immunsystems. Im Gegensatz dazu führten soziale Fellpflege mit einer Vielzahl an Partnern und enge Bindungen mit gleichgeschlechtlichen Partnern zu einer höheren Ansteckungswahrscheinlichkeit, was eine soziale Komponente bei der Parasitenübertragung nahelegt. Dabei deutet die Diskrepanz zwischen den Effekten von Bindungen 
zu getrennt- und gleichgeschlechtlichen Partnern wahrscheinlich darauf hin, dass spezifische Verhaltensweisen unterschiedlich stark zum Kontakt mit Parasiten und der Infektionsanfälligkeit beitragen.

Zusammenfassend legen die Ergebnisse nahe, dass Infektionen mit gastrointestinalen Parasiten das Sozialverhalten nichtmenschlicher Primaten beeinflussen können. In Anbetracht der zweischneidigen Rolle sozialer Beziehungen erscheint das Ausprägen weniger, starker Bindungen als mögliche Strategie, die Vorteile von Beziehungen voll auszukosten und gleichzeitig die Nachteile zu minimieren - mit dem Vorbehalt, dass einige Interaktionsmuster mehr Vorteile mit sich bringen können als andere. Durch meine Ergebnisse ergeben sich eine Reihe neuer Fragen, die in zukünftigen Studien beantwortet werden sollten, insbesondere ob Primaten Parasitentoleranzstrategien nutzen können, um die Kosten von Parasiteninfektionen einzudämmen. $\mathrm{Zu}$ entschlüsseln, welche Komponenten des Sozialverhaltens mit Kontakt zu Krankheitserregern und der Anfälligkeit für Infektionen zusammenhängen ist wichtig, um die Variation des Infektionsrisikos zwischen einzelnen Tieren und deren Beitrag zur Übertragung von Krankheiten innerhalb einer Population zu verstehen. $\mathrm{Zu}$ untersuchen, ob Unterschiede in der Reaktion auf Parasiteninfektionen Langzeitfolgen für Gesundheit und Fitness vorhersagen, ist ein wichtiger nächster Schritt, um den Einfluss der WirtParasitenbeziehung auf das Verhalten möglicherweise die soziale Evolution von Wirtstieren zu verstehen. 


\section{Chapter 1}

\section{General Introduction}

"Friendship is unnecessary, like philosophy, like art.... It has no survival value; rather it is one of those things which give value to survival."

C.S. Lewis - The Four Loves

While C.S. Lewis was undeniably right that friendship makes human life worth living, his observation that it does not contribute to survival could hardly be further from the truth. There is overwhelming support for the idea that social bonds and support are not only vital for personal fulfilment and wellbeing, but also for health and survival. Despite the evidence for the positive impact of sociality on health and longevity in social animals, our understanding of the underlying mechanisms and the evolutionary foundation of this link is still limited. To understand the adaptive value and evolution of human friendship, studying the relationship between social interactions, health and fitness in our phylogenetic brethren, the nonhuman primates, is vital. Investigating the role of health for social evolution has been largely neglected in the fields of behavioural ecology and evolutionary biology, but is attracting increasing attention recently.

While some parts of the picture linking social behaviour with physiology, health and fitness are well understood in wildlife, the complete picture remains elusive. In the following chapter, I will elaborate on the current state of knowledge on the sociality-health-fitness nexus, culminating in the identification of open questions and how this thesis can contribute to answering them.

\subsection{Sociality and health}

\subsubsection{Evolution of group living}

One of the major transitions in evolution, changing the level of organization and consequently selection, (Maynard Smith et al. 1994) was the switch from solitary to group living (Szathmáry \& Smith 1995). As general consensus, conspecifics of one group consistently aggregate and interact more with each other than with other conspecifics, although there are various definitions of what constitutes a group (Krause and Ruxton 2002). More than two thirds of mammal species are classified as solitary (Lukas \& Clutton-Brock 2013), indicating that group living is not by default adaptive. Rather, specific benefits of associating with conspecifics, like protection from predation (Rubenstein 1978; Van Schaik 1983) or better access to and defensibility of resources (Wrangham 1980; Packer \& Ruttan 1988; Packer et al. 1990), can outweigh the costs of long-term associations (Sterck et al. 1997; Wrangham 1980; Krause \& Ruxton 2002) and lead to the evolution of permanent group living. 
Once arisen, group living individuals are subject to a range of trade-off between costs and benefits inherent to gregariousness, sometimes different from original drivers of selection for group living. Explaining the origins and ecology of sociality is a major aim of evolutionary ecology (CluttonBrock \& Janson 2012; Thierry 2013). Consequently, selective forces shaping the evolution of group living are intensely studied (Emlen \& Oring 1977; Van Schaik \& Van Hooff 1983; Sterck et al. 1997) and ecological correlates of its costs and benefits are relatively well understood. Potential fitness costs of group living do not necessarily affect all individuals in the same manner and can depend on individual traits. As an example, mating competition in multi-male groups is considered a major cost for males (Emlen \& Oring 1977), whereas female fitness can influenced by limited reproductive success due to feeding competition (Wrangham 1980; Janson \& Van Schaik 1988) or the risk of infanticide (Sterck et al. 1997; Pusey \& Packer 1994). Depending the environmental conditions, feeding competition and the subsequent energetic costs of traveling and foraging can become a limiting factor to group size, leading to markedly different group sizes within the same species (Brown 1982; Snaith \& Chapman 2007; VanderWaal et al. 2009; Markham \& Gesquiere 2017). Integrating various costs and benefits and their impact on shaping fitness in groups of different sizes gave rise to the formulation of optimal group size theory, predicting an optimal, often intermediate, group size to offer the best trade-off and highest fitness benefits (Brown 1982; Sibly 1983). Strategies beyond adapting group sizes to environmental conditions, like cooperation (Packer \& Ruttan 1988; van Schaik et al. 2004; Henzi et al. 2010; Schülke et al. 2010) and forming strong affiliative relationships (Silk et al. 2003; Cameron et al. 2009; Archie et al. 2014) can further mitigate costs of group living and increase individual fitness.

There is, however, another mechanism potentially driving social evolution, which has been largely neglected in behavioural ecology until recently: the link between sociality and health (Kappeler et al. 2015). Pathogens have been considered as a potential selective force for social evolution since the 1970s (Alexander 1974; Freeland 1976) and are almost universally present throughout the animal kingdom (Bordes \& Morand 2011; Ezenwa 2016). Recognizing the impact of parasitism on individual fitness (Tompkins \& Begon 1999; Pedersen \& Greives 2008), evolutionary biologists increasingly study the determinants of individual parasite infection risk (Lloyd-Smith et al. 2005; Hawley \& Altizer 2011; Vanderwaal \& Ezenwa 2016) and how infections influence social systems (Chapman et al. 2009; Kappeler et al. 2015). In the following paragraphs, I will introduce the current state of knowledge of the interplay between social behaviour, health and pathogen infection and how sociality could impact individual fitness.

\subsubsection{The adaptive value of social relationships}

Individuals form differentiated relationships within their group in most social species throughout the mammalian kingdom, including equids (Cameron et al. 2009; Stanley et al. 2017), elephants (Moss et al. 2011; Goldenberg \& Wittemyer 2017), cetaceans (Connor et al. 2000; Ellis et al. 
2017; Louis et al. 2017), hyenas (Smith et al. 2010) and primates (Silk et al. 2003; Mitani 2009; Schülke et al. 2010; Wittig et al. 2016). If these relationships are characterized by affiliative interactions, biased towards specific partners, and stable over longer periods, they are referred to as social bonds (Silk 2002). Non-random interactions between group members give rise to higher level organisation patterns within the social network (Krause et al. 2007; Wey et al. 2008; Kasper \& Voelkl 2009). Consequently, social network analysis, i.e. investigating social structures through the use of networks constructed from interaction patterns, is increasingly used as a tool to study social behaviour (see for example Godfrey et al. 2009; Brent et al. 2013; VanderWaal et al. 2014). Social network analyses allows researchers to identify the role of network substructure for parasite and information transmission and assess the role of variation in individual network integration, centrality and connectedness on fitness correlates (Franz \& Nunn 2009; Griffin \& Nunn 2012; Brent 2015; White et al. 2017b).

Individuals form social bonds despite temporal and energetic constraints and costs (Dunbar et al. 2009) and compete over valuable partners (Palombit et al. 2001; Mielke et al. 2017), indicating the importance of social bonds. Social bonds convey adaptive benefits beyond mere association within groups and potentially buffer against costs of group living. One of these benefits is support in agonistic encounters in female spotted hyenas (Crocuta crocuta) (Smith et al. 2010) and male nonhuman primates, where coalitionary support increases reproductive success (Schülke et al. 2010; Berghänel et al. 2011; Young et al. 2013, 2014b). Reproductive success is also increased in strongly bonded females in several species, including bottlenose dolphins (Tursiops truncates) (Frère et al. 2010), humpbacked whales (Megaptera novaeangliae) (Ramp et al. 2010), horses (Equus caballus) (Cameron et al. 2009) and baboons (Silk et al. 2003, 2009), and female baboons with strong bonds benefited from higher longevity (Silk et al. 2010). Female-female bonds are usually formed with closely related kin (Silk et al. 2003, 2009), yet bonding with unrelated males can increase survival (Archie et al. 2014), offer protection from infanticide (Palombit et al. 1997) and reduce feeding competition (Haunhorst et al. 2017) in nonhuman primates.

The relative importance of quality vs. quantity of social bonds is still debated (Silk et al. 2018). Alongside the evidence for bond quality predicting fitness correlates (Cameron et al. 2009; Silk et al. 2010; Archie et al. 2014), high interaction partner numbers predicted increased survival during a harsh winter in Barbary macaques (Macaca sylvanus) (McFarland \& Majolo 2013), better thermoregulation in vervet monkeys (Chlorocebus pygerythrus) (McFarland et al. 2015), and increased infant survival in a study on chacma baboons (Papio ursinus) (McFarland et al. 2017). Additionally, the importance of individual integration within the social network beyond dyadic relationships is increasingly recognized (Brent 2015). Measures of individual centrality, integration and importance for information transmission within a group (Wey et al. 2008; Kasper \& Voelkl 2009; Farine \& Whitehead 2015) predict fitness correlates in primates (Brent et al. 2013; Brent 2015) and cetaceans (Stanton \& Mann 2012; Ellis et al. 2017), sometimes with stronger signals than dyadic bonds (Cheney et al. 2016). 
Similar patterns emerge in humans, where social integration and strong social bonds predict lower mortality (House et al. 1988; Holt-Lunstad et al. 2010), with effect sizes comparable to known predictors of mortality risk, like smoking or heavy alcohol consumption (Holt-Lunstad et al. 2010)

Despite the relatively clear picture of adaptive benefits linked with sociality, strong bonds are not universally beneficial and can even be costly. In marmots (Marmota flaviventer), a facultative social species, winter survival was lower in individuals with higher partner numbers and network integration (Blumstein et al. 2018), suggesting different selection pressures on obligatory than facultative social species. In blue monkeys (Cercopithecus mitis stublmanni), consistent strong bonds increased survival, while inconsistent strong bonds had the opposite effect (Thompson \& Cords 2018), and in tufted capuchins (Sapajus apella), infants of highly social females were at highest risk from infanticide upon alpha male takeovers (Kalbitzer et al. 2017). These findings point to context specificity of consequences of bonding and potential fitness trade-offs. The mechanisms linking sociality to fitness outcomes are still poorly understood to date (Uchino 2006; Thoits 2011; Hawkley \& Capitanio 2015; Ostner \& Schülke 2018). Immediate benefits of social bonding can be increased access to resources, especially food (Tiddi et al. 2011; Sabbatini et al. 2012; Haunhorst et al. 2017), or protection from predation (Micheletta et al. 2012). Improved health and consequently survival have been put forward as mediating positive effects of social interactions on fitness, with different mechanisms explaining the link between sociality and health, which will be discussed in detail in the next paragraphs.

\subsubsection{Sociality and health - some mechanisms}

In humans, the importance of social relationships for individual health and longevity and the detrimental effects of social isolation are well established (Berkman \& Syme 1979; Uchino et al. 1996; Cacioppo \& Hawkley 2003; Holt-Lunstad et al. 2010, 2015). Evidence is mostly correlational, yet longitudinal approaches allow the conclusion that sociality is causally connected to longevity (Uchino 2006; Holt-Lunstad et al. 2010). Research aiming to explain this causal connection and the mediating mechanisms gave rise to the interdisciplinary field of "social neuroscience" (Cacioppo et al. 2000; Eisenberger \& Cole 2012). With growing interest in the link between sociality, health and fitness, concepts of social neuroscience increasingly receive attention in behavioural ecology (Engh et al. 2006a; Crockford et al. 2008; Demas \& Carlton 2015; Wittig et al. 2016).

Health and fitness are inextricably linked with social environment in gregarious animals, and social dominance status, similar to socio-economic status in humans, can predict health outcomes (Sapolsky 2004; Cavigelli \& Chaudhry 2012; Muscatell et al. 2016; Marescot et al. 2018). Dominance rank predicts aggressive interactions and challenges of the dominance position. These stimuli evoke physiological stress responses, including the activation of the hypothalamic-pituitary-adrenal (HPA) axis which culminates in glucocorticoid (GC) release (Sapolsky 2005). Periods of rank instability or male immigration generally lead to such stress responses (Sapolsky 2005; Engh et al. 2006b; Wittig et 
al. 2008), yet depending on the social system, higher or lower ranking individuals can be subject to more socially stressful conditions (Abbott et al. 2003; Sapolsky 2005). Instead of being costly per se, HPA axis activation is an adaptive response to challenges that contributes to survival (Romero 2004; Cavigelli \& Chaudhry 2012). GCs have various immunomodulatory functions (Besedovsky et al. 1986; Dhabhar 2009), including regulation and termination of inflammatory responses (Besedovsky et al. 1986; Eisenberger \& Cole 2012). High GC levels can even enhance immune function under certain conditions, as in yellow baboons (Papio cynocephalus), where alpha males, but not lower ranking individuals, with high GC levels showed accelerated wound healing (Archie 2013). Social rank position also alters expression patterns of immune-related genes, linking social environment to immune function and disease susceptibility (Tung \& Gilad 2013; Snyder-Mackler et al. 2016).

While short term activation of the HPA axis is adaptive (Romero 2004), long-term activation is considered to have detrimental effects (Apanius 1998). Although the fitness costs of elevated GC levels in wildlife are currently disputed (Boonstra 2013; Beehner \& Bergman 2017), human and laboratory animal studies describe a range of adverse physiological effects of repeated or chronic HPA axis activation (Apanius 1998; Yang \& Glaser 2002; Glaser \& Kiecolt-Glaser 2005). These include dysregulation of GC excretion, resulting in elevated baseline levels (Yang \& Glaser 2002; Cole et al. 2009), uncoupling of immune cells from GC regulation (Cole et al. 2009), low level inflammation (Dhabhar 2009; Hawkley et al. 2013; Hawkley \& Capitanio 2015) and a shift towards cell mediated T-helper type 2 (Th2) responses (Elenkov \& Chrousos 1999). Experiencing social stressors also leads to sympathetic nervous system (SNS) activation, with negative health effects of repeated stress responses, profound changes in immune gene expression in rhesus macaques (Macaca mulatta) (Sloan et al. 2008; Capitanio \& Cole 2015) and upregulation of inflammatory signalling resulting from increased lymph node innervation by SNS fibres (Sloan et al. 2007). These long-term effects of social stress can culminate in increased disease susceptibility (Capitanio et al. 1998; Glaser \& Kiecolt-Glaser 2005; Dhabhar 2009).

Social isolation, real or perceived, is another very potent stressor linked with adverse health outcomes in gregarious animals (Eisenberger \& Cole 2012; Hawkley et al. 2013; Hawkley \& Capitanio 2015), also predicting worse health and lower life expectancy in humans (Hawkley \& Capitanio 2015; Holt-Lunstad et al. 2015). Social isolation increases HPA axis activity and inflammatory signalling (Hawkley et al. 2013; Hennessy et al. 2014), resulting in detrimental health effects that include metabolic and cardiovascular disease and mental illness in humans (Dantzer et al. 2008; KiecoltGlaser et al. 2010; Hawkley \& Capitanio 2015). Isolation is thus a second pathway for social environment to shape individual health.

In contrast, social relationships can alter individual physiology beyond the effects of social isolation and stressors: affiliative interactions and social support can profoundly increase health outcomes, also by attenuating responses to perceived threats and thus mitigating costs of social stress 
(Cohen \& Wills 1985; Kikusui et al. 2006; Kiyokawa \& Hennessy 2018), referred to as social buffering (Cohen \& Wills 1985). The social buffering hypothesis thus offers a mechanism explaining the health benefits of social relationships (Berkman \& Syme 1979; House et al. 1988; Holt-Lunstad et al. 2010). Indeed, socially well integrated individuals have a lower risk of contracting infections and developing symptoms upon experimental exposure with respiratory viruses in humans (Cohen et al. 1991, 2003, 2015) and long tailed macaques (Macaca fascicularis) (Cohen et al. 1997). Social buffering comes in two flavours: structural support, i.e. the integration of individuals within a social network (Cohen \& Janicki-Deverts 2009; Holt-Lunstad et al. 2010) or being housed with social partners in case of experimental animals (Kikusui et al. 2006; Kiyokawa 2018), and direct support, i.e. the presence of or interaction with a conspecific in face of a stressor (Ishii et al. 2016; Kiyokawa 2018). Both mechanisms have distinct underlying principles by which they attenuate stress responses (reviewed in Kiyokawa 2018; Kiyokawa \& Hennessy 2018): Structural support influences the initial reaction to a stressor, direct support the recovery from a stressor. Beyond lowering the perceived severity of a stressor if support is available, social buffering can alter individual physiology also in absence of an acute stressor (Kikusui et al. 2006), leading to beneficial health outcomes.

There are several physiological mechanism by which social buffering can impact susceptibility to infectious and non-infectious diseases. In humans, these include lower SNS activation (Cacioppo \& Hawkley 2003; Eisenberger \& Cole 2012; Inagaki 2018), lower baseline blood pressure (Uchino et al. 1996), lower levels of inflammation (Cacioppo \& Hawkley 2003; Kiecolt-Glaser et al. 2010), better sleep quality and overall higher maintenance function (Cacioppo et al. 2002; Cacioppo \& Hawkley 2003). Many of these mechanisms are difficult to assess in natural populations, yet correlates of HPA axis activation and oxytocin release, which both play important roles for stress buffering (Crockford et al. 2017; Kiyokawa \& Hennessy 2018), can reliably be measured in wildlife to study social buffering effects (Crockford et al. 2013, 2017; Young et al. 2014a; Beehner \& Bergman 2017).

In primates, grooming has been linked with endorphin (Keverne et al. 1989) and oxytocin release (Crockford et al. 2013) and reduced HPA activation (Shutt et al. 2007; Aureli \& Yates 2010), illustrating the potential for social interactions to buffer against the adverse effects stressors. Whether social interactions lower overall activation or improve HPA axis regulation is currently under debate, and both processes are not necessarily mutually exclusive. While male Barbary macaques with stronger bonds had lower faecal GC metabolite (fGCM) levels when faced with social and environmental stressors (Young et al. 2014a), strongly bonded chimpanzees showed overall lower HPA activity across every day and challenging contexts (Wittig et al. 2016). Oxytocin, which can downregulate HPA axis activity (Kikusui et al. 2006; Li et al. 2017), is increased in socio-positive interactions and intergroup conflicts in chimpanzees (Crockford et al. 2013; Samuni et al. 2016). Besides anxiolytic effects and HPA axis regulation (Uvnäs-Moberg 1998; Crockford et al. 2017), oxytocin can also facilitate social interactions (Witt et al. 1992). This indicates that faced with certain 
stressors, e.g. the threat of an intergroup encounter (Samuni et al. 2016), physiological mechanisms mediate active support seeking, which could functionally alleviate the threat posed by the stressor. Similar patterns were observed in baboons, where individuals reacted to stressors (male rank instability and loss of a bonded partner) not only with increased HPA axis activation, but subsequently focused their grooming network, resulting in fGCM levels or quicker fGCM level return to baseline (Engh et al. 2006a; Wittig et al. 2008). This interplay between physiology and behaviour could be the evolutionary root of social buffering (Kiyokawa \& Hennessy 2018). In summary, social interactions induce various physiological changes that can influence health outcomes and thus predict variance in survival and fitness based on social interaction patterns.

\subsubsection{Sociality's role for pathogen exposure}

Social contacts may be beneficial for individual health due to improved immune function and lower susceptibility, but also carry risks. Increased exposure to infectious diseases has been suggested as one of the major costs of group living (Freeland 1976), with evidence for higher infection risk in bigger groups (Altizer et al. 2003; Patterson \& Ruckstuhl 2013). Interactions within a group are usually non-random, and higher level organisation patterns, like subgrouping within a social network, can modulate individual exposure and the transmission of pathogens through the network (Cross $e t$ al. 2004; Salathé \& Jones 2010) and predict transmission more precisely than group size alone (Griffin \& Nunn 2012; Nunn et al. 2015). Depending on their network position and disease susceptibility, individuals can contribute disproportionally to disease transmission (Woolhouse et al. 1997; LloydSmith et al. 2005; Hawley \& Altizer 2011). Identifying these highly vulnerable individuals is particularly important in the light of conservation and medical interventions, which can require targeting specific individuals to succeed (Smith et al. 2009; Rushmore et al. 2013).

One strategy to handle this cost of social aggregation and interaction is social immunity (Cremer et al. 2007; Schmid-Hempel 2017), mostly employed by colony living insects. Social insects are particularly vulnerable to pathogen invasion due to the high spatial proximity of closely related individuals (Cremer et al. 2007; Schmid-Hempel 2017), and defence against pathogens is usually considered on a colony rather than an individual level. Strategies to prevent pathogen invasion of the colony are the isolation of heavily (Cremer et al. 2007) or support of mildly infected individuals (Konrad et al. 2012). Grooming individuals with fungal infections can be mutual beneficial in ants, simultaneously alleviating infection and transferring immunity to the respective pathogen (Konrad et al. 2012). Similar patterns can be observed in vertebrates if low level exposure to pathogens leads to development of adaptive immunity without developing serious infections (Burnet et al. 1972; Hart 2011). Given the close relatedness of individuals within a colony and the subsequent inclusive fitness benefits of giving support, this strategy is generally more common in insects than mammals (Cremer et al. 2007; Schmid-Hempel 2017), where intragroup-competition for mates and resources is often harsh (Koenig 2002; van Schaik et al. 2004) and individuals do not usually adapt their behaviour to 
benefit the group. Thus, insect immunity offers a valuable model system for understanding the evolution of immune responses and social strategies to counter disease risk (Schmid-Hempel 2003), although patterns cannot be directly applied to mammal sociality.

Transmission pathways can be vastly different between pathogens, so social interactions can shape infection risk differently. Sleep site choice, as an example, has been suggested as a defence strategies against contracting vector borne diseases (Nunn \& Heymann 2005). Grooming reduces ectoparasite load and subsequent exposure to vector borne diseases, exemplified by lower lice loads in Japanese macaques grooming with many partners (Macaca fuscata) (Duboscq et al. 2016). In case of diseases transmitted via contact or close proximity, social contacts can have immediate impacts on infection risk. The spread of viral infections in humans closely follows the social network structure (Mossong et al. 2008) for influenza, human immunodeficiency virus (HIV) and Hepatitis C (Klovdahl \& Australian 1985; Klovdahl et al. 1994; Rothenberg et al. 1998; Romano et al. 2010; Cauchemez et al. 2011), and from insects to mammals, highly connected individuals are more likely to be infected with bacteria or viruses (Vicente et al. 2007; Godfrey et al. 2009; Craft et al. 2011; Konrad et al. 2012). Close contact is not always a strong predictor of infection risk, as not all interactions contribute equally to pathogen transmission: in meerkats (Suricata suricatta), not the most connected, but the individuals giving grooming and receiving aggression are most vulnerable to tuberculosis infection (Drewe 2009), and in Tasmanian devils (Sarcophilus harrisii), the transmission of an infectious tumour disease is closely linked to aggressive behaviours (Hamede et al. 2013).

Social interactions can also predict acquisition of environmentally transmitted bacteria (VanderWaal et al. 2014; Tung et al. 2015; Springer et al. 2016; Balasubramaniam et al. 2018) and gastrointestinal (GI) parasites (Fenner et al. 2011; MacIntosh et al. 2012; Rimbach et al. 2015). High numbers of interaction partners (Wren et al. 2016) and central network positions (VanderWaal et al. 2013; Rimbach et al. 2015; Friant et al. 2016a) are the most common predictors of high infection risk. Although predominantly transmitted via the environment, close social contact can contribute to transmission to GI parasites, (Hernandez \& Sukhdeo 1995; MacIntosh et al. 2012; GonzálezHernández et al. 2014; Friant et al. 2016b), leading to heterogeneous results in assigning social behaviours to parasite exposure. The contributions of environmental and social factors to the transmission of GI parasites depend on the parasite in question, yet are difficult to identify, as often environmental exposure is not measured (Pebsworth et al. 2012; Grear et al. 2013). In this thesis, I aim to disentangle these two components of GI parasite transmission.

\subsection{Gastrointestinal parasites}

Parasitism is rather the norm than the exception in the animal kingdom (Grencis et al. 2014). Pathogens causing severe diseases, e.g. AIDS, tuberculosis, anthrax and malaria receive high levels of attention in humans and wildlife (Rothenberg et al. 1998; Nunn \& Heymann 2005; Leendertz et al. 
2006, 2010; Vicente et al. 2007; Di Fiore et al. 2009; Drewe 2009; Deeks 2011). In comparison, mild diseases, like helminth infections, are often neglected (Hotez et al. 2005; Bethony et al. 2006; Ghai et al. 2014), despite their strong implications for host health and evolution (Freeland 1976; Hawley \& Altizer 2011; Ezenwa \& Jolles 2015; Ezenwa et al. 2016). Helminths is a general term describing a large group of parasitic worms within the phyla nematoda and platyhelmintha (Díaz \& Allen 2007). Here, I will restrict myself to discussing environmentally transmitted GI helminths, including, Ascaris spp. and Trichuris spp. and strongyle nematodes like hookworms (Ancylostoma spp. and Nercator spp.), Trichostrongylus spp. and Oesophagostomum spp..

GI helminth infections are highly prevalent in humans, with an estimated 2 billion people infected (Nutman 2015), yet are surprisingly neglected in human medical research (Bethony et al. 2006; Ojha et al. 2014). Infections can cause morbidity, developmental retardation and serious complications in severe infections (Degarege et al. 2014; Nutman 2015), yet often do not cause overt symptoms (Nutman 2015). Sharing long co-evolutionary histories, host immune systems evolved in GI-helminths presence (Yazdanbakhsh et al. 2002; Carvalho et al. 2009; Jackson et al. 2009). The hygiene hypothesis proposes that absence of infections leads to immune dysregulation (Yazdanbakhsh et al. 2002; Carvalho et al. 2009), culminating in allergies and asthma (Kitagaki et al. 2006; Briggs et al. 2016). The immunomodulatory potential of helminths (Nutman 2015) has even resulted in infections being used as therapeutic intervention for inflammatory, autoimmune and allergy-related diseases (Cooper 2002; Lopes et al. 2016; Hansen et al. 2017). As a consequence, their status as a pathogen is still debated. Similar to infection in humans, GI helminths usually do not cause overt symptoms in wildlife (Stien et al. 2002; Krief et al. 2008). Nonetheless, GI helminth infections can severely impact hosts on individual and population levels (Tompkins et al. 2011), and are a powerful tool to study behavioural and evolutionary host-parasite feedback loops (Tompkins \& Begon 1999; Tompkins et al. 2011), which led to their increasing importance for the study of wildlife health (Hawley \& Altizer 2011; Martin et al. 2011; Pedersen \& Babayan 2011).

\subsubsection{Studying GI helminth infections: Chances and challenges}

Soil transmitted helminths have complex, often host specific, life cycles, yet share an essential environmental life cycle stage: eggs are shed in the faeces of infected host and develop into infective stages in the environment, with the time to infectivity depending on species and environmental conditions (Dash 1973; Bethony et al. 2006; Viney 2017). Infective stages can be mobile, like strongyle nematode larvae (Dash 1973; Ojha et al. 2014), or immobile, like embryonated Trichuris eggs (Stephenson et al. 2000a). The most common infection route is ingestion of infective stages upon contact with contaminated soil or food. Hookworm and strongyloides larvae can also pierce the skin of the host to initiate infections (Loukas et al. 2005; Bethony et al. 2006; Viney 2017). Within hosts, helminths develop into adult worms, sometimes passing through multiple organ systems (Hotez et 
al. 2004; Bethony et al. 2006), and begin producing eggs to be shed in faeces, completing the life cycle.

GI helminth infections can be assessed noninvasively via standardized, routinely used coproscopic methods for detection and quantification of egg shedding (Gillespie 2006). As egg morphology can be highly similar between different taxa, identification beyond the genus or taxon level can be challenging. Molecular methods like genotyping (Gasser et al. 1999; McLean et al. 2012; Roeber et al. 2013), identification based on larval morphology (Ota et al. 2015), and combined coproscopic and molecular approaches (Budischak et al. 2015a; Ota et al. 2015) complement microscopic approaches. Egg shedding patterns can be closely correlated to actual worm burden (Roberts \& Swan 1981; Seivwright et al. 2004), but are not always (Christensen et al. 1995; Roepstorff et al. 1996). Additionally, infected individuals do not consistently excrete eggs, but characteristics, like age, sex, and reproductive status (Klein 2004) can alter egg shedding patterns. Microscopic analyses are subject to uncertainty due to e.g. detection sensitivity leading to statistical non-detection of low egg numbers in faeces. Consequently, reliable infection assessment requires multiple samples per individual (Gillespie 2006).

\subsubsection{Host-parasite interactions}

\subsection{2a Parasites and host physical condition}

Infections with GI helminths correlate with poorer nutritional status from mice to men (Stephenson et al. 2000a; Ezenwa 2004b; Irvine et al. 2006; Szyszka \& Kyriazakis 2013). Mounting immune responses is energetically costly (Ing et al. 2000; Bonneaud et al. 2003; Derting \& Compton 2003; Forbes et al. 2016), and failing to meet the energetic demands of immune reactions can increase infection susceptibility. Poorer nutritional status increases GI helminth susceptibility in e.g. rodents (Ing et al. 2000; Forbes et al. 2016), ruminants (Coop \& Kyriazakis 1999) and ungulates (Ezenwa 2004b). Diet also influences susceptibility, with a major role of low protein availability, increasing the risk of GI helminth infections (Chandra 1997; Ing et al. 2000; Koski \& Scott 2001).

Infections with GI helminths in turn impact host nutritional status due to energy demands of immune responses, reduced food intake (Sykes \& Coop 1976; Crompton \& Nesheim 2002), impaired nutrient absorption (Coop \& Holmes 1996; Koski \& Scott 2001; Greer et al. 2005) and dietary changes (Kyriazakis et al. 1998). Infections can have detrimental effects on hosts, measurable as slower development (Sykes \& Coop 1976; Adams et al. 1994; Greer et al. 2005), lower reproductive success (Coop \& Holmes 1996), decreased survival (Gulland 1992; Murray 2002; Pedersen \& Greives 2008), and impaired cognitive development in human children (Eppig et al. 2010; Degarege et al. 2014). Feedback-loops between infection status and host condition can give rise to vicious circles (Koski \& Scott 2001) and make determining the directionality of the nutrition-parasite link challenging (Coop \& Kyriazakis 1999; Beldomenico \& Begon 2010). 


\subsection{2b Parasite-immune interactions}

GI helminth infections profoundly affect the host's immune systems via multiple pathways. HPA axis activation, vital for regulating energy metabolism and inflammatory immune reactions (Hart 1988; Konsman et al. 2002), is often linked with GI helminth infections (Pedersen \& Greives 2008; Friant et al. 2016b). The directionality of the relationship is often unclear, as acute GI helminth infections can induce HPA axis activation, while immunoregulatory effects of HPA dysregulation can increase susceptibility to infections (Apanius 1998; Glaser \& Kiecolt-Glaser 2005; Beldomenico \& Begon 2016). Similar to nutritional status, the negative effects of stress and infection can exacerbate each other (Beldomenico \& Begon 2016).

In addition to acute responses to tissue damage caused by GI helminths, infections elicit specific immune responses, which are generally characterised by strong Th2 activation and anti-inflammatory in nature (Loukas et al. 2005; Carvalho et al. 2009). Preferential Th1 or Th2 responsiveness is a genetic trait (Else \& Grencis 1991; Ezenwa et al. 2010), and individuals failing to mount strong Th2 responses generally suffer from chronic rather than transient GI helminth infections (Else \& Grencis 1991). More mixed Th1-Th2 responses have been described (Anthony et al. 2007) in humans (Pit et al. 2001) and experimental studies on pigs (Andreasen et al. 2015, 2016), emphasizing the specificity of host immune responses to GI helminths. The two arms of the immune system are mutually inhibitory (Long \& Nanthakumar 2004), so a shift towards Th2 type responses decreases Th1 response efficiency. GI helminths are therefore powerful immune modulators (Jackson et al. 2009) that can affect hosts' immune efficiency against various parasites (Cox 2001; Lello et al. 2004; Graham 2008; Vaumourin et al. 2015). GI helminths also actively manipulate host immune signalling in their favour by excreting secretory products (Hsieh et al. 2004; Hewitson et al. 2009; Grencis et al. 2014). Human hookworms and murine Trichuris, for example, increase host $\gamma$-interferon (IFN $\gamma$ ) signalling, inducing Th1 prone responses (Grencis \& Entwistle 1997; Hsieh et al. 2004; Hewitson et al. 2009). Immunomodulatory effects of GI helminth infections can even persist after parasite clearance (Wright et al. 2009) and thus influence hosts beyond acute infections (Jackson et al. 2009).

\subsection{2c Parasites and host behaviour}

Given the profound impact of GI helminth infections on host physiology, their influence on host behaviour is unsurprising. Injuries and infections induce sickness behaviour (Hart 1988), a range of behavioural changes aimed at limiting infection costs and increasing survival chances (Hart 1988; Kyriazakis et al. 1998; Konsman et al. 2002; Dantzer 2004). Sickness behaviour is mediated by inflammatory cytokine signalling (Dantzer 2001; Konsman et al. 2002), induced by e.g. tissue damage in the gut mucosa in the case of GI helminth infections (Dash 1973; Hotez et al. 2004; Hsieh et al. 2004). Behavioural changes include lethargy and reduced activity, social withdrawal, heat conserving body postures, and anorexia, all contributing to energy conservation and immune response efficiency (Kyriazakis et al. 1998; Konsman et al. 2002; Hennessy et al. 2014). There is ample evidence for 
sickness behaviour responses to GI helminths, e.g. reduced activity in cattle (Szyszka \& Kyriazakis 2013) and primates (Ghai et al. 2015; Chapman et al. 2016; Friant et al. 2016b), reduced food intake in ruminants (Sykes \& Coop 1976; Greer et al. 2005) and reduced foraging in infected red-capped mangabeys (Cercocebus torquatus) (Friant et al. 2016b).

Hosts employ several behavioural strategies to avoid infections (Hart 2011; Curtis 2014), like adapting foraging behaviour (Keymer et al. 1983; Hutchings et al. 2002; Gunn \& Irvine 2003), alternating between territoriality and roaming (Ezenwa \& Snider 2016) and avoiding contact with faecal contamination (Curtis 2014; Sarabian \& MacIntosh 2015; Amoroso et al. 2017; Weinstein et al. 2018) to avoid exposure to infective parasite stages. Individuals also avoid direct contact to conspecifics likely to transmit parasites (Curtis 2014): mice express preferences for non-parasitized mating partners (Ehman \& Scott 2002), and mandrills (Mandrillus spbinx) avoid grooming individuals infected with unicellular GI parasites (Poirotte et al. 2017). Infection status is likely assessed via olfactory cues (Ehman \& Scott 2002; Olsson et al. 2014; Poirotte et al. 2017). Contracting GI helminth infections directly from infected conspecifics is unlikely due to their environmental transmission, yet avoiding infected individuals can be adaptive when GI helminth infections correlate with more directly transmissible infections.

\subsection{2d Coinfection}

GI helminth infections can protect from infection with other helminth taxa as a result of crossimmunity and within host competition (Cox 2001; Lello et al. 2004; Vaumourin et al. 2015), or increase host susceptibility to infection via immunosuppression (Lello et al. 2004). In pigs coinfected with Trichuris and Oesophagostomum, for example, antibody responses against Oesophagsotomum were markedly increased compared to single infections. Within host helminth-helminth interactions can be quite complex, with multiple species impacting each other, including positive feedback loops (Lello et al. 2004). GI helminths can also alter host susceptibility to a variety of microparasites and influence duration, severity and transmission of infections (Vaumourin et al. 2015), like in the cases of the three of the most important diseases with regard to global human health (Salgame et al. 2013), malaria (Hartgers \& Yazdanbakhsh 2006), tuberculosis (Rafi et al. 2012) and HIV/AIDS (Borkow et al. 2007). These interactions are mostly mediated by the immunomodulatory properties of GI helminth infections (Maizels \& Yazdanbakhsh 2003; Long \& Nanthakumar 2004; Anthony et al. 2007), which can impair anti-microparasite immune control (Cox 2001; Graham 2008; Jackson et al. 2009). GI helminths can also limit microparasite transmission, underlining the importance of considering GI helminths for disease epidemiology in wildlife: long-term experimental parasite clearance increases Th1 immune function and individual survival in African buffaloes (Syncerus caffer). (Ezenwa et al. 2010; Ezenwa \& Jolles 2015), yet simultaneously accelerates the spread of Mycobacterium bovis through the population due to prolonged contribution of treated individuals to $M$. bovis transmission (Ezenwa et al. 2010; Ezenwa \& Jolles 2015). Similarly, anthelmintic treatment increases 
shedding of protozoan Eimeria spp. in wild mice (Knowles et al. 2013; Pedersen \& Antonovics 2013), and malaria burdens (Budischak et al. 2018), as blood sucking worms compete with Plasmodia for red blood cells as a resource (Graham 2008; Budischak et al. 2018). Consequently, coinfections need to be considered to understand the full impact of GI helminth infections on individual and population levels (Ezenwa \& Jolles 2011; Martin et al. 2011; Tompkins et al. 2011; Ezenwa 2016).

\subsection{2e Parasite defence strategies}

Considering the effects of GI helminth infections on host physiology and behaviour, developing resistance, i.e. the reduction of parasite burden via efficient immune responses, appears to be an adaptive strategy. There is, however, an alternative strategy to manage infections, namely parasite tolerance, i.e. decreasing the costs of infection without affecting parasite burden (Råberg et al. 2009; Medzhitov et al. 2012). Mounting immune responses has considerable energetic costs (Colditz 2008, but see above) and can cause immunopathology in case of too strong or inadequate responses. Immunopathology can have more severe results than the damage resulting from infections, like autoimmune reactions, allergies, and severe tissue damage (Graham et al. 2005; Maizels et al. 2009). Consequently, damage rather than parasite control might be the most important goal of anti GI helminth defences (Read et al. 2008; Medzhitov et al. 2012; Råberg 2014), with optimal trade-off between costs of infection and costs of immunopathology (Medzhitov et al. 2012) depending on parasite pathogenicity (Greer 2008).

Tolerance to infections is measured as the slope of health costs against parasite intensity measures, i.e. weight loss with increasing egg counts, with more tolerant individuals suffering lower costs with higher infection intensity (Hayward et al. 2014b; Jackson et al. 2014). In wild Soay sheep (Ovis aries), tolerance is related to increased reproductive success (Hayward et al. 2014b), whereas females with resistance prone immune responses are characterized by increased survival of harsh winters at the expense of lower fecundity (Graham et al. 2010), a pattern that extends to GI helminth specific immune responses (Hayward et al. 2014a). There are similar trade-off between high tolerance, increasing body condition and survival at the expense of reproductive success in wild mice, with individuals shifting their strategy from resistance to tolerance as they age (Jackson et al. 2014). Understanding the causes and physiological correlates of resistance vs. tolerance strategies can thus profoundly contribute to our understanding of wildlife health and the impact of infections on fitness.

\subsection{Study aims and approach}

\subsubsection{Study site and species}

To assess the GI helminth related costs and benefits of sociality, I conducted my study on two groups of semi-free ranging Barbary macaques at Affenberg Salem (de Turckheim \& Merz 1984) in Southwest Germany. Barbary macaques are the phylogenetically most basal species of the genus 
Macaca, most closely resembling ancestral macaque species (Purvis 1995; Morales \& Melnick 1998). In their natural habitat, the Atlas Mountains of Morocco and Algeria (Fooden 2007), populations are declining, and Barbary macaques are considered "Endangered" by the IUCN (van Lavieren \& Wich 2010). Like macaques in general, Barbary macaques form multi-male multi-female groups with female phylopatry and male dispersal (Mehlman 1986; Aureli et al. 1997; Thierry 2007) with a relatively tolerant social style (Thierry et al. 1999). They are seasonal breeders with promiscuous mating by both sexes (Small 1990; Kuester \& Paul 1992) and a mating season in winter ( October to February), followed by birth season in early summer, peaking around June (Ménard \& Vallet 1997; Brauch et al. 2007). Like most primates, Barbary macaques differentiated social relationships (Berghänel et al. 2011; Young et al. 2014a). Males form linear dominance hierarchies, with male relationships predicting support in the frequently occurring coalitions, which are particularly frequent during the mating season (Paul et al. 1992; Widdig et al. 2000; Berghänel et al. 2011; Young et al. 2014b). Socio-positive interactions can decrease physiological stress in Barbary macaques (Shutt et al. 2007), yet frequent agonistic interactions and prolonged male associations with infants increase HPA axis activity (Henkel et al. 2010; Young et al. 2014a). Strong social bonds attenuate stress responses to intense aggression and cold stress in males (Young et al. 2014a), and social integration as well as a high number of grooming partners increase survival under harsh climate conditions (McFarland \& Majolo 2013; Lehmann et al. 2016; Campbell et al. 2018), making the Barbary macaque an interesting system to study the effects of sociality on health and fitness.

The study site was Affenberg Salem, a 20 ha large outdoor enclosure of beech/spruce mixed forest (see de Turckheim \& Merz 1984 for a detailed account of the population and study site). Macaques live outdoors year round under climatic conditions similar to their natural habitat. They are provided once daily with fresh fruits and vegetables and have ad libitum access to commercial monkey chow and water, but frequently forage on natural food sources like insects, leaves and beechnuts. Intergroup interactions are frequent and males can migrate between the groups. Two groups have daily contact with park visitors, who are restricted to a path while macaques can move freely within the entire enclosure, and all individuals are fully habituated to human presence. Semifree ranging housing conditions with minimal human impact (de Turckheim \& Merz 1984; Paul \& Kuester 1988), and similar group structure and dispersal behaviour as displayed by wild individuals (Paul \& Kuester 1985, 1988; Ménard \& Vallet 1993; Ménard 1996) allow for studying macaque behaviour closely resembling that wild Barbary macaques.

GI parasite infections are routinely monitored in the population. Trichuris spp. and strongyle nematode infections are detected regularly, with Oesophagostomum spp. infections confirmed by presence of intestinal nodules in necropsies (Dr. Roland Hilgartner, personal communication; analyses performed by the "Staatliches Tierärztliches Untersuchungsamt Aulendorf"). The study population routinely receives anthelminthic treatment twice per year, offering an ideal opportunity 
to study host-parasite dynamics in a nonhuman primate. Host-parasite interactions have mostly been studied using correlational and cross-sectional study designs (Godfrey et al. 2009; Fenner et al. 2011; MacIntosh et al. 2012; Rimbach et al. 2015), so the directionality of the links between parasite infections, host physiology and behaviour is largely unclear. Correlational studies are valuable in their own right, yet to draw causal inferences, experimental studies are needed (Pedersen \& Greives 2008; Ezenwa et al. 2010; Ezenwa \& Jolles 2015; Pedersen \& Fenton 2015; Chapman et al. 2016; Friant et al. 2016a, b). Capitalizing on parasite treatment, I can investigate both directions of the relationships between host behaviour, physiology, and GI helminth infection risk to contribute to our current understanding of the links between host sociality, parasites and health.

\subsubsection{Assessing health in wildlife}

Assessing host physiological status and immune function under natural conditions is a vital step for studying wildlife health (Jackson 2015), yet in contrast laboratory studies, reliable markers of individual condition, stress responsiveness (beyond HPA axis activity) and immune function are not always available. Endocrinological parameters, like steroid hormones, are already routinely measured in field studies (Pedersen \& Greives 2008; Muehlenbein \& Watts 2010; Young et al. 2014a), and a multitude of immune system parameters can be assessed from blood samples, like immune cell reactivity (Ezenwa et al. 2010), cytokine levels (Vandeleest et al. 2016), antibody levels (Graham et al. 2010), blood parasite presence (Springer et al. 2015), and immune gene expression (Tung \& Gilad 2013). However, handling of wild animals is not always possible for ethical and feasibility reasons, so noninvasive markers of immune function and physical condition are needed.

Recent advances in the fields of medical diagnostics and wildlife endocrinology led to the validation of several promising markers of immune function (Peterson et al. 2002; Reimert et al. 2008; Higham et al. 2015; Behringer \& Deschner 2017) and energy balance (Deschner et al. 2008; Emery Thompson et al. 2009; Girard-Buttoz et al. 2011; Schaebs et al. 2016) from urine and faeces, two of which are employed here: urinary neopterin (uNEO), a marker of immune function, and urinary CPeptide (uCP) immune function, a marker of physical condition.

\subsection{2a Measuring immune function: urinary neopterin}

The pteridin neopterin is released by macrophages, monocytes and dendritic cells in response to IFN $\gamma$ stimulation and activates Th1-helper cells (Murr et al. 2002; Plata-Nazar et al. 2010). It is a general marker of Th1 immune activation and responses against intracellular pathogens (Widner et al. 1999; Murr et al. 2002) widely used in human medical diagnostics. Serum, urinary and faecal levels are linked to various diseases, including gastrointestinal infections and inflammation (Ledochowski et al. 2001; Husain et al. 2013), viral infections like HIV (Fuchs et al. 1988) and viral hepatitis (Reibnegger et al. 1988a), bacterial infections like tuberculosis (Fuchs et al. 1984), and non-infectious diseases like cancer (Unal et al. 2009; Sucher et al. 2010), autoimmune and coronary heart disease 
(Berdowska \& Zwirska-Korczala 2001). High NEO levels indicate higher disease severity and worse prognosis (Unal et al. 2009; Sucher et al. 2010). NEO is also elevated in response to acute stress (Breinekova et al. 2007) and physical strain (Moser et al. 2008), potentially due to cellular immune system activation.

NEO is cleared via the kidneys unchanged (Berdowska \& Zwirska-Korczala 2001) and can reliably be measured from urine samples. NEO is relatively stable under field conditions, making it a promising marker for immune system monitoring in wildlife (Heistermann \& Higham 2015; Higham et al. 2015; Behringer et al. 2017). Urinary NEO levels have been shown to track simian immunodeficiency virus infections in rhesus macaques (Fendrich et al. 1989; Higham et al. 2015) and acute respiratory disease in bonobos (Pan paniscus) (Behringer et al. 2017), providing the biological validity of NEO levels as markers of immune activation. I aimed to assess the feasibility of uNEO as a noninvasive marker of immune regulation in relation to GI helminth infections. Given the crossinhibition of Th1 and Th2 immune responses (Long \& Nanthakumar 2004) and the usually predominant Th2 response against GI helminths (Carvalho et al. 2009; Grencis et al. 2014), uNEO level variations could indicate infection with or susceptibility to GI helminth infections. These hypotheses were tested in detail in Chapter 2 and Chapter 4 of this thesis.

\subsection{2b Measuring physical condition: urinary C-peptide}

Physical condition, nutritional status and energy availability are important variables to consider for individual health, yet assessing them wild animals is not straightforward. Current methods include assessment of body weight and weight changes (Hayward et al. 2014a), relating body mass to body length (Peig \& Green 2009), use of a combination of visual markers, such as pelage condition and visually assessed body fat (Borg et al. 2014; Friant et al. 2016b), or manual palpation, often used in combination with visual assessment (Ezenwa et al. 2009). While some of the scores have been validated against invasive measures of body conditions (Ezenwa et al. 2009), assessment based on visual cues can be unreliable if handling study animals is not possible. Measuring physiological markers of individual energetic status, like thyroid hormones linked to energy metabolism and growth (Behringer et al. 2014; Schaebs et al. 2016), and uCP, a measure of nutritional status and energy balance (Deschner et al. 2008), can be valid alternatives.

C-peptide, a small polypeptide of pro-insulin, is enzymatically cleaved off pro-insulin during insulin synthesis in pancreatic $\beta$-cells (Horwitz et al. 1975; Bonser et al. 1984) and released into the bloodstream in equimolar numbers with insulin. C-peptide is cleared via the kidneys (Bonser et al. 1984) and urinary levels closely resemble plasma insulin levels (Goetz et al. 2002; Tsai et al. 2006). $\mathrm{uCP}$ levels have been experimentally validated as a measure of energetic status in macaques, with levels decreasing under fasting and increasing under re-feeding conditions (Girard-Buttoz et al. 2011; Higham et al. 2011). They also track food availability, energy intake (Emery Thompson \& Knott 
2008; Emery Thompson et al. 2009), and energy expenditure (Grueter et al. 2014) in nonhuman primates. Consequently, uCP levels can be employed to assess individual physical condition. Measuring uCP could readily be applied for this project to address the open questions with regard to the directionality of the relationship between host nutrition and parasite infections.

\subsection{2c Aging and immunosenescence}

Age is one major predictor of heterogeneity in parasite distribution within a host population (Wilson et al. 2002; MacIntosh et al. 2010; Poirotte et al. 2016). Susceptibility to infections can be influenced by age, with the acquisition of protective immunity being a prominent example (reviewed in Wilson et al. 2002). If hosts develop protective immunity against a pathogen infection, infection prevalence or intensity displays a U-shaped distribution: it peaks at a young age, followed by a rapid decrease upon acquisition of protective immunity. If infections are chronic, parasites can accumulate in individuals that fail to elicit efficient immune responses (Else \& Grencis 1991; Else et al. 1992). Immune function can be flexible and change according to individual condition and life history (Jackson et al. 2014). Physiological correlates of aging and senescence have attracted much attention in studies of human health, but are still largely neglected wildlife (Nussey et al. 2013; Reichard 2016).

Aging has profound effects on immune system regulation and efficiency, resulting from age related physical decline referred to as immunosenescence. These changes occur consistently in both the innate and adaptive immune system and include altered cytokine profiles, like increases in IFN-y and NEO levels (Frick et al. 2004; Murr et al. 2004; Leng et al. 2011), depletion of naïve T-cell population with simultaneous increase in differentiated T-cell population (Faria et al. 2008; Deeks 2011), changes of monocyte phenotypes (Hearps et al. 2012; Martin et al. 2013) and decline in innate immune response and natural killer cell function (Hawkley \& Cacioppo 2004; Goodwin et al. 2006; Deeks 2011; Li et al. 2011; Solana et al. 2012). Another major correlate of immunosenescence is chronic low level inflammation (Fulop et al. 2010; Li et al. 2011; Solana et al. 2012), which can also be induced by social and physiological stress (Hawkley \& Cacioppo 2004; Kiecolt-Glaser et al. 2010).

The changes corresponding to immunosenescence predict lower vaccination efficiency (Goodwin et al. 2006; Čičin-Šain et al. 2010) and thus indicate higher disease susceptibility. Immunosenescence is also linked to morbidity, frailty and cognitive decline in humans (Li et al. 2011; Parker et al. 2013; Wang \& Casolaro 2014). Immune physiology and immune aging are comparable between humans and nonhuman primates (Haberthur et al. 2010; Messaoudi et al. 2011; Meyer et al. 2012; Didier et al. 2016). The study population at Affenberg Salem provides an excellent system to study age related variation in health and parasite susceptibility, as semi-free ranging conditions, including food provisioning and absence of predation) result in the opportunity to study a high number of senescent individuals. I focus specifically on the feasibility of uNEO levels as a marker of immunosenescence in Chapter 2 of this thesis. 


\subsubsection{Behaviour and pathogen transmission}

For successful transmission, susceptible host must be exposed to the respective pathogen (Hawley et al. 2011). For many host traits and behaviours, their roles and relative contribution to either component of transmission are not clear-cut. Physiological processes can simultaneously determine host susceptibility and behavioural patterns relating to pathogen exposure, creating either positive or negative covariation (Hawley et al. 2011). Dominance rank serves as an intuitive example: high ranking individuals usually express specific endocrinological patterns, often characterized by high levels of GCs and testosterone (Sapolsky 2005; Muehlenbein \& Watts 2010; Archie 2013), and specific social behaviour patterns, like occupying central positions in a social network and frequently participating in agonistic or affiliative interactions (Sapolsky 2005; Drewe 2009; MacIntosh et al. 2012; Tiddi et al. 2012). Covariation between susceptibility and exposure can also explain variation of infection risk based on individual characteristics, like sex and rank (Habig \& Archie 2015; Habig et al. 2018).

Both components of transmission and their respective links with behaviour have been intensely studied (Altizer et al. 2003; Cohen et al. 2003; Ezenwa 2004a; Sapolsky 2004, 2005; Pedersen \& Greives 2008; Muehlenbein \& Watts 2010), yet studies assessing both processes simultaneously are relatively rare (MacIntosh et al. 2012; Friant et al. 2016a), and covariation between exposure and susceptibility has been largely neglected (Hawley et al. 2011). Consequently, to which extend certain behaviours contribute to exposure, susceptibility, or both, is still largely unclear. Here, I investigate the role of several exposure and susceptibility measures on GI helminth transmission simultaneously to provide a more complete picture of the interplay between host physiology, behaviour and parasite infections in Chapter 4.

\subsubsection{Specific aims and contributions to the field}

The overall aim of this study is to provide a comprehensive picture of the relationship between GI helminths and their host, the Barbary macaque (illustrated in Figure I), with special focus on the role of social relationships. Taking advantage of experimental strongyle nematode clearance, I test the directionality of the relationships between host physiology, behaviour and strongyle nematodes, assessing costs of infections and predictors of reinfection.

In study 1 (Chapter 2), I focus on assessing the feasibility of uNEO as a marker for immune function in semi-free ranging Barbary macaques at Affenberg Salem. I take two predictors of uNEO levels into account: Anthelmintic treatment, as parasite clearance could shift Th1/Th2 immune balance towards Th1-type responses, and aging, as NEO levels correspond with a range of markers of immunosenescence in humans and nonhuman primate models of aging.

In study 2 (Chapter 3), I investigate the consequences and potential health costs of strongyle nematode infection linking host physiology and behaviour to parasite infections. To account for 
uncertainty in noninvasively assessed infection status, I estimate infection probabilities using patch occupancy modelling. I test if individual infection probability affects HPA axis activation (fGCM levels), body condition (uCP levels) and activity (proportion of time individuals spent active vs. resting) as estimates of sickness behaviour. I also test whether social behaviour is influenced by parasite clearance and which underlying process, sickness behaviour or avoidance of infected conspecifics, explains these changes by including both own and partner infection status as predictors of individual proximity initiations.

In study 3 (Chapter 4), I assess the predictors of reinfection after strongyle parasite clearance. I include measures of exposure and susceptibility and use a combination of patch occupancy modelling and information theoretic model selection to find the models best predicting reinfection patterns. To test whether social bonds protect from infection via reduced susceptibility, I include a measure of social bond strength for same and opposite sex partners. I include fGCM, uCP and uNEO levels and coinfection with further helminths as physiological measures of susceptibility. To disentangle environmental and social components of transmission, I include measures of environmental exposure (individual space use and exposure to faecal contaminations on the soil), and social contact (grooming) simultaneously.

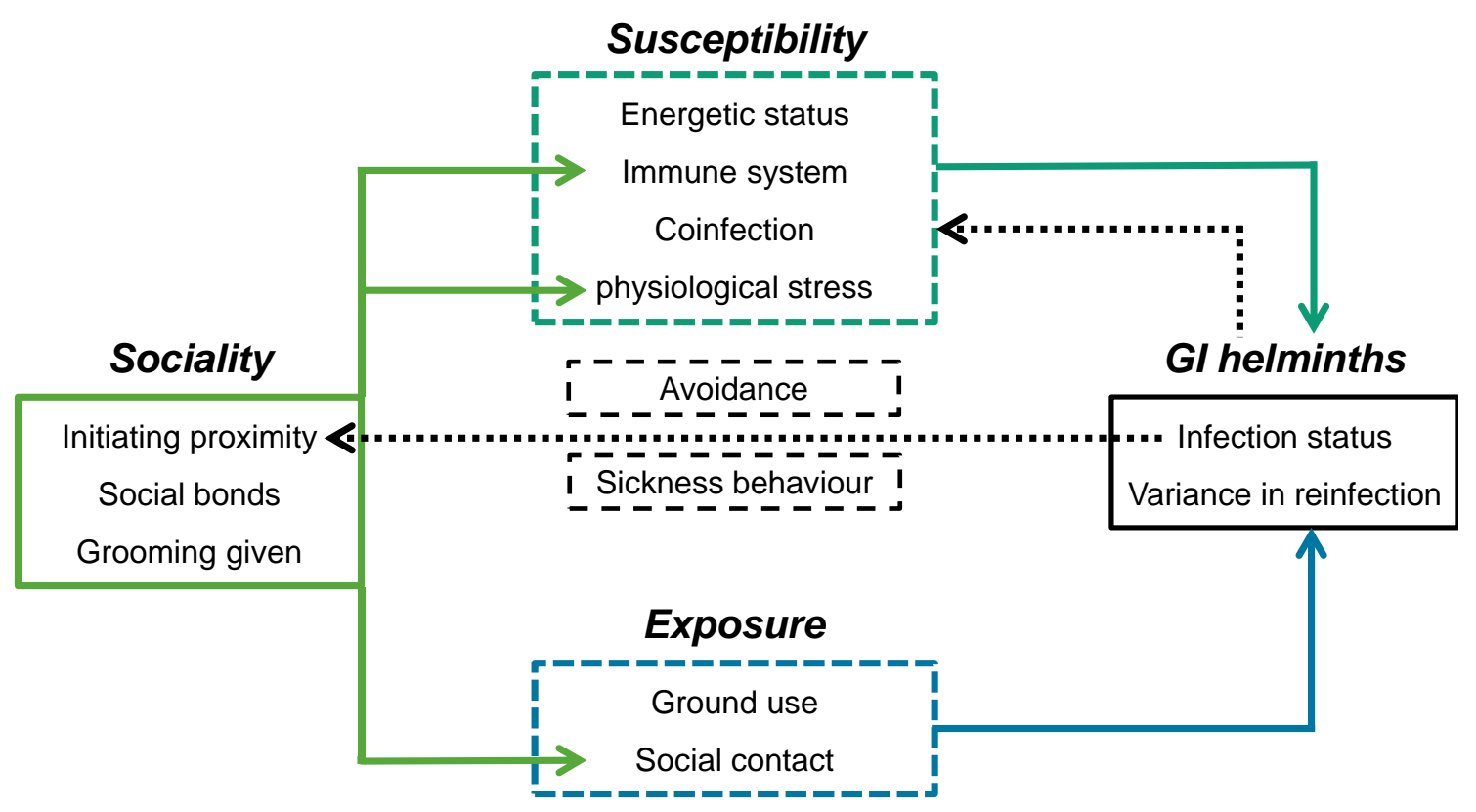

Figure I: Flowchart illustrating the links investigated in this thesis, with solid lines indicating the host to parasite and dashed lines the parasite to host direction. Arrowheads ending at the respective boxes indicate the entire aspect is potentially influenced, while arrowheads crossing into the boxes represent a link to a specific measure. Parasite clearance after anthelmintic treatment allows me to test the connections in both directions. 


\section{Chapter 2}

Age, but not anthelmintic treatment, is associated with urinary neopterin levels in semi-free ranging Barbary macaques

Nadine Müller ${ }^{1)}$, Michael Heistermann²), Christina Strube ${ }^{3)}$, Oliver Schülke ${ }^{1,4^{*}}$, Julia Ostner $\left.{ }^{1,4^{*}}\right)$

1) Department of Behavioural Ecology, University of Göttingen, Germany 2) Endocrinology Laboratory, German Primate Centre, Germany

3) Institute for Parasitology, University of Veterinary Medicine Hannover, Germany

4) Research Group Primate Social Evolution, German Primate Centre, Germany

* Oliver Schülke and Julia Ostner contributed equally as last authors

\section{Scientific Reports (2017)}

7:41973 | DOI: 10.1038/srep41973 https://www.nature.com/articles/srep41973 


\section{Abstract}

Studying host parasite interactions and their implications for evolution and ecology recently received increasing attention, particularly with regard to host physiology and immunity. Here we assess variation of urinary neopterin (uNEO), a marker of cellular immune activation and immunosenescence, in response to age and anthelmintic treatment in semi-free ranging Barbary macaques (Macaca sylvanus). Urinary NEO levels were measured via enzyme-immunoassay from 179 urine samples of 43 individuals between 5-29 years of age. Efficiency of treatment was assessed by Mc Master flotation on repeated faecal samples, including 18 untreated individuals as control group. We used linear mixed models with age and parasite status as main effects, controlling for sex and physical condition, assessed through urinary C-peptide levels, with social group and ID as random factors. Urinary NEO levels significantly increased with age, suggesting that changes in aging Barbary macaque immune responses are consistent with immunosenescence described in humans and nonhuman primates and can be detected via uNEO measurements. Anthelmintic treatment, however, had no influence on uNEO levels, potentially due to quick reinfections or attenuated immune responses in repeated infections. We conclude that uNEO is a potential non-invasive marker for immune function and particularly immunosenescence in wildlife. 


\section{Chapter 3}

\section{Physiological and social consequences}

\section{of gastrointestinal nematode infection in a nonhuman primate}

Nadine Müller-Klein ${ }^{1)}$, Michael Heistermann ${ }^{2)}$, Christina Strube ${ }^{3)}$, Zina Maria Morbach ${ }^{1,4)}$, Navina Lilie ${ }^{1,5)}$, Mathias Franz 6), Oliver Schülke ${ }^{1,7)^{\star}}$, Julia Ostner ${ }^{1,7)^{\star}}$

1) Department of Behavioural Ecology, University of Göttingen, Germany

2) Endocrinology Laboratory, German Primate Centre, Germany

3) Institute for Parasitology, University of Veterinary Medicine, Hannover, Germany

4) Department of Life Sciences, University of Roehampton, United Kingdom

5) Department of Animal Behaviour, Bielefeld University, Germany

6) Department of Wildlife Diseases, Leibniz Institute for Zoo and Wildlife Research,

Germany

7) Primate Social Evolution, German Primate Centre, Germany

* OS and JO contributed equally as senior authors

Behavioral Ecology (2018)

available online | DOI: 10.1093/beheco/ary168

https://doi.org/10.1093/beheco/ary168 


\section{Abstract}

Gastrointestinal nematodes are intensely studied models for host-pathogen interactions in wildlife, yet consequences of infections are not fully understood. Among the potential costs of nematode infection are physiological changes caused by immune system activation, reduction or reallocation of available energy, as well as potential social consequences in terms of decreased social activity or avoidance of infected individuals. We used experimental anthelmintic treatment to investigate effects of strongyle nematode infection in Barbary macaques (Macaca sylvanus), comparing 56 treated to 17 untreated individuals. Deworming success was monitored by coproscopy and infection probability estimated from patch occupancy models. Increasing strongyle infection probabilities were associated with increased fecal glucocorticoid metabolite levels and slightly decreased activity and had no significant effect on energy balance quantified as urinary C-Peptide levels. The frequency to approach into close spatial proximity of a partner was predicted by the partner's, but not focal individual's infection status, with a tendency toward infected individuals being approached less frequently. Although effects were weak, they suggest a co-occurrence of sickness behavior and avoidance of infected conspecifics, both possibly shaping social interaction patterns with potential consequences for an individual's social relationships. This study adds to the growing body of research on the complex interactions of sociality, health, and fitness in a group living species.

Keywords: avoidance behavior, parasites, physiology, primates, sickness behavior 


\title{
Chapter 4
}

\section{Exposure and susceptibility drive reinfection}

\section{with gastrointestinal parasites in a social primate}

\begin{abstract}
Nadine Müller-Klein 1), Michael Heistermann 2), Christina Strube ${ }^{3)}$, Mathias Franz ${ }^{4)}$, Oliver Schülke ${ }^{1,5)^{\star}}$, Julia Ostner ${ }^{1,5)^{*}}$
\end{abstract}

1) Behavioural Ecology, University of Göttingen, Germany

2) Endocrinology Laboratory, German Primate Centre, Germany

3) Institute for Parasitology, University for Veterinary Medicine, Hannover, Germany

4) Department of Wildlife Diseases, Leibniz Institute for Zoo and Wildlife Research,

Germany

5) Primate Social Evolution, German Primate Centre, Germany

* OS and JO contributed equally as senior authors

Functional Ecology (2019)

available online | DOI: 10.1111/1365-2435.13313

https://doi.org/10.1111/1365-2435.13313 


\section{Abstract}

1. Increased risk of infectious disease transmission has been proposed as one major cost of group living. While factors corresponding to transmission via exposure to infectious stages and susceptibility to contracting infections upon contact are relatively well understood, both aspects are rarely investigated simultaneously.

2. Here, we assessed the influence of exposure and susceptibility measures on strongyle nematode reinfection after experimental deworming of Barbary macaques (Macaca sylvanus) $(\mathrm{n}=57)$. We investigated impacts of behaviour (social bonds, grooming and ground use) and physiology (faecal glucocorticoids, urinary C-Peptides, urinary neopterin, gastrointestinal [G] helminth coinfection) on the likelihood of reinfection, using patch occupancy modelling and information theoretic model selection to determine the best models predicting reinfection patterns.

3. Coinfection was the most consistent risk factor, spending time on presumably contaminated soil, interacting with many partners and forming strong same sex bonds also tended to increase infection risk. In contrast, strong social bonds with opposite sex partners had a consistently protective effect.

4. Our results indicate that coinfections could serve as an integrative measure of individual disease susceptibility. Furthermore, we show that social contact contributes to both exposure and susceptibility to environmentally transmitted parasites, with the outcome depending on specific interactions patterns.

Keywords: anthelmintic treatment, exposure, gastrointestinal parasites, nonhuman primate, reinfection, susceptibility, social relationships 


\section{Chapter 5}

\section{General Discussion}

In the following chapter, I will summarize and discuss the host-parasite interactions between Barbary macaques and strongyle nematodes with a specific focus on the role of sociality. Having established the effectiveness of treatment against strongyle nematodes in Chapters 2, 3 and 4, I will discuss causes and effects of infections, drawing stronger causal inferences than possible in correlational studies. I will set the results in context with the current knowledge of the connections between parasites, behaviour and physiology in wildlife, particularly primates. To this end, I will discuss the impact of GI helminths on health related parameters and the factors predicting reinfections, with regard to both physiology and behaviour. I will briefly discuss the connection between aging and GI helminth infections and the role of aging for individual health parameters. Drawing on results on the relationship between social behaviour and parasite infections, I will discuss how GI helminths can influence sociality and impact social evolution. I will end with an outlook on steps for future research needed to disentangle the roles of social interactions for exposure and susceptibility and to further our understanding of host-behaviour-physiology relationships and their evolutionary implications in wildlife.

\subsection{Consequences of GI helminth infections}

To ensure their own reproductive success and transmission, GI nematodes usually do not cause overt sickness in their hosts (Greer 2008; Krief et al. 2008). In our study population, infection with strongyle nematodes, most prominently Oesophagostomum spp., was the norm rather than the exception, with generally low egg counts and comparably low variation in egg shedding (see Figure II). As individuals are likely faced with trickle infections and constant reinfection, persistent egg shedding does not necessarily represent chronic infection, but can also result from a balance between parasite clearance and becoming reinfeced (Wilson et al. 2002). Faecal egg counts are not always related to actual worm burden in Oesophagostomum infections (Christensen et al. 1995; Roepstorff et al. 1996), with lowest egg shedding in pigs infected with the highest number of larvae in an experimental study (Christensen et al. 1995). Thus, it is difficult to assess parasite resistance in my dataset, but the absence of natural parasite clearance is not necessarily suggestive of a lack of protective immunity (Grencis et al. 2014). Despite the overall low egg counts and absence of obvious behavioural signs of infections, infections are not arbitrary to Barbary macaques, as became apparent upon closer investigation of the physiological and behavioural consequences relating to infection. 
Treatment did not influence Th1 immunity, measured as uNEO (Chapter 2), but fGCM levels were associated with infection (Chapter 3), with higher levels in infected individuals (Fleming 1997; Pedersen \& Greives 2008; Friant et al. 2016b), indicating that GI helminths lead to HPA axis activation (Friant et al. 2016b). Given the ubiquity of strongyle infections and the low likelihood of natural parasite clearance in the study population (see Chapter 3 Figure 1), it is likely that infections lead to higher baseline fGCM levels. As chronic HPA axis activation and GI helminth infection generally lead to suppression of immune function and lowered Th1 responses (Maizels \& Yazdanbakhsh 2003; Glaser \& Kiecolt-Glaser 2005; Grencis et al. 2014), this could be considered a health cost with potentially detrimental consequences (Apanius 1998; Glaser \& Kiecolt-Glaser 2005).

Individuals infected with strongyle nematodes were less active (Chapter 3), which, like elevated fGCM levels, can be a sign of inflammatory cytokine induced sickness behaviour (Hart 1988; Dantzer 2009). Inflammatory responses due to tissue damage are common in GI helminth infections (Stephenson et al. 2000a; Loukas et al. 2005; Bethony et al. 2006), resulting also from larval encystation in the gut mucosa in case of Oesophagostomum infections (Dash 1973; Krief et al. 2008; Terio et al. 2016). Similar associations of GI helminth infections and reduced activity have been described in correlational (MacIntosh et al. 2011; Ghai et al. 2014) and experimental studies (Adams et al. 1994; Chapman et al. 2016; Friant et al. 2016b) and interpreted as an attempt to conserve energy (Hart 1988; Dantzer 2001; Konsman et al. 2002), or as a result of decreased physical condition due to infection (Coop \& Kyriazakis 1999; Ezenwa 2004b). In the present study, physical condition, monitored by uCP levels, was not affected by strongyle nematode infections (Chapter 3). The results closely resemble those of a recent parasite clearance study on semi-free ranging, provisioned mangabeys, reporting increased GC levels and decreased activity prior to treatment, but no relationship between GI nematodes and body condition (Friant et al. 2016b), maybe suggestive of a general primateparasite interaction pattern. The absence of an effect of parasites on physical condition may be the result of provisioning, allowing ample access to high quality food and buffering against nutritional costs of GI nematode infection in both studies, or effectiveness of energy conservation via reduced activity. Considering the suggested effect of high $\mathrm{uCP}$ levels leading to increased reinfection risk in the study population at Affenberg (Chapter 4), I suggest the alternative interpretation that good physical condition during persisting infections can result from parasite tolerance as a defence strategy to mitigate the costs of GI parasite infections.

Faced with GI helminth infections and the likelihood of chronic infections (Grencis et al. 2014), there are essentially three available strategies: avoidance, which I will discuss in detail below, resistance, and tolerance (Råberg et al. 2009; Hart 2011; Medzhitov et al. 2012; Curtis 2014). The overall picture in the study population is suggestive of the presence of tolerance mechanisms in response to strongyle infections, which is not mutually exclusive with resistance (Hayward et al. 2014a). Considering the low pathogenicity of GI helminths under normal conditions (Greer 2008; 
Krief et al. 2008), the idea that health costs do not necessarily result from infections, but are consequences of immunopathology and unchecked immune responses (Graham et al. 2005; Colditz 2008), has been put forward. Experimental GC level elevations led to higher egg counts, but prevented reduction in weight gain in an experimental study in lambs (Greer et al. 2005), indicating a potentially beneficial role of HPA axis activity induced immunomodulation. Similarly, Soay sheep mounting strong resistance responses to GI helminth infections suffered from poorer physical condition than those more tolerant of GI infections (Hayward et al. 2014a, b). My results suggest that individuals with high uCP levels prior to treatment become reinfected quicker (Chapter 4). Evidence from both humans and ungulates suggests that parasite burdens after anthelmintic treatment return to levels similar to those before treatment (Grencis et al. 2014; Budischak et al. 2016), indicating some predisposition to infections. Assuming similar processes in Barbary macaques, high pre-treatment physical condition predicting earlier reinfection can be interpreted as a sign of tolerance rather than higher susceptibility to strongyle infections.

There was no evidence for parasite induced suppression of Th1 immune responses, i.e. lower uNEO levels in infected individuals (Murr et al. 2002; Ezenwa et al. 2010). This suggests that individuals did not mount strong Th2 responses (Long \& Nanthakumar 2004), which could lead to chronic rather than transient GI nematode infections (Else \& Grencis 1991; Urban et al. 1992; Else \& Finkelman 1998). A possible benefit is the mitigation of the energetic costs of mounting an immune response (Bonneaud et al. 2003; Derting \& Compton 2003) and prevention of increased susceptibility to microparasite infections as a result of parasite induced Th2 immune dominance (Graham 2008; Salgame et al. 2013; Ezenwa \& Jolles 2015). Testing whether strongyle infections indeed contribute to microparasite transmission or disease progression is beyond the scope of this thesis, but instead of being detrimental, the immunomodulatory effects of GCs could be a sign of parasite tolerance and advantageous, with higher levels in infected individuals leading to increased long-term fitness and health.

The relationship between parasite infection and tolerance is likely not as straightforward as presented here, and distinguishing tolerance from resistance is difficult as mechanisms mediating parasite resistance and tolerance can result in very similar physiological outcomes. Tolerance is typically measured by assessing the costs of infection in relation to infection severity, with tolerant individuals characterized by lower health costs of higher pathogen burdens (Råberg et al. 2009; Medzhitov et al. 2012; Hayward et al. 2014b). Intriguingly, the levels of tolerance vs. resistance displayed by the host could play a role in explaining why GI helminth infections in primates are usually subclinical, but can be detrimental and even cause mortality (Hotez et al. 2005; Bethony et al. 2006; Krief et al. 2008; Degarege et al. 2014; Terio et al. 2016). Additionally, there is likely not one optimal strategy to handle GI helminth infections: tolerance has been linked to a trade-off between reproduction and physical condition repeatedly (Hayward et al. 2014a, b; Jackson et al. 2014), with 
increased chances of survival after investing in physical condition coming at costs for reproductive success (Graham et al. 2010; Hayward et al. 2014b). Understanding the health and fitness consequences of employing different defence strategies and under which conditions tolerating infections is more advantageous than mounting immune responses aimed at parasite clearance will be important steps in future research on the impact of GI helminth infections on host evolution.

Parasites can change host behaviour via social withdrawal connected to sickness behaviour, and behavioural strategies of infection avoidance (Dantzer 2004; Medzhitov et al. 2012; Hennessy et al. 2014; Eisenberger et al. 2017). In past studies on nonhuman primates, reduced sociality has been attributed to avoidance of infected individuals (Chapman et al. 2016; Friant et al. 2016b) rather than sickness behaviour. Both mechanisms are not mutually exclusive and can even reinforce each other, i.e. infected individuals avoiding others likely to be infected in order to avoid exposure to further, especially directly transmitted, pathogens (Curtis 2014; Eisenberger et al. 2017). To test whether social behavioural changes result from sickness behaviour or avoidance, I analysed behavioural changes in response to GI helminth infection on a dyadic level, accounting for both individual and potential partner infection status.

Despite the reduced activity in response to infection, individuals did not initiate proximity less often or depart more often from others if they were infected with GI helminths (Chapter 3). This illustrates the importance of maintaining social bonds for social animals like nonhuman primates (Silk et al. 2009; Micheletta et al. 2012; Ostner \& Schülke 2014), even in situations where energy needs to be allocated away from overall activity. Instead, individuals seemed to avoid infected conspecifics, as they were less likely to approach infected partners. Avoiding infected individuals is frequently reported for directly transmitted unicellular parasites (Kavaliers \& Choleris 2011; Curtis 2014; Poirotte et al. 2017) and GI helminths (Kavaliers \& Colwell 1995). Avoidance is likely mediated by olfactory cues (Kavaliers \& Colwell 1995; Hennessy et al. 2014; Poirotte et al. 2017) corresponding to innate immune system activation (Olsson et al. 2014). Therefore, it is probably not directed towards GI helminth infected conspecifics, but rather to individuals displaying general signs of sickness and infection (Hart 2011; Curtis 2014). Although Th1 responses were not obviously influenced in my study population (Chapter 2), strongyle infections could be predictive of infections with microparasites (Cox 2001; Fenton et al. 2008; Graham 2008) transmitted via physical contact (Balasubramaniam et al. 2016; Poirotte et al. 2017; Springer et al. 2017), with avoidance as a viable strategy to minimize the risk of disease transmission.

At first sight, given the overall tendency of reduced social contact linked to inflammatory cytokine mediated sickness behaviour (Hennessy et al. 2014; Eisenberger et al. 2017) and infection with GI parasites (Chapman et al. 2016; Friant et al. 2016b), the absence of social withdrawal as part of sickness behaviour in the study population seems counterintuitive. However, the expression of sickness behaviour in response to inflammatory cytokines is context dependent in laboratory studies 
and can be suppressed in e.g. mating or pup rearing context (Hennessy et al. 2014). Furthermore, in both rodents and rhesus macaques, inflammatory signalling can lead to increased social contact (Willette et al. 2007; Hennessy et al. 2014; Eisenberger et al. 2017), especially with familiar partners. Faced with infection, seeking out social support may be beneficial for survival and even contribute to enhanced immune efficiency (Hennessy et al. 2014), e.g. if social interactions convey thermoregulatory benefits (McFarland et al. 2015). Consequently, individuals could adapt their social behaviour to their own infection status and their social environment, i.e. infection status of available partners, simultaneously, creating complex interactions between sociality and GI nematode infection. If individuals with similar social environments are also experience similar exposure and susceptibility to infections (Hawley et al. 2011; Ezenwa et al. 2016), parasite infections could contribute to sub-structuring within a social group. High clustering within networks can reduce transmission of pathogens and overall parasite prevalence within a group (Griffin \& Nunn 2012; Nunn et al. 2015), adding a further level of complexity.

Strongyle infections did not appear to alter immune function in Barbary macaques, but immuneparasite interactions could be influenced by individual aging. In the study population, uNEO levels increased with age (Chapter 2), resembling patterns in humans (Hawkley \& Cacioppo 2004; Murr et al. 2004; Deeks 2011; Didier et al. 2016) and indicative of decreasing immune function in older individuals (Murr et al. 2004). Older Barbary macaques did not only suffer from decreased immune function, but also experienced increased fGCM levels, reduced activity and poorer physical condition, observations often made in aging primates and humans (Fulop et al. 2010; Didier et al. 2016). These findings are also in line with increased low level inflammation in older individuals (Hawkley \& Cacioppo 2004; Deeks 2011).

Lacking longitudinal data, I can only speculate on the directionality between GI parasite infection and age related physiological changes, yet want to argue that parasite infections were likely the result, not the cause of age-related decline of immune function. Egg shedding patterns in individuals aging a few months to almost 30 years were age dependent (see Figure II). For strongyle nematodes, egg counts remained largely constant after increasing for the first few years of life, with higher variation and counts in aged individuals. For the concomitant GI helminth taxa at Affenberg, Capillaria spp. and Trichuris spp., egg shedding patterns roughly followed a U-shaped distribution. Egg shedding peaked early in life, ceased by the time individuals reach adulthood and resumed in old individuals, with increasing egg counts as aging progressed.

Increased GI parasite richness with older age is common in primates and reported for e.g. Japanese macaques (MacIntosh et al. 2010) and Capuchin monkeys (Cebus capucinus) (Parr et al. 2013). The absence of parasite eggs throughout most of adult life suggests that the Barbary macaques of my study population developed protective immunity or strong immune responses capable of clearing 

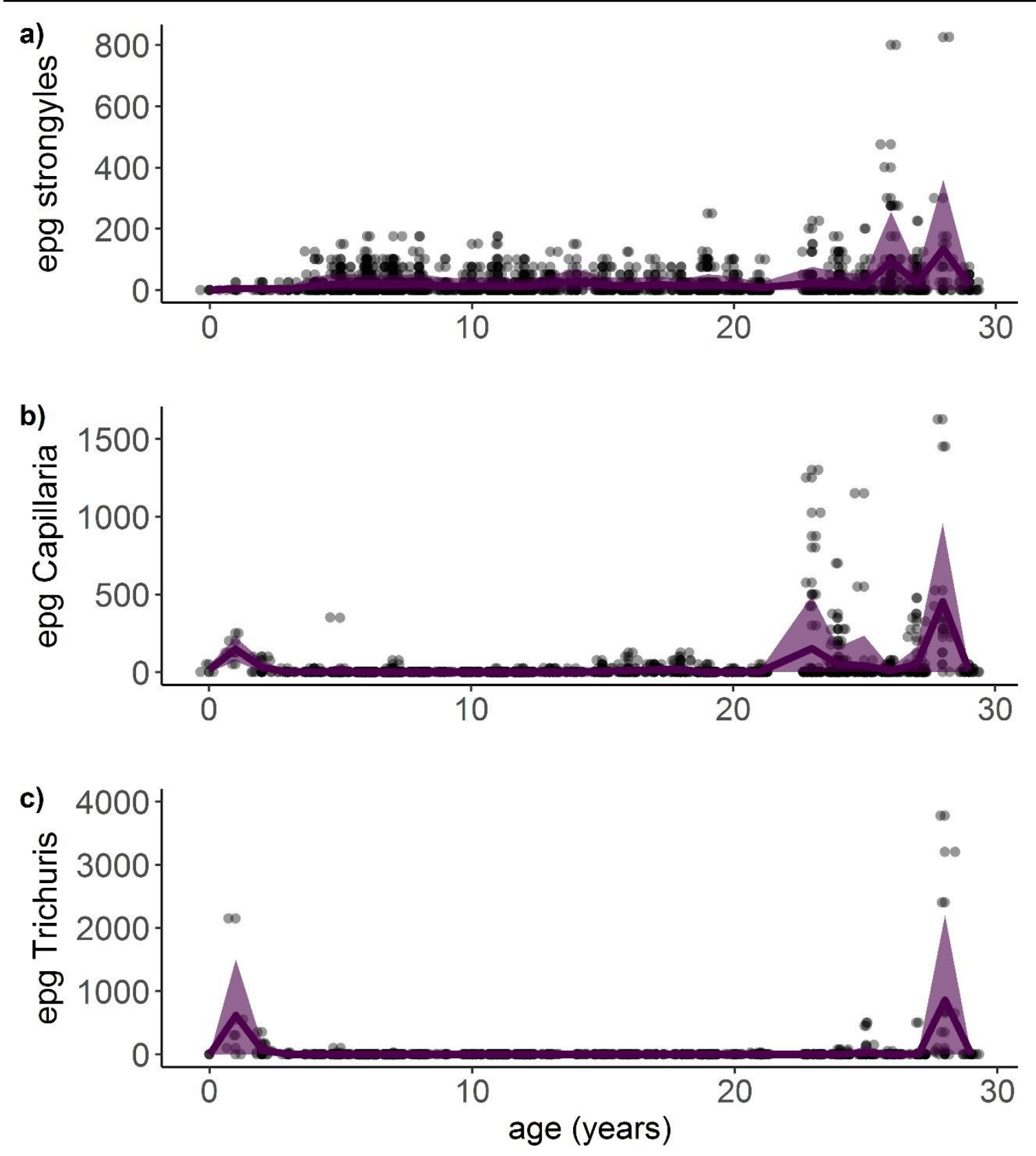

Figure II: Overview over eggs per gramm faces (epg), including 1436 samples analysed for focal individuals and additional 46 samples of infant to subadult individuals not included in the study. Data represent the age range of the Barbary macaques at Affenberg Salem, ranging from infants (individuals younger than one year coded as 0 ) to 29 years of age. Datapoints represent individual samples, lines mean eggs per gram faeces (epg) shaded areas the corresponding standard deviations of epg.

Capillaria and Trichuris infections (Else et al. 1992; Wilson et al. 2002; Grencis et al. 2014; Andreasen et al. 2015). Immunosenescence leads to increased Th1 signalling and a decline in adaptive immune system function (Murr et al. 2004; Faria et al. 2008; Bauer et al. 2009), potentially leading to the failure of protective immunity against GI helminths. Given the similar effects of aging and GI helminth infections on physiology, like increased HPA axis activity and inflammation, helminths could exacerbate the negative effects of aging, potentially leading to vicious circles and accelerating age related health deterioration (Hawkley \& Cacioppo 2004; Beldomenico \& Begon 2016). The study of 
physiological correlates of aging and age related mortality under natural condition has only recently attracted the attention of evolutionary ecologists (Hayward et al. 2009; Nussey et al. 2013; Reichard 2016), yet considering senescence and its drivers and effects has great potential to further our understanding of the interaction between ecology, life-history, physiology, parasites and health, especially in long-lived species like nonhuman primates.

\subsection{GI helminth transmission: Determinants of exposure}

Understanding parasite transmission pathways and how they relate to individual behaviour is vital for explaining inter-individual variance in infection risk as well as disease epidemiology. Despite the wealth of studies linking social network positions and behaviour to parasite transmission (Vicente et al. 2007; Drewe 2009; Godfrey et al. 2009; Fenner et al. 2011; VanderWaal et al. 2013, 2014; Weber et al. 2013), the exact mechanisms for GI helminth transmission in nonhuman primates remain elusive. Depending on the species, higher transmission risk has been described for individuals central in grooming (MacIntosh et al. 2012) or contact networks (Rimbach et al. 2015). Other studies report grooming partner diversity (Wren et al. 2016), high integration in proximity networks (Friant et al. 2016a), or combinations of partner numbers and spatial association (González-Hernández et al. 2014) to predict infection, but no impact of contact network integration (Friant et al. 2016a). Based on findings presented in Chapter 4, I will discuss how these discrepant findings could be explained and reconciled.

Strongyle nematodes have direct life cycles with mobile infective L3 larvae and their transmission usually occurs upon contact with contaminated soil or food (Dash 1973; Bethony et al. 2006; Viney 2017), yet a social component of transmission via direct contact to conspecifics has been suggested (MacIntosh et al. 2012; González-Hernández et al. 2014; Wren et al. 2016). Transmission could be linked to specific behaviours, like aggressive encounters in infectious tumour transmission in Tasmanian devils (Hamede et al. 2013) and receiving aggression and giving grooming in tuberculosis transmission in meerkats (Drewe 2009). To test for both environmental and social transmission pathways, I utilized measures of ground use and time in areas of high contamination as estimators of environmental exposure and active grooming as the most likely behaviour to contribute to transmission via social contact, based on the frequent hand to mouth contact (see Chapter 4). While ground use per se did not predict reinfection after treatment, spending time on contaminated soil did. Frequent social contact can contribute to GI helminth transmission (MacIntosh et al. 2012; Rimbach et al. 2015; Friant et al. 2016a), and infection risk increased with high grooming partner numbers and strong same sex bonds (Chapter 4), suggestive of a social component of strongyle nematode transmission.

Faecal contamination of the soil or water-source is widely recognized as a major source of exposure to GI helminths (Pebsworth et al. 2012; González-Hernández et al. 2014), yet rarely tested 
specifically. I suggest that proximity effects like detected for mangabeys (Friant et al. 2016a) are not mediated by the shared use of space per se, but result from a correlation between sharing space with conspecifics and spending time on contaminated soil. This argument can also explain the lack of proximity predicting infection risk in other studies (Rimbach et al. 2015), if contact with infective stages does not coincide with spatial proximity to others in the study groups. In Eastern chipmunks (Tamias striatus), not current, but past association networks, considering the time-gap between egg shedding and larvae becoming infective, predicted infection risk (Grear et al. 2013), illustrating the importance to consider parasite life cycles for studying transmission. In my study, ground use was not correlated with time spent in contaminated areas and did not predict infection risk, illustrating that rough approximations of exposure may not adequately capture the actual process underlying parasite transmission.

Various strongyle nematodes actively attempt to increase their transmission by positioning themselves in locations with higher likelihood of ingestion by their target host (Stromberg 1997), leading to host counterstrategies, like avoiding to forage in highly contaminated areas (Hutchings et al. 2002). Mobile hookworm larvae actively follow host cues and cling to dog hair (Granzer \& Haas 1991), and grooming can facilitate transmission of H. polygyrus larvae from mouse fur (Hernandez \& Sukhdeo 1995). Thus, transmission via contaminated fur can be an additional strongyle nematode transmission route. Grooming with a high number of partners increased infection risk in Barbary macaques (Chapter 4) and vervet monkeys (Wren et al. 2016), indicating higher risk to encounter infective larvae when grooming more different individuals. Grooming duration did not predict infection, but to which extent fur contamination is random or connected to certain partner attributes cannot be tested in the current dataset.

\subsection{GI helminth transmission: Determinants of susceptibility}

I found two major susceptibility measures predicting reinfection patterns, which will be discussed in the following: Infection with further GI helminths prior to treatment, and strong social bonds with opposite sex partners (Chapter 4).

Infections with multiple parasites are considered to be the norm rather than the exception (Graham 2008; Bordes \& Morand 2011; Ezenwa 2016). Double infections can aggravate infection intensity and duration: Mice coinfected with Nippostrongylus brasiliensis and H. polygyrus bakeri, show significantly higher egg counts and egg shedding duration of $N$. brasiliensis than single infected individuals (Budischak et al. 2015b). Coinfections can decrease susceptibility to GI helminths based on competition for resources (Lello et al. 2004; Budischak et al. 2015b; Vaumourin et al. 2015) or changes in the host immune system, including the production of cross-reactive antibodies (Cox 2001; Lello et al. 2004) and parasite excretion of cytokine-like substances (Grencis \& Entwistle 1997; Grencis et al. 2014). An example is the significantly increased anti-Oesophagostomum antibody response 
in Oesophagostomum-Trichuris infected vs. single infected pigs (Andreasen et al. 2015). With inhibitory and enhancing effects operating simultaneously, interactions between multiple parasites can be complex, as demonstrated by a study of wild rabbits: Mosgovoyia pectinate or Trichostrogylus retortaeformis infections were linked with lower Graphidium strigosum burden, whereas Cittotaenia denticulata and G. strigosum infections both increased likelihood of T. retortaeformis infections (Lello et al. 2004).

In my study population, I detected three morphotypes of two parasite orders: Strongyle nematodes of the order Strongylida, and the enoplid parasites Capillaria spp. and Trichuris spp. of the order Trichurida. Given the distant relatedness, cross-immunity reactions are unlikely, yet Trichuris infections have been shown to enhance anti-Oesophagostomum infections in pigs (Andreasen et al. 2015). However, coinfection with Capillaria, Trichuris, or both, led to higher reinfection risk with strongyle nematodes. Coinfections were largely limited to aged individuals likely to be subject to immunosenescence, so the presence of Capillaria and Trichuris could be an integrative signal of overall poorer host condition and immunocompetence. Prevalence of intestinal inflammatory and infectious diseases increases with age due to immunosenescence-related changes in the gut mucosal immune system (Mabbott et al. 2015). Young mice infected with Trichuris muris develop efficient immune responses with worm expulsion, whereas older individuals become susceptible to chronic infection (Humphreys \& Grencis 2002), with the underlying changes possibly extending to overall GI helminth susceptibility.

Immunosenescence probably contributes to coinfection and strongyle infection risk, but is likely not the only process involved, demonstrated by the lack of evidence for an impact of urinary NEO levels on reinfection. In Soay sheep, experiencing adverse environmental conditions earlier in life explained variation in egg counts beyond chronological age (Hayward et al. 2009), indicating that life history contributes to individual capacity to manage infections and age related changes in parasite responses. In the study population, increasing age was implied to reduce reinfection risk (Chapter 4), suggesting protective immunity against strongyle nematodes (Wilson $e t$ al. 2002). I suggest that in the case of Barbary macaques, infection with enoplid parasites could be a signal of increased susceptibility beyond uNEO, uCP and fGCM levels or chronological age, capturing individual life history, senescence and health deterioration. Coinfections are intensely studied to understand parasite communities and transmission dynamics (Salgame et al. 2013; Ezenwa \& Jolles 2015; Rynkiewicz et al. 2015; Ezenwa 2016), but are rarely considered as potential signals of overall host susceptibility (Pedersen \& Fenton 2015; Friant et al. 2016a).

The second strong predictor of reinfection was social bonds with opposite sex partners (Chapter 4), which reduced reinfection risk. There was no evidence of sex specific effects (Chapter 4), suggesting similar effects for both sexes. The protective effect probably resulted from lower susceptibility rather than lower exposure, as strong social bonds are inextricably linked with high 
levels of affiliative interactions. Lower susceptibility is likely mediated by better immune function and defence against pathogens in strongly bonded or socially well integrated individuals, i.e. social buffering (Cohen \& Wills 1985; Cohen et al. 1991, 1997; Kikusui et al. 2006; Cohen \& Janicki-Deverts 2009; Kiyokawa \& Hennessy 2018), with the well described protective effect against infectious diseases extending to GI helminths. The physiological processes mediating the buffering effect can be rooted in several pathways, which I will briefly discuss here.

The social buffering mechanism receiving most attention from behavioural ecologists is attenuation of HPA axis activity in face of a stressor. Socio-positive interactions and support from conspecifics reduce HPA axis activation from mouse to men (Shutt et al. 2007; Hennessy et al. 2009; Eisenberger \& Cole 2012; Kiyokawa \& Hennessy 2018), whereas social isolation, social instability and repeated exposure to severe stressors lead to increased HPA activity, dysregulation of HPA signalling and ultimately detrimental health effects (Capitanio et al. 1998; Cole et al. 2009; Hennessy et al. 2009; Hawkley et al. 2013). HPA axis activity is frequently linked to GI helminth infections (Chapman et al. 2006; Muehlenbein 2006; Pedersen \& Greives 2008; Muehlenbein \& Watts 2010; Setchell et al. 2010), and strong bonds have been demonstrated to attenuate physiological stress responses in wild male Barbary macaques (Young et al. 2014a) and chimpanzees (Wittig et al. 2016). In a range of studies (Barnard et al. 2003; MacIntosh et al. 2012; Friant et al. 2016a), including this one, HPA axis activation was not correlated with GI parasite infection risk, indicating that HPA axis regulation might not be the main mechanism linking sociality to decreased parasite infection risk. An influence of HPA axis activation cannot be excluded, yet my results suggest the presence of other mechanisms underlying the protective effect of social bonds.

A second signalling pathway for stress responses is the SNS, which has been largely neglected in studies of social buffering in natural populations due to the limits of noninvasive assessment. SNS activation often occurs in parallel to HPA axis activation and is similarly important for immune signalling, e.g. via nervous signalling to lymphatic tissue (Elenkov et al. 2000; Sloan et al. 2008; Eisenberger \& Cole 2012; Capitanio \& Cole 2015). Socio-positive interactions reduce SNS activation (Eisenberger \& Cole 2012; Inagaki \& Eisenberger 2016), facilitating the stress reducing effects of social buffering (Kiyokawa \& Hennessy 2018) and offering an alternative route of social interactions to affect health. Additionally, release of oxytocin and endorphins in responses to both stressors and socio-positive interactions could play a role for social buffering (Keverne et al. 1989; Curley \& Keverne 2005; Kikusui et al. 2006; Uchino 2006; Eisenberger \& Cole 2012; Li et al. 2017; Plein \& Rittner 2017). Oxytocin can improve health outcomes by HPA axis downregulation (Kikusui et al. 2006; Li et al. 2017), and enhanced wound healing (Archie 2013; Li et al. 2017), and is suggested to play a role in mediating the anti-inflammatory effects of endorphins (Eisenberger \& Cole 2012; Hennessy et al. 2014). Both signalling pathways can contribute to immunomodulation, facilitating later reinfection in individuals with strong opposite sex bonds, which could be a mechanism linking 
strong bonds and social integration to increased longevity and reproductive success (Silk et al. 2003, 2010; Uchino 2006; Cameron et al. 2009; Holt-Lunstad et al. 2010). However, social interactions can contribute to exposure, and social bonding is not universally beneficial with regard to GI helminth infections. Quite contrary, strong bonds with same sex partners increased reinfection risk. In the following section, I will explain this discrepancy and assess the costs and benefits of sociality with regard to parasite infections in the study population, extending to the implications for social evolution in a wormy world.

\subsection{Costs and benefits of sociality - or: how to not get cut by sociality's double-edged sword}

Social relationships, albeit crucial for both sexes, are connected to a whole range of challenges and benefits traded off against each other. Both same and opposite sex bonds can increase reproductive success and survival (Silk et al. 2003, 2009; Schülke et al. 2010; Archie et al. 2014), implying similar beneficial effects of bonding for both sexes. In my study, contrary to the protective effect of strong opposite sex bonds, same sex bonds increased reinfection risk, irrespective of individual sex (Chapter 4). I want to offer several, non-mutually exclusive explanations for this finding.

Faced with intense stressors, the presence of unfamiliar conspecifics can attenuate fear and stress responses in laboratory rodents (Ishii et al. 2016; Kiyokawa et al. 2018). However, buffering effects can be partner dependent, like oxytocin release in chimpanzees, which occurs when grooming with bonded, but not non-bonded partners (Crockford et al. 2013). Attenuated stress responses could result from a lower perceived threat of the stressor in presence of conspecifics, as the danger of confronting the stressor might be reduced with increasing numbers (Kikusui et al. 2006; Kiyokawa \& Hennessy 2018; Kiyokawa et al. 2018). Depending on the situation, buffering effects should be specific to partners able to mitigate the threat of the stressors (Kikusui et al. 2006; Kiyokawa \& Hennessy 2018), like access to strongly bonded partners who reliably provide support in agonistic interactions (Schülke et al. 2010; Berghänel et al. 2011), which reduces HPA axis activation in male macaques (Young et al. 2014a). Depending on the situation, different partner characteristics might be capable of facilitating buffering effects, explaining the different effects of same and opposite sex bonds.

A second explanation is that despite using the same measure, sum of the top three dyadic CSI (Silk et al. 2006), to social bonds, same and opposite sex bonds could be linked to different mediators of exposure and susceptibility. Social behaviour is inextricably linked with both exposure to pathogens and changes in physiology that can mediate susceptibility (Hawley et al. 2011; Ezenwa et al. 2016; White et al. 2017a), and disentangling the precise exposure and susceptibility correlates of 


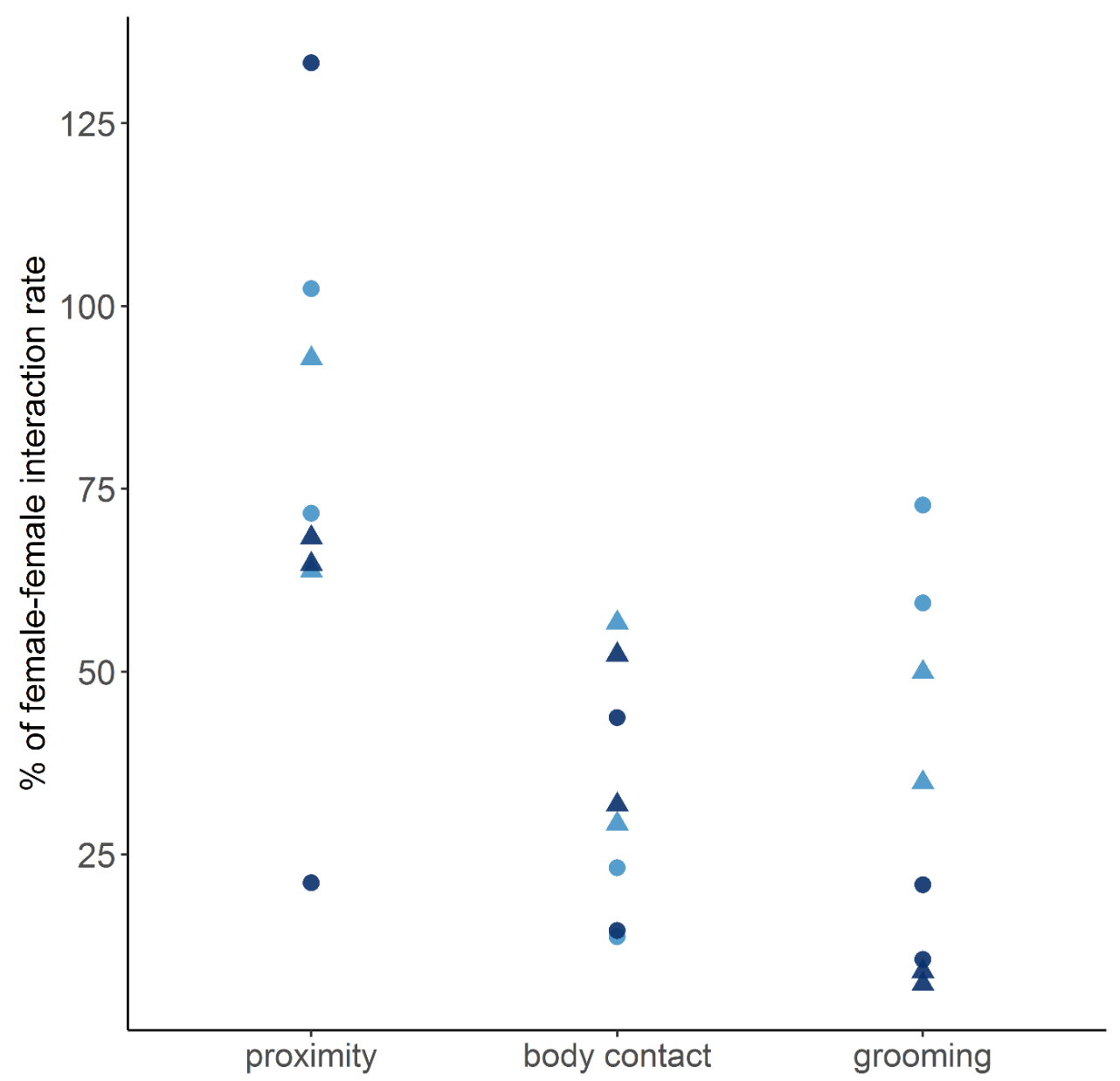

Figure III: Comparison of social interactions used for dyadic CSI construction in relation to average female-female interaction rates. Values for male-female dyads are coloured light blue, values for male-male dyads in dark blue. Displayed are average interaction rates (dots = duration, triangles $=$ frequency) divided by average female-female value of the respective interaction in the same study group (i.e. values above 1 signify higher interactions rates than found on average for female-female dyads). In both male-male and male-female dyads, both body contact and grooming are much less frequent than in female-female dyads, and grooming is markedly lower in male-male dyads than dyads with female partners.

behaviour is challenging. Same sex bonds could be linked with the costs of higher exposure rather than the benefits of reduced susceptibility, as bond strength with same, but not opposite sex partners, was weakly correlated with number of grooming partners (Chapter 4), implying that forming strong same sex bonds is linked with higher overall sociability (Brent et al. 2013; Seyfarth et al. 2014). Additionally, as interaction patterns between the sexes are very different, the mechanisms mediating increased reinfection risk in individuals with strong same sex bonds could be different for males and females, although the effect on infection could be similar.

Female cercopithecine primates are more socially active than males (Haunhorst et al. 2016), and showed higher rates of affiliation, particularly body contact and grooming, in the study population (see Figure III), with male-male dyads usually grooming ten time less frequently than female-female 
dyads, and male-female dyads grooming roughly half as much as female-female dyads. Physical contact, particularly grooming, triggers the physiological responses leading to enhanced immune function and attenuated stress responses (Shutt et al. 2007; Aureli \& Yates 2010; Eisenberger \& Cole 2012), yet carries the risk of contracting GI helminth infections from grooming partners (Granzer \& Haas 1991; Hernandez \& Sukhdeo 1995). High rates of grooming, seen in female-female bonds, could thus increase exposure beyond a level that can be compensated by the lowered susceptibility, while males groom other males too rarely to induce immunomodulatory changes that decrease susceptibility. Additionally, bond formation and maintenance could be a stressor for males, as triadic male-infant interactions elementary for bond formation in male Barbary macaques (Berghänel et al. 2011) require stressful infant interactions (Henkel et al. 2010). In contrast to same sex bonds, opposite sex bonds could offer the best balance between exposure and susceptibility.

There are further points to consider for assessing the full picture. Cercopithecine females preferentially bond with closely related female (Silk et al. 2003, 2009, 2010), leading to a connection between bonding and genetics. Traits of parasite tolerance and resistance have heritable components (Graham et al. 2010; Hayward et al. 2014a, b). As individuals using a parasite tolerance strategy generally have higher egg counts (Hayward et al. 2014b), those individuals contribute more to transmission (Medzhitov et al. 2012) and potentially increase infection risk for closely bonded partners. Infections should also be detected earliest in these individuals due to higher egg shedding, even if they have similar exposure and susceptibility to individuals using a parasite resistance strategy. Additionally, closely bonded females could face similar exposure to infective stages if socially inheriting network positions linked with exposure risk (Ilany \& Akçay 2016). Consequently, social bonds, especially between females, could be linked to reinfection via shared genetic traits, possibly confounded with shared social environment. Assessing the role of relatedness for exposure, susceptibility and tolerance strategies is beyond the scope of this thesis in the absence of relatedness information.

Reinfection risk could also be linked to social interactions beyond the dyadic level. Opposite effects of social interactions on parasite transmission are not limited to this study in macaques: Balasubramaniam et al. (2016) found low infection risk with Shigella, a bacterial pathogen, in central individuals of two groups of rhesus macaques, but high infection risk in central individuals in a third group, potentially resulting from different group sub-structure. Group structure and clustering can limit parasite transmission (Salathé \& Jones 2010; Nunn et al. 2015), so transmission patterns can differ between groups of similar sizes. In my study population, the effect of same sex social bonds is most prominent in the study group with higher interaction rates, group cohesion and lower clustering (unpublished data). Lower levels of sub-structuring could increase overall exposure to infective parasite stages, intensifying the effect of social transmission (Salathé \& Jones 2010; Griffin \& Nunn 2012; Nunn et al. 2015). Considering the proposed mechanisms explaining the discrepancy 
between same and opposite sex bond strength und GI helminth infection risk, concluding that same sex bonds are risk and opposite sex bonds are protective factors for GI helminth transmission is premature. Rather, we need to disentangle the underlying mechanisms and the relative contributions of social behaviours on exposure and susceptibility. Also, GI helminth infection risk does not negate the benefits of strong social bonds with same sex partners unrelated to infection (Cameron et al. 2009; Schülke et al. 2010; Silk et al. 2010; Smith et al. 2010; Haunhorst et al. 2017), so forming strong same sex bonds could be favourable even if connected to the costs of GI helminth infections.

In accordance with the longstanding hypothesis that pathogens are one of the main driving forces of social evolution in primates (Freeland 1976) and recent work, both empirical and theory building, emphasising the potential for behaviour-parasite-feedback loops (Poulin 2010; Ezenwa \& Snider 2016; Ezenwa et al. 2016), GI helminths impacted host social behaviour, and host sociality simultaneously predicted infection risk. Sickness behaviour responses implied costs of infections, although determining possible long-term costs of infections and differences in individual parasite defence strategies (Hayward et al. 2009; Medzhitov et al. 2012; Jackson et al. 2014) is beyond the scope of the study. Given the dual effect of social behaviour, individuals could be expected to alter their behaviour to minimize infection risk while optimizing the buffering effects of social bonding. I will discuss how Barbary macaques could achieve this in the following paragraphs.

Considering the potential role for partner diversity increasing GI helminth transmission risk (Rimbach et al. 2015; Friant et al. 2016a; Wren et al. 2016), forming strong bonds with few partners and avoiding the space commonly used by infected conspecifics (Grear et al. 2013) seems to be the ideal strategy. Forming strong bonds can increase transmission risk, so likely there is a trade-off between interaction quality and quantity, with facilitation of enhanced immune function by affiliative interactions, especially grooming (Keverne et al. 1989; Shutt et al. 2007; Crockford et al. 2017). Assuming an optimal balance between exposure costs and susceptibility benefits of sociality, the question how these behavioural strategies of bond formation and avoidance of infected conspecifics could be mediated arises. Inflammatory cytokines are strong candidates for neuro-endocrine signals linking social environment with immune function and mediating behavioural responses to both, stressors and infection (Eisenberger \& Cole 2012; Hennessy et al. 2014; Eisenberger et al. 2017). Inflammatory cytokines are not only released in the context of acute infections (Hart 1988; Dantzer 2001; Konsman et al. 2002), but also in social isolation (Cacioppo \& Hawkley 2003; Hawkley \& Capitanio 2015), most likely as an adaptive response: Inflammatory cytokines prime the immune system for inflammatory responses in anticipation of higher likelihood of injury in individuals separated from the protection of the group (Eisenberger \& Cole 2012; Eisenberger et al. 2017). Inflammatory signalling generally leads to avoidance of conspecifics, but increases social interactions with familiar partners (Willette et al. 2007; Hennessy et al. 2014). Contact with bonded partners in turn initiates anti-inflammatory signalling (Hennessy et al. 2014; Crockford et al. 2017; Kiyokawa 
2018). Consequently, inflammatory cytokines could play a part in facilitating the maintenance of social bonds and interactions in individuals infected with GI helminths.

Oxytocin signalling could play a role in detection and avoidance of infections. From mice to men, olfactory signals are used to identify infections in conspecifics (Kavaliers \& Colwell 1995; Olsson et al. 2014) and sources of contamination (Poirotte et al. 2017). Oxytocin contributes to social recognition, potentially playing a role for processing the olfactory signals needed for recognition and avoidance of infected individuals (Kavaliers \& Choleris 2011). With oxytocin and inflammatory signalling contributing to immunoregulation (Uvnäs-Moberg 1998; Hennessy et al. 2014; Kiyokawa \& Hennessy 2018), they are likely part of a feedback loop mediating both social behaviour and immune function to facilitate adaptive responses to individual social environment. These mechanisms could include seeking out support in case of severe stressors, infections and social isolation (Hennessy et al. 2014) and avoiding exposure to pathogens. If these processes translate into fitness effects, parasite infections could well contribute to the evolution of differentiated relationships and be a driver of social evolution, even if they are not immediately linked to health or reproductive costs.

This general rule to optimize the costs and benefits of interactions might not apply equally to all individuals and pathogen, especially when considering life-history trade-offs between maintenance and reproduction (Archie 2013; Hayward et al. 2014a; Jackson et al. 2014). An obvious example is the case of sexually transmitted diseases, where exposure and potential reproductive success are intimately linked (Klovdahl \& Australian 1985; Hawley et al. 2011), but similar covariation can be expected between behaviours correlating with exposure and individual susceptibility. High ranking males, particularly alpha males, are often characterized by high testosterone and GC levels linked to high susceptibility to infection (Muehlenbein \& Bribiescas 2005; Muehlenbein \& Watts 2010; Gesquiere et al. 2011; Archie et al. 2012), yet are apparently better able to tolerate the challenges of their endocrine status without overt negative health effects (Archie et al. 2012; Muscatell et al. 2016). Some individuals might thus be capable of occupying high exposure or susceptibility behavioural niches, with different social strategies being more advantageous for these individuals.

Forming strong and selective bonds may be advantageous in relation to pathogen transmission in general and GI helminth transmission in particular, but different social strategies might be more beneficial under certain environmental circumstances. The question whether quality or quantity of social bonds matters most is still debated (Cohen \& Wills 1985; Cohen \& Janicki-Deverts 2009; HoltLunstad et al. 2010; Ostner \& Schülke 2018; Silk et al. 2018), yet having high numbers of interaction partners can be literally life-saving: Faced with harsh environmental conditions, survival in Barbary macaques was best predicted by high numbers of grooming relationships, possibly as a result of better opportunity for social thermoregulation in face of extreme temperatures (McFarland \& Majolo 
2013; Lehmann et al. 2016; Campbell et al. 2018). In rhesus macaques on Cayo Santiago, the number of living kin predicted survival in adult females (Brent et al. 2017), and having more weak bonds increased infant survival in chacma baboons (McFarland et al. 2017). Similarly, high network centrality or a vital position for information transmission is simultaneously linked with parasite risk (Fenner et al. 2011; Godfrey 2013; VanderWaal et al. 2013; Rimbach et al. 2015; Friant et al. 2016a; White et al. 2017b), and increased fitness (Brent 2015; Cheney et al. 2016; Firth et al. 2017), although the underlying mechanisms are not well understood to date.

Expanding beyond the health effects of GI helminths, being overly selective with regard to interaction partners could also have negative consequences. Being socially selective can help to defend against adverse effects of directly transmitted helminths, but might not offer much protection from transmission of pathogens using different transmission routes, exemplified by the network independent infection patterns with unicellular intestinal parasite infections in spider monkeys (Ateles bybridus) and mangabeys (Rimbach et al. 2015; Friant et al. 2016a). Additionally, social immunity usually described in social insects (Cremer et al. 2007), has been suggested to occur in social mammals: if exposure to low levels of a pathogen can induce the development of acquired immunity (Hart 2011), frequent close contact and "sampling" of group pathogens becomes an adaptive strategy (Burnet et al. 1972; Hart 1990) with benefits potentially outweighing those of protection from GI helminth infections. In short, assuming one general optimal strategy might be a gross oversimplification, as depending on environmental condition, individual life history and physiology, alternative strategies could yield the biggest health and fitness benefits, especially in light of nonparasite selective pressures operating on the interface between social behaviour. 


\section{Chapter 6 \\ Conclusion and future directions}

"There is nothing like looking, if you want to find something. You certainly usually find something, if you look, but it is not always quite the something you were after."

J.R.R. Tolkien - The Hobbit

Setting out to investigate the host-parasite dynamics between Barbary macaques and GI helminths and contribute to the current understanding of the interplay between social behaviour, physiology, infection and health, I indeed found several unexpected results, alongside answers to my research questions. Here, I want to briefly summarize my findings, assess how they contribute to the fields of eco-immunology, disease ecology and wildlife health, and point out possible future research directions.

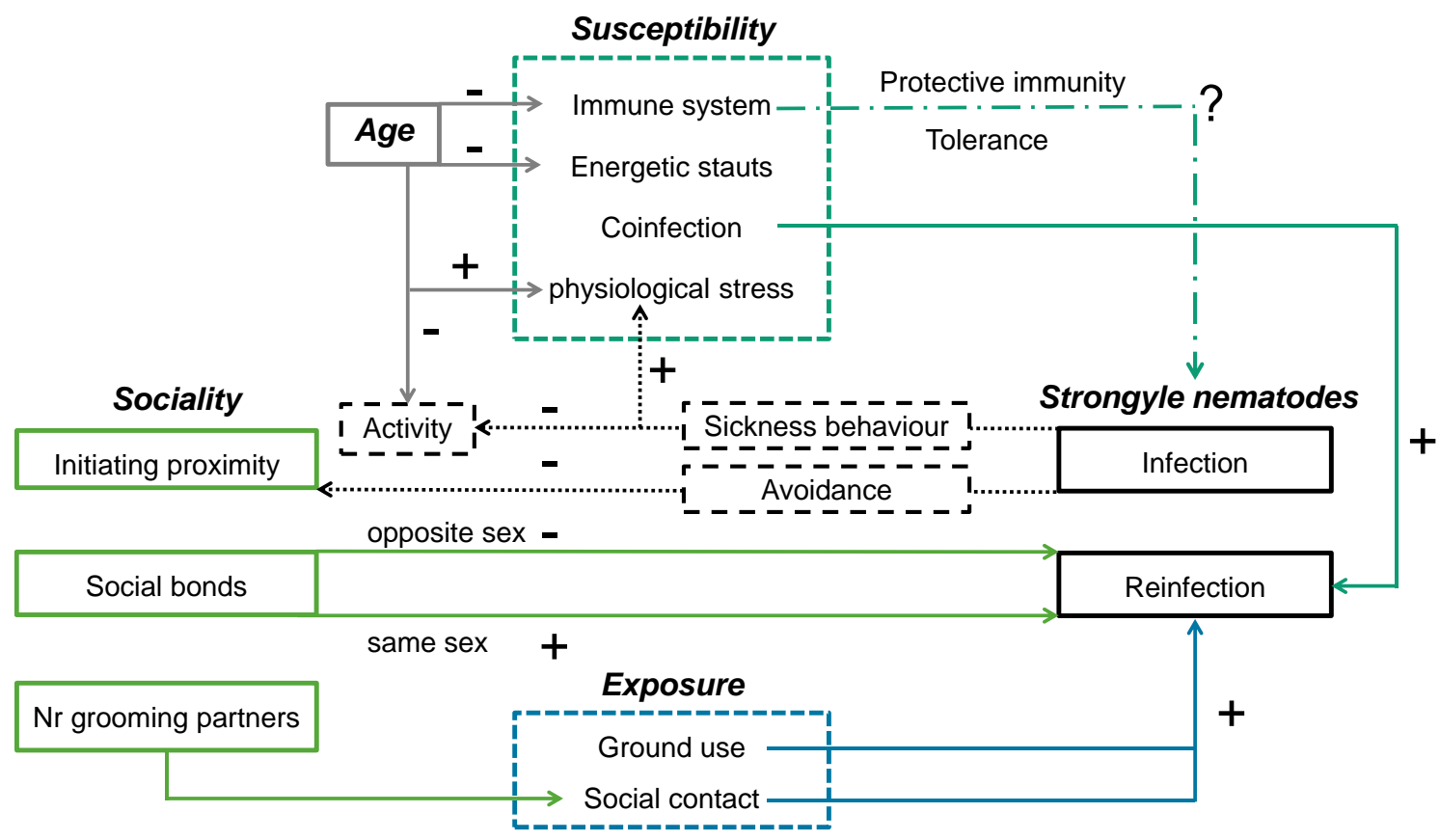

Figure IV: Flow chart illustrating the host-parasite relationship between Barbary macaques and strongyle nematodes as by the results of the thesis. Solid lines indicate the predictors influencing reinfection after parasite clearance, dashed lines the effects of parasite infections. Increases in behavioural and physiological measures and reinfection probability are indicated by a plus sign, decreases by a minus sign next to the respective line. The semi-dashed line indicates plausible links between host immune system and strongyle infection, which were not tested explicitly in the study. Age emerged as a strong predictor of host physiology and behaviour and was thus added to the chart to complete the picture. 
Assessing the effects of GI helminth infection on Barbary macaques, I found effects of sickness behaviour in response to infections, suggesting that infections lead to health costs. Despite the body of knowledge we have on primate-helminth interactions, the immediate costs of infection and how they translate into long-term effects on survival and reproduction is still unclear for many primatehelminth pairs, especially with regard to causes and consequences of inter-individual variance. Body condition was not influenced by treatment and individuals with high body condition were implied to have higher reinfection risk, which could be suggestive of parasite tolerance in the study population. Assessing parasite tolerance and the consequences of employing resistance vs. tolerance strategies opens an intriguing research avenue, calling for long-term studies incorporating specific measures of parasite tolerance under natural conditions. This might also help to assess whether sickness responses to GI helminth infections are the expression of health costs or can mitigate costs and thus even be beneficial. If this was the case, individuals with higher amplitudes of sickness behaviour responses are expected to benefit from increased fitness in the long run.

Helminth coinfections were the strongest risk factors for strongyle nematode reinfection. This finding is likely not generalizable, as within-host parasite dynamics are complex and species specific. Based on the finding that coinfections were largely limited to aged individuals, I suggest that this result is best explained by failing protective immunity against enoplid parasites in older individuals, resulting in health deterioration and increased susceptibility to GI helminths in general. I found no evidence for interactions between Barbary macaque immune balance and helminth infections, but demonstrate the usefulness of uNEO as a marker of immunosenescence. Immunosenescence, decreasing the capability to handle GI helminth infections, and similar effects of age related physiological changes and GI helminth infections, suggest the possibility of vicious circles between immune system deterioration, parasite infection and physical decline. Which factors contribute to "healthy" aging and how these are influenced by parasite infections are interesting question to address in future, longitudinal studies, particularly in light of life-history trade-offs.

Concerning the interplay between social behaviour and parasite transmission, I found evidence of both avoidance of infected individuals and social interactions predicting parasite transmission. While social interactions contribute to susceptibility and exposure simultaneously, the level at which sociality translates into exposure and susceptibility depends on the nature and frequency of interactions. Interaction frequencies and partner numbers most likely feed into exposure, whereas bond quality and socio-positive interactions most likely contribute to buffering effects on susceptibility. In case of the Barbary macaques, HPA axis activation does not appear to be the main mechanism linking sociality to susceptibility. The role of alternative routes, which could not be assessed in this thesis, offers potential explanations for the discrepancy between the protective effect of opposite sex bonds and risky same sex bonds. Additionally, there might be physiological traits underlying both social bond formation and susceptibility. The offered explanations are not mutually 
exclusive, and disentangling which aspects of sociality correlate with exposure and susceptibility as well as the extent of covariation between both transmission components remain open questions. Another interesting question is whether social interactions can play a role in mitigating costs of infections via endocrine signalling impacting the extent to which tolerance or resistance strategies are employed.

Considering the dual role of social relationships for parasite transmission, it is not surprising that I found indications of avoidance of infected individuals. How individuals identify infected conspecifics and if these avoidance strategies are effective in reducing infection risk remains to be determined. Intriguingly, the physiological mechanisms facilitating sickness behaviour and the beneficial effects of social interactions could also contribute to avoiding infected or non-bonded individuals. This suggests that mechanisms operate on the reinforcement of social selectivity and relationship differentiation while simultaneously regulating immune function and adapting it to social environment in social animals. Assessing the roles of oxytocin and inflammatory cytokines for regulating social behaviours, susceptibility and immune responses to parasites are thus important tasks for future studies aiming at understanding the costs and benefits of sociality in an infection and health context.

In summary, I found costs of sociality via increased exposure, and benefits via reduced susceptibility, to GI helminth infections and the potential of GI helminth infections to contribute to social evolution, particularly the formation of differentiated bonds. It seems that "quality over quantity" is a good rule of thumb when it comes to social bonds and reducing costs of parasite infections, while preserving health related benefits of sociality. However, GI helminths and their transmission are just one piece of the jigsaw puzzle, with many more factors like personality, social isolation, life-history, early life adversity, microbiome composition and of course further pathogens, like bacteria and viruses, contributing to the sociality-health-fitness nexus. In light of rapid advances in molecular and statistical methods for the analyses of these complex interactions, future studies hold great potential for major contributions to our understanding of wildlife health, ecoimmunology, disease ecology and host-parasite dynamics. Investigating how sociality translates into health, healthy aging and fitness will not only be important in understanding the evolution of sociality, but also offer insights for human medical studies, social medicine, the evolutionary roots of human social relationships, ultimately allowing us to understand why friendship does not only give value to survival, but might be a key for it as well. 


\section{References}

Abbott, D.H., Keverne, E.B., Bercovitch, F.B., Shively, C.A., Mendoza, S.P., Saltzman, W., et al. (2003). Are subordinates always stressed? A comparative analysis of rank differences in cortisol levels among primates. Hormones and Behavior, 43 (1), 67-82.

Adams, E.J., Stephenson, L.S., Latham, M.C. \& Kinoti, S.N. (1994). Physical activity and growth of Kenyan school children with hookworm, Trichuris trichiura and Ascaris lumbricoides infections are improved after treatment with albendazole. The Journal of Nutrition, 124 (8), 1199-1206.

Alexander, R.D. (1974). The evolution of social behavior. Annual Review of Ecology and Systematics, 5 (1), 325-383.

Altizer, S.M., Nunn, C.L., Thrall, P.H., Gittleman, J.L., Antonovics, J., Cunningham, A.A., et al. (2003). Social organization and parasite risk in mammals: integrating theory and empirical studies. Annual Review of Ecology, Evololution and Systematics, 34 (1), 517-547.

Altmann, J. (1974). Observational study of behavior: sampling methods. Behaviour, 49 (3), 227-266.

Amoroso, C.R., Frink, A.G. \& Nunn, C.L. (2017). Water choice as a counterstrategy to faecally transmitted disease: an experimental study in captive lemurs. Behaviour, 154 (13-15), 1239-1258.

Anderson, M. \& Colman, J. (2011). Prospects and perspectives in primate aging research. Antioxidants \& Redox Signaling, 14 (2), 203-205.

Anderson, R.C. (2000). Nematode parasites of vertebrates: Their development and transmission. 2nd Edition, CABI publishing, Wallingford.

Andreasen, A., Petersen, H.H., Kringel, H., Iburg, T.M., Skovgaard, K., Dawson, H., et al. (2015). Immune and inflammatory responses in pigs infected with Trichuris suis and Oesophagostomum dentatum. Veterinary Parasitology, 207 (3-4), 249-258.

Andreasen, A., Skovgaard, K., Klaver, E.J., van Die, I., Mejer, H., Thamsborg, S.M., et al. (2016). Comparison of innate and Th1-type host immune responses in Oesophagostomum dentatum and Trichuris suis infections in pigs. Parasite Immunology, 38 (1), 53-63.

Anthony, R.M., Rutitzky, L.I., Urban Jr, J.F., Stadecker, M.J. \& Gause, W.C. (2007). Protective immune mechanisms in helminth infection. Nature Reviews Immunology, 7 (12), 975-987.

Apanius, V. (1998). Stress and immune defense. Advances in the Study of Behavior Vol. 27, Academic Press, pp. 133-153.

Archie, E.A. (2013). Wound healing in the wild: Stress, sociality and energetic costs affect wound healing in natural populations. Parasite Immunology, 35 (11), 374-385.

Archie, E.A., Altmann, J. \& Alberts, S.C. (2012). Social status predicts wound healing in wild baboons. Proceedings of the National Academy of Sciences, 109 (23), 9017-9022.

Archie, E.A., Tung, J., Clark, M., Altmann, J. \& Alberts, S.C. (2014). Social affiliation matters: both same-sex and opposite-sex relationships predict survival in wild female baboons. Proceedings of the Royal Society B, 281 (1793), 20141261.

Arshadi, D., Nikbin, B., Shakiba, Y., Kiani, A., Jamshidi, A.R. \& Boroushaki, M.T. (2013). Plasma level of neopterin as a marker of disease activity in treated rheumatoid arthritis patients: association with gender, disease activity and anti-CCP antibody. International Immunopharmacology, 17 (3), 763-767.

Association for the Study of Animal Behaviour (2012) Guidelines for the treatment of animals in behavioural research and teaching. Animal Behaviour, 83 (1), 301-309.

Aulitzky, W.E., Tilg, H., Niederwieser, D., Riccabona, G., Obendorf, L., Margreiter, R., et al. (1988). Comparison of serum neopterin levels and urinary neopterin excretion in renal allograft recipients. Clinical Nephrology, 29 (5), 248-252. 
Aureli, F., Das, M. \& Veenema, H.C. (1997). Differential kinship effect on reconciliation in three species of macaques (Macaca fascicularis, M. fuscata, and M. sylvanus). Journal of Comparative Psychology, 111 (1), 91-99.

Aureli, F. \& Yates, K. (2010). Distress prevention by grooming others in crested black macaques. Biology Letters, 6 (1), 27-29.

Balasubramaniam, K., Beisner, B., Guan, J., Vandeleest, J., Fushing, H., Atwill, E., et al. (2018). Social network community structure and the contact-mediated sharing of commensal E. coli among captive rhesus macaques (Macaca mulatta). PeerJ, 6, e4271.

Balasubramaniam, K., Beisner, B., Vandeleest, J., Atwill, E. \& McCowan, B. (2016). Social buffering and contact transmission: network connections have beneficial and detrimental effects on Shigella infection risk among captive rhesus macaques. PeerJ, 4, e2630.

Barnard, C.J., Sayed, E., Barnard, L.E., Behnke, J.M., Nabi, I.A., Sherif, N., et al. (2003). Local variation in helminth burdens of Egyptian spiny mice (Acomys cabirinus dimidiatus) from ecologically similar sites: relationships with hormone concentrations and social behaviour. Journal of Helminthology, 77 (3), 197-207.

Bauer, M.E., Jeckel, C.M.M. \& Luz, C. (2009). The role of stress factors during aging of the immune system. Annals of the New York. Academy of Sciences, 1153 (1), 139-152.

Beehner, J.C. \& Bergman, T.J. (2017). The next step for stress research in primates: To identify relationships between glucocorticoid secretion and fitness. Hormones and Behavior, 91, 68-83.

Behringer, V. \& Deschner, T. (2017). Non-invasive monitoring of physiological markers in primates. Hormones and Behavior, 91, 3-18.

Behringer, V., Deschner, T., Murtagh, R., Stevens, J.M.G. \& Hohmann, G. (2014). Age-related changes in thyroid hormone levels of bonobos and chimpanzees indicate heterochrony in development. Journal of Human Evolution, 66, 83-88.

Behringer, V., Stevens, J., Leendertz, F., Hohmann, G. \& Deschner, T. (2017). Validation of a method for the assessment of urinary neopterin levels to monitor health status in non-humanprimate species. Frontiers in Physiology, 8, 51.

Beldomenico, P. \& Begon, M. (2016). Stress-host-parasite interactions: A vicious triangle? FAVE Sección Ciencias Veterinarias, 14 (1-2), 6-19.

Beldomenico, P.M. \& Begon, M. (2010). Disease spread, susceptibility and infection intensity: vicious circles? Trends in Ecology and Evolution, 25 (1), 21-27.

Berdowska, A. \& Zwirska-Korczala, K. (2001). Neopterin measurement in clinical diagnosis. Journal of Clinical Pharmacy and Therapeutics, 26 (5), 319-329.

Berghänel, A., Ostner, J., Schröder, U. \& Schülke, O. (2011). Social bonds predict future cooperation in male Barbary macaques, Macaca sylvanus. Animal Behaviour, 81 (6), 1109-1116.

Berkman, L.F. \& Syme, S.L. (1979). Social networks, host resistance, and mortality: A nine-year follow-up study of Alameda County residents. American Journal of Epidemiology, 109 (2), 186-204.

Besedovsky, H., del Rey, A., Sorkin, E. \& Dinarello, C. (1986). Immunoregulatory feedback between interleukin-1 and glucocorticoid hormones. Science, 233, 652-654.

Bethony, J., Brooker, S., Albonico, M., Geiger, S.M., Loukas, A., Diemert, D., et al. (2006). Soiltransmitted helminth infections: ascariasis, trichuriasis, and hookworm. The Lancet, 367 (9521), $1521-1532$.

Blumstein, D.T., Williams, D.M., Lim, A.N., Kroeger, S. \& Martin, J.G.A. (2018). Strong social relationships are associated with decreased longevity in a facultatively social mammal. Proceedings of the Royal Society B, 285 (1871), 20171934.

Bolker, B., Skaug, H., Magnusson, A. \& Nielsen, A. (2011). Getting started with the glmmADMB package. Available from: http://glmmadmb.r-forge.r-project.org/glmmADMB.pdf. 
Bonneaud, C., Mazuc, J., Gonzalez, G., Haussy, C., Chastel, O., Faivre, B., et al. (2003). Assessing the cost of mounting an immune response. The American Naturalist, 161 (3), 367-379.

Bonser, A.M., Garcia-Webb, P. \& Harrison, L.C. (1984). C-peptide measurement: methods and clinical utility. CRC Critical Reviews in Clinical Laboratory Sciences, 19 (4), 297-352.

Boonstra, R. (2013). Reality as the leading cause of stress: Rethinking the impact of chronic stress in nature. Functional Ecology, 27 (1), 11-23.

Bordes, F. \& Morand, S. (2011). The impact of multiple infections on wild animal hosts: a review. Infection Ecololgy \& Epidemiology, 1 (1), 7346.

Borg, C., Majolo, B., Qarro, M. \& Semple, S. (2014). A comparison of body size, coat condition and endoparasite diversity of wild Barbary macaques exposed to different levels of tourism. Anthrozoos, 27 (1), 49-63.

Borkow, G., Teicher, C. \& Bentwich, Z. (2007). Helminth-HIV Coinfection: Should We Deworm? PLoS Neglected Tropical Diseases, 1 (3), e160.

Brauch, K., Pfefferle, D., Hodges, K., Möhle, U., Fischer, J. \& Heistermann, M. (2007). Female sexual behavior and sexual swelling size as potential cues for males to discern the female fertile phase in free-ranging Barbary macaques (Macaca sylvanus) of Gibraltar. Hormones and Behavior, 52 (3), 375-383.

Breinekova, K., Svoboda, M., Smutna, M. \& Vorlova, L. (2007). Markers of acute stress in pigs. Pbysiological Research, 56 (3), 323-329.

Brent, L.J.N. (2015). Friends of friends: Are indirect connections in social networks important to animal behaviour? Animal Behaviour, 103, 211-222.

Brent, L.J.N., Heilbronner, S.R., Horvath, J.E., Gonzalez-Martinez, J., Ruiz-Lambides, A., Robinson, A.G., et al. (2013). Genetic origins of social networks in rhesus macaques. Scientific Reports, 3 (1042), 1-8.

Brent, L.J.N., Ruiz-Lambides, A. \& Platt, M.L. (2017). Family network size and survival across the lifespan of female macaques. Proceedings of the Royal Society B, 284 (1854), 20170515.

Briggs, N., Weatherhead, J., Sastry, K.J. \& Hotez, P.J. (2016). The Hygiene Hypothesis and Its Inconvenient Truths about Helminth Infections. Plos Neglected Tropical Diseases, 10 (9), e0004944.

Brown, A.E., Webster, H.K., Teja-Isavadharm, P. \& Keeratithakul, D. (1990). Macrophage activation in falciparum malaria as measured by neopterin and interferon-gamma. Clinical \& Experimental Immunology, 82 (1), 97-101.

Brown, J.L. (1982). Optimal group size in territorial animals. Journal of Theoretical Biology, 95 (4), $793-$ 810.

Budischak, S.A., Hoberg, E.P., Abrams, A., Jolles, A.E. \& Ezenwa, V.O. (2015a). A combined parasitological molecular approach for noninvasive characterization of parasitic nematode communities in wild hosts. Molecular Ecology Resources, 15 (5), 1112-1119.

Budischak, S.A., Hoberg, E.P., Abrams, A., Jolles, A.E. \& Ezenwa, V.O. (2016). Experimental insight into the process of parasite community assembly. Journal of Animal Ecology, 85 (5), 1222-1233.

Budischak, S.A., Sakamoto, K., Megow, L.C., Cummings, K.R., Urban, J.F. \& Ezenwa, V.O. (2015b). Resource limitation alters the consequences of co-infection for both hosts and parasites. International Journal for Parasitology, 45 (7), 455-463.

Budischak, S.A., Wiria, A.E., Hamid, F., Wammes, L.J., Kaisar, M.M.M., Lieshout, L., et al. (2018). Competing for blood: the ecology of parasite resource competition in human malaria-helminth co-infections. Ecology Letters, 21 (4), 536-545.

Buer, J. \& Balling, R. (2003). Mice, microbes and models of infection. Nature Reviews Genetics, 4 (3), 195-205. 
Burnet, F.M., Burnet, M. \& White, D.O. (1972). Natural History of Infectious Disease. Cambridge University Press, Cambridge.

Cacioppo, J.T., Berntson, G.G., Sheridan, J.F. \& McClintock, M.K. (2000). Multilevel integrative analyses of human behavior: social neuroscience and the complementing nature of social and biological approaches. Psychological Bulleting, 126 (6), 829-843.

Cacioppo, J.T. \& Hawkley, L.C. (2003). Social isolation and health, with an emphasis on underlying mechanisms. Perspectectives in Biology and Medicine, 46 (3), 39-52.

Cacioppo, J.T., Hawkley, L.C., Berntson, G.G., Ernst, J.M., Gibbs, A.C., Stickgold, R., et al. (2002). Do lonely days invade the nights? Potential social modulation of sleep efficiency. Psychological Science, 13 (4), 384-387.

Cain, D.W. \& Cidlowski, J.A. (2017). Immune regulation by glucocorticoids. Nature Reviews Immunology, 17 (4), 233-247.

Cameron, E.Z., Setsaas, T.H. \& Linklater, W.L. (2009). Social bonds between unrelated females increase reproductive success in feral horses. Proceedings of the National Academy of Sciences, 106 (33), 13850-13853.

Campbell, L.A.D., Tkaczynski, P.J., Lehmann, J., Mouna, M. \& Majolo, B. (2018). Social thermoregulation as a potential mechanism linking sociality and fitness: Barbary macaques with more social partners form larger huddles. Scientific Reports, 8 (1), 6074.

Capitanio, J.P. \& Cole, S.W. (2015). Social instability and immunity in rhesus monkeys: the role of the sympathetic nervous system. Pbilosophical Transactions of the Royal Society B, 370 (1669), 20140104.

Capitanio, J.P., Mendoza, S.P., Lerche, N.W. \& Mason, W.A. (1998). Social stress results in altered glucocorticoid regulation and shorter survival in simian acquired immune deficiency syndrome. Proceedings of the National Academy of Sciences, 95 (8), 4714-4719.

Capuron, L., Geisler, S., Kurz, K., Leblhuber, F., Sperner-Unterweger, B. \& Fuchs, D. (2014). Activated immune system and inflammation in healthy ageing: relevance for tryptophan and neopterin metabolism. Current Pharmaceutical. Design, 20 (38), 6048-6057.

Carvalho, L., Sun, J., Kane, C., Marshall, F., Krawczyk, C. \& Pearce, E.J. (2009). Review series on helminths, immune modulation and the hygiene hypothesis: Mechanisms underlying helminth modulation of dendritic cell function. Immunology, 126 (1), 28-34.

Cauchemez, S., Bhattarai, A., Marchbanks, T.L., Fagan, R.P., Ostroff, S., Ferguson, N.M., et al. (2011). Role of social networks in shaping disease transmission during a community outbreak of 2009 H1N1 pandemic influenza. Proceedings of the National Academy of Sciences, 108 (7), 28252830.

Cavigelli, S.A. \& Chaudhry, H.S. (2012). Social status, glucocorticoids, immune function, and health: Can animal studies help us understand human socioeconomic-status-related health disparities? Hormones and Behavior, 62 (83), 295-313.

Chandra, R.K. (1997). Nutrition and the immune system: an introduction. American Journal of Clinical Nutrition, 66 (2), 460-463.

Chapman, C.A., Friant, S., Godfrey, K., Liu, C., Sakar, D., Schoof, V.A.M., et al. (2016). Social behaviours and networks of vervet monkeys are influenced by gastrointestinal parasites. PLoS One, 11 (8), e0161113.

Chapman, C.A., Rothman, J.A. \& Hodder, S.A.M. (2009). Can parasite infections be a selective force influencing primate group size? A test with red colobus. Primate Parasite Ecology: The Dynamics and Study of Host-Parasite Relationships. Cambridge University Press, Cambridge, pp. 423-440.

Chapman, C.A., Saj, T.L. \& Snaith, T. V. (2007). Temporal dynamics of nutrition, parasitism, and stress in colobus monkeys: Implications for population regulation and conservation. American Journal of Physical Anthropology, 134 (2), 240-250. 
Chapman, C.A., Wasserman, M.D., Gillespie, T.R., Speirs, M.L., Lawes, M.J., Saj, T.L., et al. (2006). Do food availability, parasitism, and stress have synergistic effects on red colobus populations living in forest fragments? American Journal of Physical Anthropology, 131, 525-534.

Cheney, D.L., Silk, J.B. \& Seyfarth, R.M. (2016). Network connections, dyadic bonds and fitness in wild female baboons. Royal Society Open Science, 3 (7), 160255.

Christensen, C.M., Barnes, E.H., Nansen, P., Roepstorff, A. \& Slotved, H.-C. (1995). Experimental Oesophagostomum dentatum infection in the pig: Worm populations resulting from single infections with three doses of larvae. International Journal for Parasitology. 25 (12), 1491-1498.

Čičin-Šain, L., Smyk-Paerson, S., Currier, N., Byrd, L., Koudelka, C., Robinson, T., et al. (2010). Loss of naive $\mathrm{T}$ cells and repertoire constriction predict poor response to vaccination in old primates. Journal of Immunology, 184 (12), 6739-6745.

Clutton-Brock, T. \& Janson, C. (2012). Primate socioecology at the crossroads: Past, present, and future. Evolutionary Anthropology: Issues, News, and Reviews, 21 (4), 136-150.

Cohen, S., Doyle, W.J., Turner, R., Alper, C.M. \& Skoner, D.P. (2003). Sociability and susceptibility to the common cold. Psychological Science, 14 (5), 389-395.

Cohen, S. \& Janicki-Deverts, D. (2009). Can We Improve Our Physical Health by Altering Our Social Networks? Perspectives in Psychological Science, 4 (4), 375-378.

Cohen, S., Janicki-Deverts, D., Turner, R.B. \& Doyle, W.J. (2015). Does hugging provide stressbuffering social support? A study of susceptibility to upper respiratory infection and illness. Psychological Science, 26 (2), 135-147.

Cohen, S., Line, S., Manuck, S.B., Rabin, B.S., Heise, E.R. \& Kaplan, J.R. (1997). Chronic social stress, social status, and susceptibility to upper respiratory infections in nonhuman primates. Psychosomatic Medicine, 59 (3), 213-221.

Cohen, S., Tyrrell, D.A.J. \& Smith, A.P. (1991). Psychological stress and susceptibility to the common cold. New England Journal of Medicine, 325 (9), 606-612.

Cohen, S. \& Wills, T.A. (1985). Stress, social support, and the buffering hypothesis. Psychological Bulleting, 98 (2), 310-357.

Colditz, I.G. (2008). Six costs of immunity to gastrointestinal nematode infections. Parasite Immunology, 30 (2), 63-70.

Cole, S.W., Mendoza, S.P. \& Capitanio, J.P. (2009). Social stress desensitizes lymphocytes to regulation by endogenous glucocorticoids: insights from in vivo cell trafficking dynamics in rhesus macaques. Psychosomomatic Medicine, 71 (6), 591-597.

Connor, R.C., Wells, R.S., Mann, J. \& Read, A.J. (2000). The bottlenose dolphin. Cetacean Societies. University of Chicago Press, Chicago, pp. 91-125.

Coop, R.L. \& Holmes, P.H. (1996). Nutrition and parasite interaction. International Journal for Parasitology, 26 (8-9), 951-962.

Coop, R.L. \& Kyriazakis, I. (1999). Nutrition-parasite interaction. Veterinary Parasitology, 84 (3-4), 187-204.

Cooper, P.J. (2002). Can intestinal helminth infections (geohelminths) affect the development and expression of asthma and allergic disease? Clinical \& Experimental Immunology, 128 (3), 398-404.

Cox, F.E.G. (2001). Concomitant infections, parasites and immune responses. Parasitology, 122 (S1), S23-S38.

Craft, M.E., Volz, E., Packer, C. \& Meyers, L.A. (2011). Disease transmission in territorial populations: the small-world network of Serengeti lions Journal of the Royal Society Interface, 8 (59), 776-786. 
Cremer, S., Armitage, S.A.O. \& Schmid-Hempel, P. (2007). Social immunity. Current Biology, 17 (16), 693-702.

Cristóbal-Azkarate, J., Maréchal, L., Semple, S., Majolo, B. \& MacLarnon, A. (2016). Metabolic strategies in wild male Barbary macaques: evidence from faecal measurement of thyroid hormone. Biology Letters, 12 (4), 20160168.

Crockford, C., Deschner, T. \& Wittig, R.M. (2017). The role of oxytocin in social buffering: what do primate studies add? Current Topics in Behavioural Neurosciences. Springer, Berlin, Heidelberg.

Crockford, C., Wittig, R.M., Langergraber, K., Ziegler, T.E., Zuberbuhler, K. \& Deschner, T. (2013). Urinary oxytocin and social bonding in related and unrelated wild chimpanzees. Proceedings of the Royal Society B, 280 (1755), 20122765.

Crockford, C., Wittig, R.M., Whitten, P.L., Seyfarth, R.M. \& Cheney, D.L. (2008). Social stressors and coping mechanisms in wild female baboons (Papio hamadryas ursinus). Hormones and Behavior, 53 (1), 254-265.

Crompton, D.W.T. \& Nesheim, M.C. (2002). Nutritional impact of intestinal helminthiasis during the human life cycle. Annual Review of Nutrition, 22 (1), 35-59.

Cross, P.C., Lloyd-Smith, J.O., Bowers, J.A., Hay, C.T., Hofmeyr, M. \& Getz, W.M. (2004). Integrating association data and disease dynamics in a social ungulate: bovine tuberculosis in African buffalo in the Kruger National Park. Annales Zoologici Fennici, Finnish Zoological and Botanical Publishing Board. pp 879-892.

Curley, J.P. \& Keverne, E.B. (2005). Genes, brains and mammalian social bonds. Trends in Ecology and Evolution, 20 (10), 561-567.

Curtis, V.A. (2014). Infection-avoidance behaviour in humans and other animals. Trends in Immunology, 35 (10), 457-464.

Danish, L.M., Heistermann, M., Agil, M. \& Engelhardt, A. (2015). Validation of a novel collection device for non-invasive urine sampling from free-ranging animals. PLoS One, 10 (11), e0142051.

Dantzer, R. (2001). Cytokine-induced sickness behavior: Where do we stand? Brain, Behavior and Immunity, 15 (1), 7-24.

Dantzer, R. (2004). Cytokine-induced sickness behaviour: A neuroimmune response to activation of innate immunity. European Journal of Pharmacology, 500 (1-3), 399-411.

Dantzer, R. (2009). Cytokine, sickness behaviour, and depression. Immunol. Allergy Clinics, 29 (2), 247264.

Dantzer, R., O’Connor, J.C., Freund, G.G., Johnson, R.W. \& Kelley, K.W. (2008). From inflammation to sickness and depression: when the immune system subjugates the brain. Nature Reviews Neuroscience, 9 (1), 46-56.

Dash, K.M. (1973). The life cycle of Oesophagostomum columbianum (Curtice, 1890) in sheep. International Journal for Parasitology, 3 (6), 843-851.

Deeks, S.G. (2011). HIV infection, inflammation, immunosenescence, and aging. Annual Review of Medicine, 62, 141-155.

Degarege, A., Animut, A., Medhin, G., Legesse, M. \& Erko, B. (2014). The association between multiple intestinal helminth infections and blood group, anaemia and nutritional status in human populations from Dore Bafeno, southern Ethiopia. Journal of Helminthology, 88 (2), 152 159.

Demas, G.E. \& Carlton, E.D. (2015). Ecoimmunology for psychoneuroimmunologists: Considering context in neuroendocrine-immune-behavior interactions. Brain, Bebavior and Immunity, 44, 916. 
Derting, T.L. \& Compton, S. (2003). Immune response, not immune maintenance, is energetically costly in wild white-footed mice (Peromyscus leucopus). Physiological and Biochememical Zoology, 76 (5), 744-752.

Deschner, T., Kratzsch, J. \& Hohmann, G. (2008). Urinary C-peptide as a method for monitoring body mass changes in captive bonobos (Pan paniscus). Hormones and Behavior, 54 (4), 620-626.

Dhabhar, F.S. (2009). Enhancing versus suppressive effects of stress on immune function: implications for immunoprotection and immunopathology. Neuroimmunomodulation, 16 (5), 300317.

Diamondstone, L.S., Tollerud, D.J., Fuchs, D., Wachter, H., Brown, L.M., Maloney, E., et al. (1994). Factors influencing serum neopterin and $\beta 2$-microglobulin levels in a healthy diverse population. Journal of Clinical Immunology, 14 (6), 368-374.

Díaz, A. \& Allen, J.E. (2007). Mapping immune response profiles: The emerging scenario from helminth immunology. European Journal of Immunology, 37 (12), 3319-3326.

Díaz, M. \& Alonso, C.L. (2003). Wood mouse Apodemus sylvaticus winter food supply: density, condition, breeding, and parasites. Ecology, 84 (10), 2680-2691.

Didier, E.S., MacLean, A.G., Mohan, M., Didier, P.J., Lackner, A.A. \& Kuroda, M.J. (2016). Contributions of nonhuman primates to research on aging. Veterinary Pathology, 53 (2), 277-290.

Didier, E.S., Sugimoto, C., Bowers, L.C., Khan, I.A. \& Kuroda, M.J. (2012). Immune correlates of aging in outdoor-housed captive rhesus macaques (Macaca mulatta). Immunity \& Ageing, 9 (1), 25-39.

Dourmishev, A.L., Dourmishev, L.A. \& A., S.R. (2005). Ivermectin: pharmacology and application in dermatology. International Journal of Dermatology, 44 (12), 981-988.

Drewe, J.A. (2010). Who infects whom? Social networks and tuberculosis transmission in wild meerkats. Proceedings of the Royal Society B, 277, 633-642.

Duboscq, J., Romano, V., Sueur, C. \& MacIntosh, A.J.J. (2016). Network centrality and seasonality interact to predict lice load in a social primate. Scientific Reports, 6, 22095.

Dunbar, R.I.M., Korstjens, A.H., Lehmann, J. \& British Centenary Research Project. (2009). Time as an ecological constraint. Biological Reviews, 84 (3), 413-429.

Ehman, K.D. \& Scott, M.E. (2002). Female mice mate preferentially with non-parasitized males. Parasitology, 125 (5), 461-466.

Eisenberger, N.I. \& Cole, S.W. (2012). Social neuroscience and health: neurophysiological mechanisms linking social ties with physical health. Nature Neuroscience, 15 (5), 669-674.

Eisenberger, N.I., Moieni, M., Inagaki, T.K., Muscatell, K.A. \& Irwin, M.R. (2017). In sickness and in health: the co-regulation of inflammation and social behavior. Neuropsychopharmacology, 42 (1), $242-253$.

Elenkov, I.J. \& Chrousos, G.P. (1999). Stress hormones, Th1/Th2 patterns, pro/anti-inflammatory cytokines and susceptibility to disease. Trends in Endocrinology \& Metabolism, 10 (9), 359-368.

Elenkov, I.J., Wilder, R.L., Chrousos, G.P. \& Vizi, E.S. (2000). The sympathetic nerve-an integrative interface between two supersystems: the brain and the immune system. Pharmacological Reviews, 52 (4), 595-638.

Ellis, S., Franks, D.W., Nattrass, S., Cant, M.A., Weiss, M.N., Giles, D., et al. (2017). Mortality risk and social network position in resident killer whales: sex differences and the importance of resource abundance. Proceedings of the Royal Society B, 284, 20171313.

Else, K.J. \& Finkelman, F.D. (1998). Intestinal nematode parasites, cytokines and effector mechanisms. International Journal for Parasitology, 28 (8), 1145-1158. 
Else, K.J. \& Grencis, R.K. (1991). Cellular immune responses to the murine nematode parasite Trichuris muris: Differential cytokine production during acute or chronic infection. Immunology, $72(2), 508-513$.

Else, K.J., Hültner, L. \& Grencis, R.K. (1992). Cellular immune responses to the murine nematode parasite Trichuris muris. II. Differential induction of Th-cell subsets in resistant versus susceptible mice. Immunology, 75 (2), 232-237.

Emery Thompson, M. \& Knott, C. (2008). Urinary C-peptide of insulin as a non-invasive marker of energy balance in wild orangutans. Hormones and Behavior, 53 (4), 526-535.

Emery Thompson, M., Muller, M.N. \& Wrangham, R.W. (2012). Technical note: Variation in muscle mass in wild chimpanzees: Application of a modified urinary creatinine method. American Journal of Physical Anthropology, 149 (4), 622-627.

Emery Thompson, M., Muller, M.N., Wrangham, R.W., Lwanga, J.S. \& Potts, K.B. (2009). Urinary C-peptide tracks seasonal and individual variation in energy balance in wild chimpanzees. Hormones and Behavior, 55 (2), 299-305.

Emlen, S.T. \& Oring, L.W. (1977). Ecology, sexual selection, and the evolution of mating systems. Science, 197 (4300), 215-223.

Engh, A.L., Beehner, J.C., Bergman, T.J., Whitten, P.L., Hoffmeier, R.R., Seyfarth, R.M., et al. (2006a). Behavioural and hormonal responses to predation in female chacma baboons (Papio hamadryas usrsinus). Proceedings of the Royal Society B, 273 (1587), 707-712.

Engh, A.L., Beehner, J.C., Bergman, T.J., Whitten, P.L., Hoffmeier, R.R., Seyfarth, R.M., et al. (2006b). Female hierarchy instability, male immigration and infanticide increase glucocorticoid levels in female chacma baboons. Animal Behaviour, 71 (5), 1227-1237.

Eppig, C., Fincher, C.L. \& Thornhill, R. (2010). Parasite prevalence and the worldwide distribution of cognitive ability. Proceedings of the Royal Society B, 277 (1701), 3801-3808.

Ezenwa, V.O. (2004a). Host social behavior and parasitic infection: A multifactorial approach. Behavioral Ecology, 15 (3), 446-454.

Ezenwa, V.O. (2004b). Interactions among host diet, nutritional status and gastrointestinal parasite infection in wild bovids. International Journal for Parasitology, 34 (4), 535-542.

Ezenwa, V.O. (2016). Helminth-microparasite co-infection in wildlife: lessons from ruminants, rodents and rabbits. Parasite Immunology, 38 (9), 527-534.

Ezenwa, V.O., Archie, E.A., Craft, M.E., Hawley, D.M., Martin, L.B., Moore, J., et al. (2016). Host behaviour-parasite feedback: an essential link between animal behaviour and disease ecology. Proceedings of the Royal Society B, 283 (1828), 20153078.

Ezenwa, V.O., Etienne, R.S., Luikart, G., Beja-Pereira, A. \& Jolles, A.E. (2010). Hidden consequences of living in a wormy world: nematode-induced immune suppression facilitates tuberculosis invasion in African buffalo. The American Naturalist, 176 (5), 613-624.

Ezenwa, V.O. \& Jolles, A.E. (2011). From host immunity to pathogen invasion: The effects of helminth coinfection on the dynamics of microparasites. Integrative \& Comparative Biology, 51 (4), $540-551$.

Ezenwa, V.O. \& Jolles, A.E. (2015). Opposite effects of anthelmintic treatment on microbial infection at individual versus population scales. Science, 347 (6218), 175-177.

Ezenwa, V.O., Jolles, A.E. \& O’Brien, M.P. (2009). A reliable body condition scoring technique for estimating condition in African buffalo. African Journal of Ecology, 47 (4), 476-481.

Ezenwa, V.O. \& Snider, M.H. (2016). Reciprocal relationships between behaviour and parasites suggest that negative feedback may drive flexibility in male reproductive behaviour. Proceedings of the Royal Society B, 283 (1831), 20160423. 
Faria, A.M.C., Monteiro De Moraes, S., Ferreira De Freitas, L.H., Speziali, E., Figueiredo Soares, T., Pretti Figueiredo-Neves, S., et al. (2008). Variation rhythms of lymphocyte subsets during healthy aging. Neuroimmunomodulation, 15 (4-6), 365-379.

Farine, D.R. \& Whitehead, H. (2015). Constructing, conducting and interpreting animal social network analysis. Journal of Animal Ecology, 84 (5), 1144-1163.

Fendrich, C., Lüke, W., Stahl-Hennig, C., Herchenröder, O., Fuchs, D., Wachter, H., et al. (1989). Urinary neopterin concentrations in rhesus monkeys after infection with SIV. AIDS, 3 (5), 305307.

Fenner, A.L., Godfrey, S.S. \& Bull, C.M. (2011). Using social networks to deduce whether residents or dispersers spread parasites in a lizard population. Journal of Animal Ecology, 80, 835-843.

Fenton, A., Lamb, T. \& Graham, A.L. (2008). Optimality analysis of Th1/Th2 immune responses during microparasite-macroparasite co-infection, with epidemiological feedbacks. Parasitology, 135 (4), 841-853.

Ferrari, N., Cattadori, I.M., Nespereira, J., Rizzoli, A. \& Hudson, P.J. (2004). The role of host sex in parasite dynamics: Field experiments on the yellow-necked mouse Apodemus flavicollis. Ecology Letters, 7 (2), 88-94.

Finkelman, F.D., Shea-Donohue, T., Goldhill, J., Sullivan, C.A., Morris, S.C., Madden, K.B., et al. (1997). Cytokine regulation of host defense against parasitic gastrointestinal nematodes: lessons from studies with rodent models. Annual Review of Immunology, 15 (1), 505-533.

Di Fiore, A., Disotell, T., Gagneux, P. \& Ayala, F. (2009). Primate malarias: evolution, adaptation and species jumping. Primate Parasite Ecology: The Dynamics and Study of Host-Parasite Relationships. Cambridge University Press, Cambridge, pp. 141-182.

Firth, J.A., Sheldon, B.C. \& Brent, L.J.N. (2017). Indirectly connected: simple social differences can explain the causes and apparent consequences of complex social network positions. Proceedings of the Royal Society B, 284 (1867), 20171939.

Fiske, I. \& Chandler, R. (2011). Unmarked: An R package for fitting hierarchical models of wildlife occurrence and abundance. Journal of Statistical Software, 43 (10), 1-23.

Fleming, M.W. (1997). Cortisol as an indicator of severity of parasitic infections of Haemonchus contortus in lambs (Ovis aries). Comparative Biochemistry and Physiology Part B: Biochemistry and Molecular Biology, 116 (1), 41-44.

Fooden, J. (2007). Systematic review of the Barbary macaque, Macaca sylvanus (Linnaeus, 1758). Fieldiana Zoology, 113, 1-60.

Forbes, K.M., Mappes, T., Sironen, T., Strandin, T., Stuart, P., Meri, S., et al. (2016). Food limitation constrains host immune responses to nematode infections. Biology Letters, 12 (9), 20160471.

Franz, M. \& Nunn, C.L. (2009). Network-based diffusion analysis: a new method for detecting social learning. Proceedings of the Royal Society B, 276 (1663), 1829-1836.

Freeland, W.J. (1976). Pathogens and the evolution of primate sociality. Biotropica, 8 (1), 12-24.

Frère, C.H., Krützen, M., Mann, J., Connor, R.C., Bejder, L. \& Sherwin, W.B. (2010). Social and genetic interactions drive fitness variation in a free-living dolphin population. Proceedings of the National Academy of Sciences, 107 (46), 19949-19954.

Friant, S., Ziegler, T.E. \& Goldberg, T.L. (2016a). Primate reinfection with gastrointestinal parasites: Behavioural and physiological predictors of parasite acquisition. Animal Behaviour, 117, 105-113.

Friant, S., Ziegler, T.E., Goldberg, T.L., Anderson, R., May, R., Leroy, E., et al. (2016b). Changes in physiological stress and behaviour in semi-free-ranging red-capped mangabeys (Cercocebus torquatus) following antiparasitic treatment. Proceedings of the Royal Society B, 283 (1835), 20161201. 
Frick, B., Schroecksnadel, K., Neurauter, G., Leblhuber, F. \& Fuchs, D. (2004). Increasing production of homocysteine and neopterin and degradation of tryptophan with older age. Clinical Biochemistry, 37 (8), 684-687.

Fuchs, D., Hausen, A., Kofler, M., Kosanowski, H., Reibnegger, G. \& Wachter, H. (1984). Neopterin as an index of immune response in patients with tuberculosis. Lung, 162 81), 337-346.

Fuchs, D., Hausen, A., Reibnegger, G., Werner, E.R., Dierich, M.P. \& Wachter, H. (1988). Neopterin as a marker for activated cell-mediated immunity: application in HIV infection. Immunolology Today, 9 (5), 150-155.

Fulop, T., Larbi, A., Witkowski, J.M., McElhaney, J., Loeb, M., Mitnitski, A., et al. (2010). Aging, frailty and age-related diseases. Biogerontology, 11 (5), 547-563.

Ganswindt, A., Palme, R., Heistermann, M., Borragan, S. \& Hodges, J.K. (2003). Non-invasive assessment of adrenocortical function in the male African elephant (Loxodonta africana) and its relation to musth. General and Comparative Endocrinology, 134 (2), 156-166.

Garamszegi, L.Z. (2011). Information-theoretic approaches to statistical analysis in behavioural ecology: an introduction. Behavioral Ecology and Sociobiology, 65 (1), 1-11.

Gardner, M.B. \& Luciw, P.A. (2008). Macaque models of human infectious disease. ILAR Journal., 49 (2), 220-255.

Gasser, R.B., Woods, W.G., Huffman, M.A., Blotkamp, J. \& Polderman, A.M. (1999). Molecular separation of Oesophagostomum stephanostomum and Oesophagostomum bifurcum (Nematoda: Strongyloidea) from non-human primates. International Journal for Parasitology, 29 (7), 1087-1091.

Gesquiere, L.R., Learn, N.H., Simao, M.C.M., Onyango, P.O., Alberts, S.C. \& Altmann, J. (2011). Life at the top: rank and stress in wild male baboons. Science, 333 (6040), 357-360.

Ghai, R.R., Chapman, C.A., Omeja, P.A., Davies, T.J. \& Goldberg, T.L. (2014). Nodule worm infection in humans and wild primates in Uganda: cryptic species in a newly identified region of human transmission. Plos Neglected Tropical Diseases, 8 (1), e2641.

Ghai, R.R., Fugère, V., Chapman, C.A., Goldberg, T.L. \& Davies, T.J. (2015). Sickness behaviour associated with non-lethal infections in wild primates. Proceedings of the Royal Society B, 282 (1814), 20151436.

Gillespie, T.R. (2006). Noninvasive assessment of gastrointestinal parasite infections in free-ranging primates. International Journal of Primatology, 27 (4), 1129-1143.

Gillespie, T.R., Greiner, E.C. \& Chapman, C.A. (2004). Gastrointestinal parasite of the guenons of western Uganda. The Journal of Parasitology, 90, 1356-1360.

Girard-Buttoz, C., Higham, J.P., Heistermann, M., Wedegärtner, S., Maestripieri, D. \& Engelhardt, A. (2011). Urinary C-peptide measurement as a marker of nutritional status in macaques. PLoS One, 6 (3), e18042.

Glaser, R. \& Kiecolt-Glaser, J.K. (2005). Stress-induced immune dysfunction: implications for health. Nature Reviews Immunology, 5 (3), 243.

Godfrey, S.S. (2013). Networks and the ecology of parasite transmission: A framework for wildlife parasitology. International Journal for Parasitology: Parasites and Wildlife, 2, 235-245.

Godfrey, S.S., Bull, C.M., James, R. \& Murray, K. (2009). Network structure and parasite transmission in a group living lizard, the gidgee skink, Egernia stokesii. Behavioral Ecology and Sociobiology, 63 (7), 1045-1056.

Goetz, F.C., Roel, J., Jacobs, D.R., Barbosa, J., Hannan, P., Palmer, J., et al. (2002). Declining [beta]cell function in type 2 diabetes: 5 -year follow-up and immunologic studies of the population of Wadena, MN. Metabolism-Clinical and Experimental, 51 (2), 144-148.

Goldenberg, S.Z. \& Wittemyer, G. (2017). Orphaned female elephant social bonds reflect lack of access to mature adults. Scientific Reports, 7 (1), 14408. 
González-Hernández, M., Rangel-Negrín, A., Schoof, V.A.M., Chapman, C.A., Canales-Espinosa, D. \& Dias, P.A.D. (2014). Transmission patterns of pinworms in two sympatric congeneric primate species. International Journal of Primatology, 35 (2), 445-462.

Goodwin, K., Viboud, C. \& Simonsen, L. (2006). Antibody response to influenza vaccination in the elderly: a quantitative review. Vaccine, 24 (8), 1159-1169.

Graham, A.L. (2008). Ecological rules governing helminth-microparasite coinfection. Proceedings of the National Academy of Sciences, 105 (2), 566-570.

Graham, A.L., Allen, J.E. \& Read, A.F. (2005). Evolutionary causes and consequences of immunopathology. Review of Ecology, Evolution, and Systematics, 36, 373-397.

Graham, A.L., Hayward, A.D., Watt, K.A., Pilkington, J.G., Pemberton, J.M. \& Nussey, D.H. (2010). Fitness correlates of heritable variation in antibody responsiveness in a wild mammal. Science, 330 (6004), 662-666.

Granzer, M. \& Haas, W. (1991). Host-finding and host recognition of infective Ancylostoma caninum larvae. International Journal for Parasitology, 21 (4), 429-440.

Grear, D.A., Luong, L.T. \& Hudson, P.J. (2013). Network transmission inference: host behavior and parasite life cycle make social networks meaningful in disease ecology. Ecological Applications, 23 (8), 1906-1914.

Greer, A.W. (2008). Trade-offs and benefits: implications of promoting a strong immunity to gastrointestinal parasites in sheep. Parasite Immunology, 30 (2), 123-132.

Greer, A.W., Stankiewicz, M., Jay, N.P., McAnulty, R.W. \& Sykes, A.R. (2005). The effect of concurrent corticosteroid induced immuno-suppression and infection with the intestinal parasite Trichostrongylus colubriformis on food intake and utilization in both immunologically naïve and competent sheep. Animal Science, 80 (1), 89-99.

Grencis, R.K. \& Entwistle, G.M. (1997). Production of an interferon-gamma homologue by an intestinal nematode: functionally significant or interesting artefact? Parasitology, 115 (7), 101105.

Grencis, R.K., Humphreys, N.E. \& Bancroft, A.J. (2014). Immunity to gastrointestinal nematodes: Mechanisms and myths. Immunological Reviews, 260 (1), 183-205.

Griffin, R.H. \& Nunn, C.L. (2012). Community structure and the spread of infectious disease in primate social networks. Evolutionary Ecology, 26 (4), 779-800.

Grueter, C.C., Deschner, T., Behringer, V., Fawcett, K. \& Robbins, M.M. (2014). Socioecological correlates of energy balance using urinary $\mathrm{C}$-peptide measurements in wild female mountain gorillas. Physiology \& Behavior, 127, 13-19.

Gulland, F.M.D. (1992). The role of nematode parasites in Soay sheep (Ovis aries L.) mortality during a population crash. Parasitology, 105 (3), 493-503.

Gunn, A. \& Irvine, R.J. (2003). Subclinical parasitism and ruminant foraging strategies: a review. Wildlife Society Bulletin, 31 (1), 117-126.

Haberthur, K., Engelman, F., Barron, A. \& Messaoudi, I. (2010). Immune senescence in aged nonhuman primates. Experimental Gerontolology, 45 (9), 655-661.

Habig, B. \& Archie, E.A. (2015). Social status, immune response and parasitism in males: a metaanalysis. Philosophical Transactions of the Royal Society B, 370 (1669), 20140109.

Habig, B., Doellman, M.M., Woods, K., Olansen, J. \& Archie, E.A. (2018). Social status and parasitism in male and female vertebrates: a meta-analysis. Scientific Reports, 8 (1), 3629.

Hamede, R. K., Mccallum, H., \& Jones, M. (2008). Seasonal, demographic and density-related patterns of contact between Tasmanian devils (Sarcophilus harrisiz): implications for transmission of devil facial tumour disease. Austral Ecology, 33(5), 614-622. 
Hamede, R.K., McCallum, H. \& Jones, M. (2013). Biting injuries and transmission of Tasmanian devil facial tumour disease. Journal of Animal Ecology, 82 (1), 182-190.

Hansen, C.S., Hasseldam, H., Bacher, I.H., Thamsborg, S.M., Johansen, F.F. \& Kringel, H. (2017). Trichuris suis secrete products that reduce disease severity in a multiple sclerosis model. Acta Parasitologica, 62 (1), 22-28.

Hart, B. (1988). Biological basis of the behavior of sick animals. Neuroscience \& Biobehavoral Reviews, $12(2), 123-137$.

Hart, B. (1990). Behavioral adaptations to pathogens and parasites: five strategies. Neuroscience \& Biobehavoral Reviews., 14 (3), 273-294.

Hart, B. (2011). Behavioural defences in animals against pathogens and parasites: parallels with the pillars of medicine in humans. Philosophical Transactions of the Royal Society B, 366 (1583), 34063417.

Hartgers, F.C. \& Yazdanbakhsh, M. (2006). Co-infection of helminths and malaria: modulation of the immune responses to malaria. Parasite Immunology, 28 (10), 497-506.

Haunhorst, C.B., Heesen, M., Ostner, J. \& Schülke, O. (2017). Social bonds with males lower the costs of competition for wild female Assamese macaques. Animal Behaviour, 125, 51-60.

Haunhorst, C.B., Schülke, O. \& Ostner, J. (2016). Opposite-sex social bonding in wild Assamese macaques. American Journal of Primatology, 78 (8), 872-882.

Hawkley, L.C. \& Cacioppo, J.T. (2004). Stress and the aging immune system. Brain, Behavior and Immunity, 18 (2), 114-119.

Hawkley, L.C. \& Capitanio, J.P. (2015). Perceived social isolation, evolutionary fitness and health outcomes: a lifespan approach. Philosophical Transactions of the Royal Society B, 370 (1669), 20140114.

Hawkley, L.C., Cole, S.W., Capitanio, J.P., Norman, G.J. \& John, T. (2013). Effects of social isolation on glucocorticoid regulation in social mammals. Hormones and Behavior, 62 (3), 314-323.

Hawley, D.M. \& Altizer, S.M. (2011). Disease ecology meets ecological immunology: Understanding the links between organismal immunity and infection dynamics in natural populations. Functional Ecology, 25 (1), 48-60.

Hawley, D.M., Etienne, R.S., Ezenwa, V.O. \& Jolles, A.E. (2011). Does animal behavior underlie covariation between hosts' exposure to infectious agents and susceptibility to infection? Implications for disease dynamics. Integrative \& Comparative Biology, 51 (4), 528-539.

Hayward, A.D., Garnier, R., Watt, K.A., Pilkington, J.G., Grenfell, B.T., Matthews, J.B., et al. (2014a). Heritable, heterogeneous, and costly resistance of sheep against nematodes and potential feedbacks to epidemiological dynamics. The American Naturalist, 184 (1), S58-S76.

Hayward, A.D., Nussey, D.H., Wilson, A.J., Berenos, C., Pilkington, J.G., Watt, K.A., et al. (2014b). Natural selection on individual variation in tolerance of gastrointestinal nematode infection. PLoS Biology., 12 (7), e1001917.

Hayward, A.D., Wilson, A.J., Pilkington, J.G., Pemberton, J.M. \& Kruuk, L.E.B. (2009). Ageing in a variable habitat: environmental stress affects senescence in parasite resistance in St Kilda Soay sheep. Proceedings of the Royal Society B, 276 (1672), 3477-3485.

Hearps, A.C., Martin, G.E., Angelovich, T.A., Cheng, W.J., Maisa, A., Landay, A.L., et al. (2012). Aging is associated with chronic innate immune activation and dysregulation of monocyte phenotype and function. Aging Cell, 11 (5), 867-875.

Heistermann, M., Ademmer, C. \& Kaumanns, W. (2004). Ovarian cycle and effect of social changes on adrenal and ovarian function in pygathrix nemaeus. International Journal of Primatology, 25 (3), 689-708. 
Heistermann, M., Finke, M. \& Hodges, J.K. (1995). Assessment of female reproductive status in by measurement of urinary and fecal steroid excretion patterns. American Journal of Primatology, 284 (4), 275-284.

Heistermann, M. \& Higham, J.P. (2015). Urinary neopterin, a non-invasive marker of mammalian cellular immune activation, is highly stable under field conditions. Scientific Reports, 5, 16308.

Heistermann, M., Palme, R. \& Ganswindt, A. (2006). Comparison of different enzymeimmunoassays for assessment of adrenocortical activity in primates based on fecal analysis. American Journal of Primatology, 68 (3), 257-273.

Henkel, S., Heistermann, M. \& Fischer, J. (2010). Infants as costly social tools in male Barbary macaque networks. Animal Behaviour, 79 (6), 1199-1204.

Hennessy, M.B., Deak, T. \& Schiml, P.A. (2014). Sociality and sickness: have cytokines evolved to serve social functions beyond times of pathogen exposure? Brain, Behaviour and Immunity, 37, 1520.

Hennessy, M.B., Kaiser, S. \& Sachser, N. (2009). Social buffering of the stress response: Diversity, mechanisms, and functions. Frontiers in Neuroendocrinology, 30 (4), 470-482.

Henzi, S.P., Clarke, P.M.R., Van Schaik, C.P., Pradhan, G.R. \& Barrett, L. (2010). Infanticide and reproductive restraint in a polygynous social mammal. Proceedings of the National Academy of Sciences, 107 (5), 2130-2135.

Hernandez, A.D. \& Sukhdeo, M.V.K. (1995). Host grooming and the transmission strategy of Heligmosomoides polygyrus. The Journal of Parasitology, 81, 865-869.

Hewitson, J.P., Grainger, J.R. \& Maizels, R.M. (2009). Helminth immunoregulation: the role of parasite secreted proteins in modulating host immunity. Molecular and Biochemical Parasitology, 167 (1), 1-11.

Higham, J.P., Girard-Buttoz, C., Engelhardt, A. \& Heistermann, M. (2011). Urinary C-peptide of insulin as a non-invasive marker of nutritional status: some practicalities. PLoS One, 6 (7), e22398.

Higham, J.P., Kraus, C., Stahl-Hennig, C., Engelhardt, A., Fuchs, D. \& Heistermann, M. (2015). Evaluating noninvasive markers of nonhuman primate immune activation and inflammation. American Journal of Physical Anthropology, 158 (4), 673-684.

Hill, A.V.S. (1998). The immunogenetics of human infectious diseases. Annual Review of Immunology, 16 (1), 593-617.

Holt-Lunstad, J., Smith, T.B., Baker, M., Harris, T. \& Stephenson, D. (2015). Loneliness and social isolation as risk factors for mortality: a meta-analytic review. Perspectives on Psychological Science, 10 (2), 227-237.

Holt-Lunstad, J., Smith, T.B. \& Layton, J.B. (2010). Social relationships and mortality risk: A metaanalytic review. Plos Medicine, 7 (7), e1000316.

Horwitz, D.L., Starr, J.I., Mako, M.E., Blackard, W.G. \& Rubenstein, A.H. (1975). Proinsulin, insulin, and C-peptide concentrations in human portal and peripheral blood. The Journal of Clinical Investigation, 55 (6), 1278-1283.

Hotez, J., Brooker, S., Bethony, J., Bottazzi, M., Loukas, A. \& Xiao, S. (2004). Hookworm infection. New England Journal of Medicine, 351(8), 799-804.

Hotez, P.J., Bethony, J., Bottazzi, M.E., Brooker, S. \& Buss, P. (2005). Hookworm: “The great infection of mankind." PLoS Medicine, 2 (3), e67.

House, J.S., Landis, K.R. \& Umberson, D. (1988). Social relationships and health. Science, 241 (4865), 540-545. 
Hsieh, G.C.F., Loukas, A., Wahl, A.M., Bhatia, M., Wang, Y., Williamson, A.L., et al. (2004). A secreted protein from the human hookworm Necator americanus binds selectively to NK cells and induces IFN- $\gamma$ production. Journal of Immunology, 173 (4), 2699-2704.

Huffman, M.A. \& Chapman, C.A. (2009). Primate parasite ecology: the dynamics and study of host-parasite relationships. Cambridge University Press, Cambridge.

Humphreys, N.E. \& Grencis, R.K. (2002). Effects of ageing on the immunoregulation of parasitic infection. Infection and Immunity, 70 (9), 5148-5157.

Husain, N., Tokoro, K., Popov, J.M., Naides, S.J., Kwasny, M.J. \& Buchman, A.L. (2013). Neopterin concentration as an index of disease activity in Crohn's disease and ulcerative colitis. Journal of Clinical Gastroenterology, 47 (3), 246-51.

Hutchings, M.R., Milner, J.M., Gordon, I.J., Kyriazakis, I. \& Jackson, F. (2002). Grazing decisions of Soay sheep, Ovis aries, on St Kilda: a consequence of parasite distribution? Oikos, 96 (2), 235244.

Ilany, A. \& Akçay, E. (2016). Social inheritance can explain the structure of animal social networks. Nature Communications, 7, 12084.

Inagaki, T.K. (2018). Neural mechanisms of the link between giving social support and health. Annals of the New York. Academy of Sciences. doi:10.1111/nyas.13703

Inagaki, T.K. \& Eisenberger, N.I. (2016). Giving support to others reduces sympathetic nervous system-related responses to stress. Psychophysiology, 53 (4), 427-435.

Ing, R., Su, Z., Scott, M.E. \& Koski, K.G. (2000). Suppressed T helper 2 immunity and prolonged survival of a nematode parasite in protein-malnourished mice. Proceedings of the National Academy of Sciences, 97 (13), 7078-7083.

Irvine, R.J., Corbishley, H., Pilkington, J.G. \& Albon, S.D. (2006). Low-level parasitic worm burdens may reduce body condition in free-ranging red deer (Cervus elaphus). Parasitology, 133 (4), 465475 .

Ishii, A., Kiyokawa, Y., Takeuchi, Y. \& Mori, Y. (2016). Social buffering ameliorates conditioned fear responses in female rats. Hormones and Behavior, 81, 53-58.

Jackson, J.A. (2015). Immunology in wild nonmodel rodents: An ecological context for studies of health and disease. Parasite Immunology, 37, 220-232.

Jackson, J.A., Friberg, I.M., Little, S. \& Bradley, J.E. (2009). Review series on helminths, immune modulation and the hygiene hypothesis: immunity against helminths and immunological phenomena in modern human populations: coevolutionary legacies? Immunology, 126 (5), 18-27.

Jackson, J.A., Hall, A.J., Friberg, I.M., Ralli, C., Lowe, A., Zawadzka, M., et al. (2014). An immunological marker of tolerance to infection in wild rodents. PLoS Biology, 12 (7), e1001901.

James, R., Croft, D.P. \& Krause, J. (2009). Potential banana skins in animal social network analysis. Behavioral Ecology and Sociobiology, 63 (7), 989-997.

Janson, C.H. \& Van Schaik, C.P. (1988). Recognizing the many faces of primate food competition: methods. Behaviour, 105 (1-2), 165-186.

Jégo, M., Lemaitre, J., Bourgoin, G., Capron, G., Warnant, C., Klein, F., et al. (2014). Haematological parameters do senesce in the wild: evidence from different populations of a long-lived mammal. Journal of Evolutionary Biology, 27 (12), 2745-2752.

Kalbitz, J., Ostner, J. \& Schülke, O. (2016). Strong, equitable and long-term social bonds in the dispersing sex in Assamese macaques. Animal Behaviour, 113, 13-22.

Kalbitzer, U., Bergstrom, M.L., Carnegie, S.D., Wikberg, E.C., Kawamura, S., Campos, F.A., et al. (2017). Female sociality and sexual conflict shape offspring survival in a Neotropical primate. Proceedings of the National Academy of Sciences, 114 (8), 1892-1897. 
Kappeler, P.M., Cremer, S., Nunn, C.L. \& Kappeler, P.M. (2015). Sociality and health: impacts of sociality on disease susceptibility and transmission in animal and human societies. Philosophical Transactions of the Royal Society B, 370 (1669), 20140116

Karlsson, E.K., Kwiatkowski, D.P. \& Sabeti, P.C. (2014). Natural selection and infectious disease in human populations. Nature Reviews Genetics, 15 (6), 379-393.

Kasper, C. \& Voelkl, B. (2009). A social network analysis of primate groups. Primates, 50 (4), 343356.

Kavaliers, M. \& Choleris, E. (2011). Sociality, pathogen avoidance, and the neuropeptides oxytocin and arginine vasopressin. Psychological Science, 22 (11), 1367-1374.

Kavaliers, M. \& Colwell, D.D. (1995). Odours of parasitized males induce aversive responses in female mice. Animal Behaviour. 50, 1161-1169.

Keverne, E.B., Martensz, N.D. \& Tuite, B. (1989). Beta-endorphin concentrations in cerebrospinal fluid of monkeys are influenced by grooming relationships. Psychoneuroendocrinology, 14 (1-2), $155-161$.

Keymer, A., Crompton, D.W.T. \& Sahakian, B.J. (1983). Parasite-induced learned taste aversion involving Nippostrongylus in rats. Parasitology, 86 (3), 455-460.

Kiecolt-Glaser, J.K., Gouin, J.P. \& Hantsoo, L. (2010). Close relationships, inflammation, and health. Neuroscience \& Biobehavioral Reviens, 35(1), 33-38.

Kikusui, T., Winslow, J.T. \& Mori, Y. (2006). Social buffering: relief from stress and anxiety. Philosophical Transactions of the Royal Society B, 361 (1476), 2215.

Kitagaki, K., Businga, T.R., Racila, D., Elliott, D.E., Weinstock, J. V \& Kline, J.N. (2006). Intestinal helminths protect in a murine model of asthma. The Journal of Immunology, 177 (3), 1628-1635.

Kiyokawa, Y. (2018). Relief from stress provided by conspecifics: social buffering. Neuronal Correlates of Empathy. Elsevier, pp. 137-149.

Kiyokawa, Y. \& Hennessy, M.B. (2018). Comparative studies of social buffering: A consideration of approaches, terminology, and pitfalls. Neuroscience \&. Biobehavioral Reviews, 86, 131-141.

Kiyokawa, Y., Kawai, K. \& Takeuchi, Y. (2018). The benefits of social buffering are maintained regardless of the stress level of the subject rat and enhanced by more conspecifics. Physiology \& Behavior, 194, 177-183

Klein, S.L. (2004). Hormonal and immunological mechanisms mediating sex differences in parasite infection. Parasite Immunology, 26 (6-7), 247-264.

Klovdahl, A. S., Potterat, J.J., Woodhouse, D.E., et al. (1994). Social networks and infectious diseases: The Colorado Springs study. Social Science \& Medicine, 38 (1), 79-88.

Klovdahl, S. \& Australian, T. (1985). Social networks and the spread of infectious diseases: The AIDS example. Social Science \& Medicine, 21 (11), 1203-1216.

Knowles, S.C.L., Fenton, A., Petchey, O.L., Jones, T.R., Barber, R. \& Pedersen, A.B. (2013). Stability of within-host-parasite communities in a wild mammal system. Proceedings of the Royal Society $B$, 280 (1762), 20130598.

Koenig, A. (2002). Competition for ressources and its behavioral consequences among female primates. International Journal of Primatology. 23 (4), 759-784.

Konrad, M., Vyleta, M.L., Theis, F.J., Stock, M., Tragust, S., Klatt, M., et al. (2012). Social transfer of pathogenic fungus promotes active immunisation in ant colonies. PLoS Biology, 10 (4), e1001300.

Konsman, J.P., Parnet, P. \& Dantzer, R. (2002). Cytokine-induced sickness behaviour: mechanisms and implications. Trends in Neuroscience, 25 (3), 154-159. 
Kooriyama, T., Inaba, A., Nishida, T. \& Iwaki, T. (2010). Case report of helminths and lung mite infection in the red-tailed monkey, Cercopithecus ascanius schmidti, in Mahale Mountains National Park, Tanzania. Primates. 51 (2), 183-188.

Koski, K.G. \& Scott, M.E. (2001). Gastrointestinal nematodes, nutrition and immunity: breaking the negative spiral. Annual Review of Nutrition, 21 (1), 297-321.

Krause, J., Croft, D.P. \& James, R. (2007). Social network theory in the behavioural sciences: Potential applications. Behavioral Ecology and Sociobiology, 62 (1), 15-27.

Krause, J. \& Ruxton, G.D. (2002). Living in Groups. Oxford University Press, New York.

Krief, S., Jamart, A., Mahé, S., Leendertz, F.H., Mätz-Rensing, K., Crespeau, F., et al. (2008). Clinical and pathologic manifestation of oesophagostomosis in African great apes: does self-medication in wild Apes influence disease progression? Journal of Medical Primatology, 37 (4), 188-195.

Krief, S., Vermeulen, B., Lafosse, S., Kasenene, J.M., Nieguitsila, A., Berthelemy, M., et al. (2010). Nodular worm infection in wild chimpanzees in Western Uganda: a risk for human health? Plos Neglected Tropical Diseases, 4 (3), e630.

Kuester, J. \& Paul, A. (1992). Influence of male competition and female mate choice on male mating success in Barbary macaques (Macaca sylvanus). Behaviour, 120 (3), 192-216.

Kyriazakis, I., Tolkamp, B.J. \& Hutchings, M.R. (1998). Towards a functional explanation for the occurrence of anorexia during parasitic infections. Animal Behaviour, 56 (2), 265-274.

Laing, R., Gillan, V. \& Devaney, E. (2017). Ivermectin - Old Drug, New Tricks? Trends in Parasitology, 33 (6), 463-472.

Ledochowski, M., Murr, C., Lass-Florl, C. \& Fuchs, D. (2001). Helicobacter pylori infection and neopterin. Pteridines, 12 (3), 126-129.

Ledochowski, M., Murr, C., Widner, B. \& Fuchs, D. (1999). Association between insulin resistance, body mass and neopterin concentrations. Clinica Chimica Acta, 282 (1-2), 115-123.

Leendertz, F.H., Yumlu, S., Pauli, G., Boesch, C., Couacy-Hymann, E., Vigilant, L., et al. (2006). A new Bacillus anthracis found in wild chimpanzees and a gorilla from west and central Africa. PLoS Pathogens. 2(1), e8

Leendertz, S.A.J., Junglen, S., Hedemann, C., Goffe, A., Calvignac, S., Boesch, C., et al. (2010). High prevalence, coinfection rate, and genetic diversity of retroviruses in wild red colobus monkeys (Piliocolobus badius badius) in Tai National Park, Cote d'Ivoire. Journal of Virology, 84 (15), $7427-$ 7436.

Lehmann, J., Majolo, B. \& McFarland, R. (2016). The effects of social network position on the survival of wild Barbary macaques, Macaca sylvanus. Behavioral Ecology, 27 (1), 20-28.

Lello, J., Boag, B., Fenton, A., Stevenson, I.R., Hudson, P.J., R Stevenson, I., et al. (2004). Competition and mutualism among gut helminths of a mammalian host. Nature, 428 (6985), 840-844.

Leng, S.X., Tian, X., Matteini, A., Li, H., Hughes, J., Jain, A., et al. (2011). Il-6-independent association of elevated serum neopterin levels with prevalent frailty in community-dwelling older adults. Age and Ageing, 40 (4), 475-481.

Li, H., Manwani, B. \& Leng, S.X. (2011). Frailty, inflammation, and immunity. Aging and Disease, 2 (6), 466-473.

Li, T., Wang, P., Wang, S.C. \& Wang, Y.-F. (2017). Approaches mediating oxytocin regulation of the immune system. Frontiers in Immunology, 7, 693.

Lloyd-Smith, J.O., Schreiber, S.J., Kopp, P.E. \& Getz, W.M. (2005). Superspreading and the effect of individual variation on disease emergence. Nature, 438 (7066), 355-359. 
Long, K.Z. \& Nanthakumar, N. (2004). Energetic and nutritional regulation of the adaptive immune response and trade-offs in ecological immunology. American Journal of Human Biology, 16 (5), 499_ 507.

Lopes, F., Matisz, C., Reyes, J.L., Jijon, H., Al-Darmaki, A., Kaplan, G.G., et al. (2016). Helminth regulation of immunity: a three-pronged approach to treat colitis. Inflammatory Bowel Diseases, 22 (10), 2499-2512.

López-Olvera, J.R., Höfle, U., Vicente, J., Fernández-de-Mera, I.G. \& Gortázar, C. (2006). Effects of parasitic helminths and ivermectin treatment on clinical parameters in the European wild boar (Sus scrofa). Parasitological Research, 98 (6), 582-587.

Louis, M., Buanic, M., Lefeuvre, C., Nilliot, P. Le, Ridoux, V. \& Spitz, J. (2017). Strong bonds and small home range in a resident bottlenose dolphin community in a Marine Protected Area (Brittany, France, Northeast Atlantic). Marine Mammalal Science, 33 (4), 1194-1203.

Loukas, A., Constant, S.L. \& Bethony, J.M. (2005). Immunobiology of hookworm infection. FEMS Immunology \&. Medical Microbiology, 43 (2), 115-124.

Lukas, D. \& Clutton-Brock, T.H. (2013). The evolution of social monogamy in mammals. Science, 341 (6145), 526-530.

Mabbott, N.A., Kobayashi, A., Sehgal, A., Bradford, B.M., Pattison, M. \& Donaldson, D.S. (2015). Aging and the mucosal immune system in the intestine. Biogerontology, 16 (2), 133-145.

MacIntosh, A.J.J., Alados, C.L. \& Huffman, M.A. (2011). Fractal analysis of behaviour in a wild primate: behavioural complexity in health and disease. Journal of the Royal Society Interface 8 (63), 1497-1509.

MacIntosh, A.J.J., Hernandez, A.D. \& Huffman, M.A. (2010). Host age, sex, and reproductive seasonality affect nematode parasitism in wild Japanese macaques. Primates, 51 (4), 353-364.

MacIntosh, A.J.J., Jacobs, A., Garcia, C., Shimizu, K., Mouri, K., Huffman, M.A., et al. (2012). Monkeys in the middle: parasite transmission through the social network of a wild primate. PLoS One, 7 (12), e51144.

MacKenzie, D.I., Nichols, J.D., Lachman, G.B., Droege, S., Andrew Royle, J. \& Langtimm, C.A. (2002). Estimating site occupancy rates when detection probabilities are less than one. Ecology, 83 (8), 2248-2255.

Maizels, R.M., Pearce, E.J., Artis, D., Yazdanbakhsh, M. \& Wynn, T.A. (2009). Regulation of pathogenesis and immunity in helminth infections. Journal of Experimental Medicine, 206 (10), 2059-2066.

Maizels, R.M. \& Yazdanbakhsh, M. (2003). Immune regulation by helminth parasites: cellular and molecular mechanisms. Nature Reviews Immunology, 3 (9), 733-744.

Maréchal, L., Semple, S., Majolo, B. \& MacLarnon, A. (2016). Assessing the effects of tourist provisioning on the health of wild Barbary macaques in Morocco. PLoS One, 11 (5), e0155920.

Marescot, L., Benhaiem, S., Gimenez, O., Hofer, H., Lebreton, J.-D., Olarte-Castillo, X.A., KramerSchadt, S., et al. (2018). Social status mediates the fitness costs of infection with canine distemper virus in Serengeti spotted hyenas. Functional Ecology, 32 (5), 1237-1250.

Markham, A.C. \& Gesquiere, L.R. (2017). Costs and benefits of group living in primates: an energetic perspective. Philosophical Transactions of the Royal Society B, 372 (1727), 20160239.

Martin, G.E., Gouillou, M., Hearps, A.C., Angelovich, T.A., Cheng, A.C., Lynch, F., et al. (2013). Age-associated changes in monocyte and innate immune activation markers occur more rapidly in HIV infected women. PLoS One, 8 (1), e55279.

Martin, L.B., Hawley, D.M. \& Ardia, D.R. (2011). An introduction to ecological immunology. Functional Ecology, 25 (1), 1-4. 
Martin, L.B., Scheuerlein, A. \& Wikelski, M. (2003). Immune activity elevates energy expenditure of house sparrows: a link between direct and indirect costs? Proceedings of the Royal Society B. 270 (1511), 153-158.

Martin, P. \& Bateson, P.G. (2007). Measuring Behaviour: An Introductory Guide. Cambridge University Press.

Maynard Smith, J. \& Szathmary, E. (1994). The Major Transitions in Evolution. Freeman Spektrum, Oxford

McFarland, R., Fuller, A., Hetem, R.S., Mitchell, D., Maloney, S.K., Henzi, S.P., et al. (2015). Social integration confers thermal benefits in a gregarious primate. Journal of Animal Ecology, 84 (3), 871-878.

McFarland, R. \& Majolo, B. (2013). Coping with the cold: predictors of survival in wild Barbary macaques, Macaca sylvanus. Biology Letters, 9 (4), 20130428.

McFarland, R., Murphy, D., Lusseau, D., Henzi, S.P., Parker, J.L., Pollet, T. V., et al. (2017a). The "strength of weak ties" among female baboons: fitness-related benefits of social bonds. Animal Behaviour, 126, 101-106.

McLean, E.R., Kinsella, J.M., Chiyo, P., Obanda, V., Moss, C. \& Archie, E.A. (2012). Genetic identification of five strongyle nematode parasites in wild African elephants (Loxodonta africana). Journal of Wildlife Diseases, 48 (3), 707-716.

Medzhitov, R., Schneider, D.S.D.S. \& Soares, M.P.M.P. (2012). Disease tolerance as a defense strategy. Science, 335 (6071), 936-941.

Mehlman, P. (1986). Male intergroup mobility in a wild population of the Barbary macaque (Macaca sylvanus), Ghomaran Rif Mountains, Morocco. American Journal of Primatology, 10 81), 67-81.

Ménard, N. (1996). Demography and ecology of Barbary macaques (Macaca sylvanus) in two different habitats. Evolution and Ecology of Macaque Societies, Cambridge University Press, pp. 106-131.

Ménard, N. \& Vallet, D. (1993). Population dynamics of Macaca sylvanus in Algeria: An 8-year study. American Journal of Primatology, 30 (2), 101-118.

Ménard, N. \& Vallet, D. (1997). Behavioral responses of Barbary macaques (Macaca sylvanus) to variations in environmental conditions in Algeria. American Journal of Primatology, 43 84), 285 304.

Messaoudi, I., Estep, R., Robinson, B. \& Wong, S.W. (2011). Nonhuman primate models of human immunology. Antioxidants \& Redox Signaling, 14 (2), 261-73.

Meyer, C., Kerns, A., Haberthur, K. \& Messaoudi, I. (2012). Improving immunity in the elderly: Current and future lessons from nonhuman primate models. Age, 34 (5), 1157-1168.

Micheletta, J.J., Waller, B.M., Panggur, M.R., Neumann, C., Dubosq, J., Agil, M., et al. (2012). Social bonds affect anti-predator behaviour in a tolerant species of macaque, Macaca nigra. Proceedings of the Royal Society B, 279 (1744), 4042.

Mielke, A., Samuni, L., Preis, A., Gogarten, J.F., Crockford, C. \& Wittig, R.M. (2017). Bystanders intervene to impede grooming in Western chimpanzees and sooty mangabeys. Royal Society Open Science, 4 (11), 171296.

Miller, R.C., Brindle, E., Holman, D.J., Shofer, J., Klein, N.A., Soules, M.R., et al. (2004). Comparison of specific gravity and creatinine for normalizing urinary reproductive hormone concentrations. Clinical Chemistry, 50 (5), 924-932.

Mitani, J.C. (2009). Male chimpanzees form enduring and equitable social bonds. Animal Behaviour, 77 (3), 633-640.

Morales, J.C. \& Melnick, D.J. (1998). Phylogenetic relationships of the macaques (Cercopithecidae: Macaca), as revealed by high resolution restriction site mapping of mitochondrial ribosomal genes. Journal of Human Evolution, 34 (1), 1-23. 
Moser, B., Schroecksnadel, K., Hörtnagl, H., Rieder, J., Fuchs, D. \& Gottardis, M. (2008). Influence of extreme long endurance sports activity on neopterin excretion. Pteridines, 19 (1), 114-119.

Moss, C.J., Croze, H. \& Lee, P.C. (2011). The Amboseli Elephants: a long-term Perspective on a long-lived Mammal. University of Chicago Press.

Mossong, J., Hens, N., Jit, M., Beutels, P., Auranen, K., Mikolajczyk, R., et al. (2008). Social contacts and mixing patterns relevant to the spread of infectious diseases. PLoS Medicine, 5 (3), e74.

Muehlenbein, M.P. (2006). Intestinal parasite infections and fecal steroid levels in wild chimpanzees. American Journal of Physical Anthropology, 130 (4), 546-550.

Muehlenbein, M.P. \& Bribiescas, R.G. (2005). Testosterone-mediated immune functions and male life histories. American Journal of Human Biology, 17 (5), 527-558.

Muehlenbein, M.P. \& Watts, D.P. (2010). The costs of dominance: testosterone, cortisol and intestinal parasites in wild male chimpanzees. BioPsychoSocial Medicine, 4(1), 21.

Müller, N., Heistermann, M., Strube, C., Schülke, O. \& Ostner, J. (2017). Age, but not anthelmintic treatment, is associated with urinary neopterin levels in semi-free ranging Barbary macaques. Scientific Reports, 7, 41973.

Müller-Klein, N., Heistermann, M., Strube, C., Morbach, Z., Lilie, N., Franz, M., Schülke, O. \& Ostner, J. (2018). Physiological and social consequences of gastrointestinal nematode infection in a nonhuman primate. Behavioral Ecology. doi:10.1093/beheco/ary168.

Müller-Klein, N., Heistermann, M., Strube, C., Morbach, Z., Lilie, N., Franz, M., Schülke, O. \& Ostner, J. Data from: physiological and social consequences of gastrointestinal nematode infection in a nonhuman primate. Behavioral Ecology/Dryad Digital Repository. doi: $10.5061 /$ dryad.n7nm0g4.

Müller-Klein, N., Heistermann, M., Strube, C., Franz, M., Schülke, O., \& Ostner, J. (2019). Data from: Exposure and susceptibility drive reinfection with gastrointestinal parasites in a social primate. Functional Ecology/Dryad Digital Repository. doi: 10.5061/dryad.rr379bp

Murr, C., Hainz U., Asch E. et al. (2004). Increased neopterin concentration in older age coincides with decline of CD28+CD45RA+ T-cells. Pteridines (4), 15, 170.

Murr, C., Widner, B., Wirleitner, B. \& Fuchs, D. (2002). Neopterin as a marker for immune system activation. Current Drug Metababolism, 3 (2), 175-187.

Murray, D.L. (2002). Differential body condition and vulnerability to predation in snowshoe hares. Journal of Animal Ecology, 71 (4), 614-625.

Muscatell, K.A., Dedovic, K., Slavich, G.M., Jarcho, M.R., Breen, E.C., Bower, J.E., et al. (2016). Neural mechanisms linking social status and inflammatory responses to social stress. Social Cognitive and Affective Neuroscience, 11(6), 915-922.

Nunn, C., Altizer, S. \& Altizer, S.M. (2006). Infectious Diseases in Primates: Behavior, Ecology and Evolution. Oxford University Press, New York.

Nunn, C.L. \& Heymann, E.W. (2005). Malaria infection and host behavior: a comparative study of Neotropical primates. Behavioral Ecology and Sociobiology, 59 (1), 30-37.

Nunn, C.L., Jordan, F., McCabe, C.M., Verdolin, J.L. \& Fewell, J.H. (2015). Infectious disease and group size: more than just a numbers game. Philosophical Transactions of the Royal Society B, 370 (1669), 20140111.

Nussey, D.H., Froy, H., Lemaitre, J.-F., Gaillard, J.-M. \& Austad, S.N. (2013). Senescence in natural populations of animals: widespread evidence and its implications for bio-gerontology. Ageing Research Reviews, 12 (1), 214-225.

Nutman, T.B. (2015). Looking beyond the induction of Th2 responses to explain immunomodulation by helminths. Parasite Immunology, 37 (6), 304-313. 
Ojha, S.C., Jaide, C., Jinawath, N., Rotjanapan, P. \& Baral, P. (2014). Geohelminths: public health significance. The Journal of Infection in Developing Countries, 8 (1), 5-16.

Olsson, M.J., Lundström, J.N., Kimball, B.A., Gordon, A.R., Karshikoff, B., Hosseini, N., et al. (2014). The scent of disease: human body odor contains an early chemosensory cue of sickness. Psychological Science, 25 (3), 817-823.

Ostner, J. \& Schülke, O. (2014). The evolution of social bonds in primate males. Behaviour, 151 (7), 871-906.

Ostner, J. \& Schülke, O. (2018). Chapter Four - Linking sociality to fitness in primates: A call for mechanisms. Advances in the Study of Behavior. Vol. 50. Academic Press, pp. 127-175.

Ota, N., Hasegawa, H., McLennan, M.R., Kooriyama, T., Sato, H., Pebsworth, P.A., et al. (2015). Molecular identification of Oesophagostomum spp. from 'village' chimpanzees in Uganda and their phylogenetic relationship with those of other primates. Royal Society Open Science, 2 (11), 150471.

Packer, C. \& Ruttan, L. (1988). The evolution of cooperative hunting. The American Naturalist, 132 (2), 159-198.

Packer, C., Scheel, D. \& Pusey, A.E. (1990). Why lions form groups: food is not enough. The American Naturalist, 136 (1), 1-19.

Palme, R., Touma, C., Arias, N., Dominchin, M.F. \& Lepschy, M. (2013). Steroid extraction: get the best out of faecal samples. Wiener Tierärztliche Monatsschrift, 100 (9-10), 238-246.

Palombit, R.A., Cheney, D.L. \& Seyfarth, R.M. (2001). Female-female competition for male 'friends' in wild chacma baboons (Papio cynocephalus ursinus). Animal Behaviour, 61 (6), 1159-1171.

Palombit, R.A., Seyfarth, R.M. \& Cheney, D.L. (1997). The adaptive value of 'friendships' to female baboons: experimental and observational evidence. Animal Behaviour, 54 (3), 599-614.

Parker, D.C., Mielke, M.M., Yu, Q., Rosenberg, P.B., Jian, A., Lyketsos, C.G., et al. (2013). Plasma neopterin level as a marker of peripheral immune activation in amnestic mild cognitive impairment and Alzheimer's disease. International Journal of Geriatric Psychiatry, 28 (2), 149-154.

Paschek, N., Müller, N., Heistermann, M., Ostner, J., \& Schülke, O. (2019). Subtypes of aggression and their relation to anxiety in Barbary macaques. Aggressive Behavior, 45(2), 120-128. doi:10.1002/ab.21801

Parr, N.A., Fedigan, L.M. \& Kutz, S.J. (2013). Predictors of parasitism in wild white-faced capuchins (Cebus capucinus). International Journal of Primatology, 34 (6), 1137-1152.

Patterson, J.E.H. \& Ruckstuhl, K.E. (2013). Parasite infection and host group size: a meta-analytical review. Parasitology, 140 (7), 803-813.

Paul, A. \& Kuester, J. (1985). Intergroup transfer and incest avoidance in semifree-ranging Barbary macaques (Macaca sylvanus) at Salem (FRG). American Journal of Primatology, 8 (4), 317-322.

Paul, A. \& Kuester, J. (1988). Life history patterns of Barbary macaques at Affenberg Salem. Ecology and Behavior of Food-Enhanced Primate Groups, Liss New York, pp. 199-228.

Paul, A., Kuester, J. \& Arnemann, J. (1992). Maternal rank affects reproductive success of male Barbary macaques (Macaca sylvanus): evidence from DNA fingerprinting. Behavioral Ecology and Sociobiology, 30(5), 337-341.

Pebsworth, P.A., Archer, C.E., Appleton, C.C. \& Huffman, M.A. (2012). Parasite transmission risk from geophagic and foraging behavior in chacma baboons. American Journal of Primatology, 74 (10), 940-947.

Pedersen, A.B. \& Antonovics, J. (2013). Anthelmintic treatment alters the parasite community in a wild mouse host. Biology Letters, 9 (4), 20130205.

Pedersen, A.B. \& Babayan, S.A. (2011). Wild immunology. Molecular Ecology, 20 (5), 872-880. 
Pedersen, A.B. \& Fenton, A. (2015). The role of antiparasite treatment experiments in assessing the impact of parasites on wildlife. Trends in Parasitology, 31 (5), 200-211.

Pedersen, A.B. \& Greives, T.J. (2008). The interaction of parasites and resources cause crashes in a wild mouse population. Journal of Animal Ecology, 77 (2), 370-377.

Peig, J. \& Green, A.J. (2009). New perspectives for estimating body condition from mass/length data: the scaled mass index as an alternative method. Oikos, 118 (12), 1883-1891.

Peterson, C.G.B., Eklund, E., Taha, Y., Raab, Y. \& Carlson, M. (2002). A new method for the quantification of neutrophil and eosinophil cationic proteins in feces: establishment of normal levels and clinical application in patients with inflammatory bowel disease. The American Journal of Gastroenterology, 97 (7), 1755-1762.

Pit, D., Polderman, A.M., Baeta, S., Schulz-Key, H. \& Soboslay, P. (2001). Parasite-specific antibody and cellular immune responses in humans infected with Necator americanus and Oesophagostomum bifurcum. Parasitology Research, 87 (9), 722-729.

Plata-Nazar, K., Luczak, G., Gora-Gebka, M., Liberek, A. \& Kaminska, B. (2010). Serum neopterin concentration in children with viral gastroenteritis. Pteridines, 21 (1), 11-16.

Plein, L.M. \& Rittner, H.L. (2017). Opioids and the immune system-friend or foe. British Journal of Pharmacology, 175 (14), 2717- 2725.

Poirotte, C., Basset, D., Willaume, E., Makaba, F., Kappeler, P.M. \& Charpentier, M.J.E. (2016). Environmental and individual determinants of parasite richness across seasons in a free-ranging population of Mandrills (Mandrillus sphinx). American Journal of Physical Anthropology, 159 (3), 442456.

Poirotte, C., Massol, F., Herbert, A., Willaume, E., Bomo, P.M., Kappeler, P.M., et al. (2017). Mandrills use olfaction to socially avoid parasitized conspecifics. Science Advances, 3(4), e1601721

Poulin, R. (2010). Parasite manipulation of host behavior: an update and frequently asked questions. Advances in the Study of Behavior. Academic Press, pp. 151-186.

Purvis, A. (1995). A Composite Estimate of Primate Phylogeny Philosophical Transactions of the Royal Society B, 348 (1326), 405-421.

Pusey, A.E. \& Packer, C. (1994). Infanticide in lions: consequences and counterstrategies. Infanticide and Parental Care, Harwood Academic Publishers, Chur, pp. 277-299.

R Core Team (2014). A Language and Environment for Statistical Computing. URL https//www. Rproject. org.

Råberg, L. (2014). How to live with the enemy: understanding tolerance to parasites. PLoS Biology., 12 (11), e1001989.

Råberg, L., Graham, A.L. \& Read, A.F. (2009). Decomposing health: tolerance and resistance to parasites in animals. Philosophical Transactions of the Royal Society B, 364 (1513), 37-49.

Rafi, W., Ribeiro-Rodrigues, R., Ellner, J.J. \& Salgame, P. (2012). Coinfection-helminthes and tuberculosis. Current Opinion in HIV and AIDS, 7 (3), 239-244.

Ramp, C., Hagen, W., Palsbøll, P., Bérubé, M. \& Sears, R. (2010). Age-related multi-year associations in female humpback whales (Megaptera novaeangliae). Behavioral Ecology and Sociobiology, 64 (10), 1563-1576.

Read, A.F., Graham, A.L. \& Råberg, L. (2008). Animal defenses against infectious agents: is damage control more important than pathogen control. PLOS Biology, 6 (12), e1000004.

Reber, L.L., Sibilano, R., Mukai, K. \& Galli, S.J. (2015). Potential effector and immunoregulatory functions of mast cells in mucosal immunity. Mucosal Immunology, 8, 444-463.

Reibnegger, G., Auhuber, I., Fuchs, D., Hausen, A., Judmaier, G., Prior, C., et al. (1988a). Urinary neopterin levels in acute viral hepatitis. Hepatology, 8 (4), 771-774. 
Reibnegger, G., Huber, L.A., Jürgens, G., Schönitzer, D., Werner, E.R., Wachter, H., et al. (1988b). Approach to define "normal aging" in man. Immune function, serum lipids, lipoproteins and neopterin levels. Mechanisms of Ageing and Development, 46 (1-3), 67-82.

Reichard, M. (2016). Evolutionary ecology of aging: time to reconcile field and laboratory research. Ecology and Evololution, 6 (9), 2988-3000.

Reimert, C.M., Tukahebwa, E.M., Kabatereine, N.B., Dunne, D.W. \& Vennervald, B.J. (2008). Assessment of Schistosoma mansoni induced intestinal inflammation by means of eosinophil cationic protein, eosinophil protein $\mathrm{X}$ and myeloperoxidase before and after treatment with praziquantel. Acta Tropica, 105 (3), 253-259.

Richards, S.A., Whittingham, M.J. \& Stephens, P.A. (2011). Model selection and model averaging in behavioural ecology: the utility of the IT-AIC framework. Behavioral Ecology and Sociobiology, 65 (1), 77-89.

Rimbach, R., Bisanzio, D., Galvis, N., Link, A., Di Fiore, A., Gillespie, T.R.T.R., et al. (2015). Brown spider monkeys (Ateles hybridus): a model for differentiating the role of social networks and physical contact on parasite transmission dynamics. Philosophical Transactions of the Royal Society B, 370 (1669), 20140110.

Roberts, J.L. \& Swan, R.A. (1981). Quantitative studies of ovine haemonchosis. I. Relationship between faecal egg counts and total worm counts. Veterinary Parasitology, 8 (2), 165-171.

Roeber, F., Jex, A.R. \& Gasser, R.B. (2013). Impact of gastrointestinal parasitic nematodes of sheep, and the role of advanced molecular tools for exploring epidemiology and drug resistance - an Australian perspective. Parasites and Vectors, 6 (1), 153-165.

Roepstorff, A., Bjørn, H., Nansen, P., Barnes, E.H. \& Christensen, C.M. (1996). Experimental Oesophagostomum dentatum infections in the pig: Worm populations resulting from trickle infections with three dose levels of larvae. International Journal for Parasitology, 26 (4), 399-408.

Romano, C.M., de Carvalho-Mello, I.M.V.G., Jamal, L.F., de Melo, F.L., Iamarino, A., Motoki, M., et al. (2010). Social networks shape the transmission dynamics of hepatitis C virus. PLoS One, 5 (6), e11170.

Romero, L.M. (2004). Physiological stress in ecology: lessons from biomedical research. Trends in Ecology and Evolution, 19 (5), 249-255.

Rothenberg, R.B., Potterat, J.J., Woodhouse, D.E., Muth, S.Q., Darrow, W.W. \& Klovdahl, A.S. (1998). Social network dynamics and HIV transmission. AIDS, 12 (12), 1529-1536.

Rubenstein, D.I. (1978). On predation, competition, and the advantages of group living. Social Behavior. Perspectives in Ethology, Vol 3. Springer, Boston, pp. 205-231.

Rushmore, J., Caillaud, D., Matamba, L., Stumpf, R.M., Borgatti, S.P. \& Altizer, S. (2013). Social network analysis of wild chimpanzees provides insights for predicting infectious disease risk. Journal of Animal Ecology, 82 (5), 976-986.

Rynkiewicz, E.C., Pedersen, A.B. \& Fenton, A. (2015). An ecosystem approach to understanding and managing within-host parasite community dynamics. Trends in Parasitology, 31 (5), 212-221.

Sabbatini, G., Vizioli, A.D.B., Visalberghi, E. \& Schino, G. (2012). Food transfers in capuchin monkeys: an experiment on partner choice. Biology Letters, rsbl20120534.

Sajid, M.S., Iqbal, Z., Muhammad, G., Sandhu, M.A., Khan, M.N., Saqib, M., et al. (2007). Effect of ivermectin on the cellular and humoral immune responses of rabbits. Life Sciences, 80 (21), 19661970.

Salathé, M. \& Jones, J.H. (2010). Dynamics and control of diseases in networks with community structure. PLoS Compututational Biology, 6 (4), e1000736.

Salgame, P., Yap, G.S. \& Gause, W.C. (2013). Effect of helminth-induced immunity on infections with microbial pathogens. Nature Immunology, 14 (11), 1118-1126. 
Samuni, L., Preis, A., Mundry, R., Deschner, T., Crockford, C. \& Wittig, R.M. (2016). Oxytocin reactivity during intergroup conflict in wild chimpanzees. Proceedings of the National Academy of Sciences, 114 (2), 268-273.

Sapolsky, R.M. (2004). Social status and health in humans and other animals. Annual Review of Anthropology, 33, 393-418.

Sapolsky, R.M. (2005). The influence of social hierarchy on primate health. Science, 308 (5722), 648652.

Sarabian, C. \& MacIntosh, A.J.J. (2015). Hygienic tendencies correlate with low geohelminth infection in free-ranging macaques. Biology Letters, 11, 20150757.

Schaebs, F.S., Wolf, T.E., Behringer, V. \& Deschner, T. (2016). Fecal thyroid hormones allow for the noninvasive monitoring of energy intake in capuchin monkeys. Journal of Endocrinology, 231 (1), 1-10.

Van Schaik, C.P. (1983). Why are diurnal primates living in groups? Behaviour, 87 (1), 120-144.

Van Schaik, C.P. \& Van Hooff, J. (1983). On the ultimate causes of primate social systems. Behaviour, 85 (1), 91-117.

van Schaik, C.P., Pandit, S.A. \& Vogel, E.R. (2004). A model for within-group coalitionary aggression among males. Behavioral Ecology and Sociobiology, 57 (2), 101-109.

Schennach, H., Murr, C., Gächter, E., Mayersbach, P., Schönitzer, D. \& Fuchs, D. (2002). Factors influencing serum neopterin concentrations in a population of blood donors. Clinical Chemistry, 48 (4), 643-645.

Schmid-Hempel, P. (2003). Variation in immune defence as a question of evolutionary ecology. Proceedings of the Royal Society B, 270 (1513), 357-366.

Schmid-Hempel, P. (2017). Parasites and their social hosts. Trends in Parasitology, 33 (6), 453-462.

Schmid, V.S. \& De Vries, H. (2013). Finding a dominance order most consistent with a linear hierarchy: An improved algorithm for the I\&SI method. Animal Behaviour, 86 (5), 1097-1105.

Schülke, O., Bhagavatula, J., Vigilant, L. \& Ostner, J. (2010). Social bonds enhance reproductive success in male macaques. Current Biology, 20 (24), 2207-2210.

Seivwright, L.J., Redpath, S.M., Mougeot, F., Watt, L. \& Hudson, P.J. (2004). Faecal egg counts provide a reliable measure of Trichostrongylus tenuis intensities in free-living red grouse Lagopus lagopus scoticus. Journal of Helminthology, 78 (1), 69-76.

Setchell, J.M., Smith, T., Wickings, E.J. \& Knapp, L.A. (2010). Stress, social behaviour, and secondary sexual traits in a male primate. Hormones and Behavior, 58 (5), 720-728.

Seyfarth, R.M., Silk, J.B. \& Cheney, D.L. (2014). Social bonds in female baboons: The interaction between personality, kinship and rank. Animal Behaviour, 87, 23-29.

Shintaku, H., Isshiki, G., Hase, Y., Tsuruhara, T. \& Oura, T. (1982). Normal pterin values in urine and serum in neonates and its age-related change throughout life. Journal of Inherited Metabolic Disease, 5(4), 241-242.

Shutt, D.A., Fell, L.R., Adams, D.B. \& Lynch, J.J. (1990). Effects of Haemonchus contortus in pen-fed versus paddock sheep as determined by plasma cortisol and insulin-like growth factor 1. Proceedings of the Australian Society of Animal Production Vol.18, pp.360-363.

Shutt, K., MacLarnon, A., Heistermann, M. \& Semple, S. (2007). Grooming in Barbary macaques: better to give than to receive? Biology Letters, 3 (3), 231-233.

Sibly, R.M. (1983). Optimal group size is unstable. Animal Bebaviour, 31, 947-948.

Silk, J. (2002). Using the 'F'-word in primatology. Behaviour. 139(2-3), 421

Silk, J.B., Alberts, S.C. \& Altmann, J. (2003). Social bonds of female baboons enhance infant survival. Science, 302 (5648), 1231-1234. 
Silk, J.B., Altmann, J. \& Alberts, S.C. (2006). Social relationships among adult female baboons (Papio cynocephalus) I. Variation in the strength of social bonds. Behavioral Ecology and Sociobiology, 61 (2), 183-195.

Silk, J.B., Beehner, J.C., Bergman, T.J., Crockford, C., Engh, A.L., Moscovice, L.R., et al. (2009). The benefits of social capital: close social bonds among female baboons enhance offspring survival. Proceedings of the Royal Society B, 276(1670), 3099-3104.

Silk, J.B., Beehner, J.C., Bergman, T.J., Crockford, C., Engh, A.L., Moscovice, L.R., et al. (2010). Strong and consistent social bonds enhance the longevity of female baboons. Current Biology, 20(15), 1359-1361.

Silk, J.B., Seyfarth, R.M. \& Cheney, D.L. (2018). Quality versus quantity: do weak bonds enhance the fitness of female baboons? Animal Behaviour, 140, 207-211.

Sloan, E.K., Capitanio, J.P. \& Cole, S.W. (2008). Stress-induced remodeling of lymphoid innervation. Brain, Behaviour and Immunity, 22 (1), 15-21.

Sloan, E.K., Capitanio, J.P., Tarara, R.P., Mendoza, S.P., Mason, W.A. \& Cole, S.W. (2007). Social stress enhances sympathetic innervation of primate lymph nodes: mechanisms and implications for viral pathogenesis. Journal of Neuroscience, 27(33), 8857-8865.

Small, M. (1990). Alloparental behaviour in Barbary macaques, Macaca sylvanus. Animal Behaviour, $297-$ 306.

Smith, J.E., Van Horn, R.C., Powning, K.S., Cole, A.R., Graham, K.E., Memenis, S.K., et al. (2010). Evolutionary forces favoring intragroup coalitions among spotted hyenas and other animals. Behavioral Ecology, 21 (2), 284-303.

Smith, K.F., Acevedo-Whitehouse, K. \& Pedersen, A.B. (2009). The role of infectious diseases in biological conservation. Animal Conservation, 12 (1), 1-12.

Snaith, T. V., Chapman, C.A., Rothman, J.M. \& Wasserman, M.D. (2008). Bigger groups have fewer parasites and similar cortisol levels: A multi-group analysis in red colobus monkeys. American Journal of Primatology, 70 (11), 1072-1080.

Snaith, T. V \& Chapman, C.A. (2007). Primate group size and interpreting socioecological models: do folivores really play by different rules? Evolutionary Anthropology: Issues, News, and Reviews, 16 (3), 94-106.

Snyder-Mackler, N., Sanz, J., Kohn, J.N., Brinkworth, J.F., Morrow, S., Shaver, A.O., et al. (2016). Social status alters immune regulation and response to infection in macaques. Science, 354 (6315), 1041-1045.

Solana, R., Tarazona, R., Gayoso, I., Lesur, O., Dupuis, G. \& Fulop, T. (2012). Innate immunosenescence: Effect of aging on cells and receptors of the innate immune system in humans. Seminars in Immunology Vol. 24 (5), Academic Press, pp. 331-341.

Solichová, D., Melichar, B., Svobodová, I., Bláha, V. \& Zadák, Z. (1999). Fluorescence analysis of antioxidant vitamins and neopterin in nonagenarians. Biomedical Chromatography, 13(2), 117-118.

Spencer, M.E., Jain, A., Matteini, A., Beamer, B.A., Wang, N.Y., Leng, S.X., et al. (2010). Serum levels of the immune activation marker neopterin change with age and gender and are modified by race, BMI, and percentage of body fat. Journals of Gerontology Series A: Biomedical Sciences and Medical Sciences, 65 (8), 858-865.

Springer, A., Fichtel, C., Calvignac-Spencer, S., Leendertz, F.H. \& Kappeler, P.M. (2015). Hemoparasites in a wild primate: Infection patterns suggest interaction of Plasmodium and Babesia in a lemur species. International Journal for Parasitology: Parasites and Wildlife, 4 (3), 385-395.

Springer, A., Kappeler, P.M. \& Nunn, C.L. (2017). Dynamic vs. static social networks in models of parasite transmission: predicting Cryptosporidium spread in wild lemurs. Journal of Animal Ecology, 86 (3), 419-433. 
Springer, A., Mellmann, A., Fichtel, C. \& Kappeler, P.M. (2016). Social structure and Escherichia coli sharing in a group-living wild primate, Verreaux's sifaka. BMC Ecology, 16 (1), 6-18.

Stankiewicz, M., Cabaj, W., Jonas, W.E., Moore, L.G., Millar, K. \& Ng Chie, W. (1995). Influence of ivermectin on cellular and humoral immune responses of lambs. Veterinary Immunology and Immunopathology 44 (3-4), 347-358.

Stanley, C.R., Mettke-Hofmann, C., Hager, R. \& Shultz, S. (2017). Social stability in semiferal ponies: networks show interannual stability alongside seasonal flexibility. Animal Behaviour, 136, 175184

Stanton, M.A. \& Mann, J. (2012). Early social networks predict survival in wild bottlenose dolphins. PLoS One, 7, e47508.

Steel, C., Lujan-Trangay, A., Gonzalez-Peralta, C., Zea-Flores, G. \& Nutman, T.B. (1994). Transient changes in cytokine profiles following ivermectin treatment of onchocerciasis. Journal of Infectious Diseases, 170 (4), 962-970.

Stephenson, L.S., Holland, C. V. \& Cooper, E.S. (2000a). The public health significance of Trichuris tricbiura. Parasitology, 121 (1), 73-95.

Stephenson, L.S., Latham, M.C. \& Ottesen, E.A. (2000b). Malnutrition and parasitic helminth infections. Parasitology, 121 (1), 23-38.

Sterck, E.H.M., Watts, D.P. \& van Schaik, C.P. (1997). The evolution of female social relationships in nonhuman primates. Behavioral Ecology and Sociobiology, 41 (5), 291-309.

Stien, A., Irvine, R.J., Ropstad, E., Halvorsen, O., Langvatn, R. \& Albon, S.D. (2002). The impact of gastrointestinal nematodes on wild reindeer: Experimental and cross-sectional studies. Journal of Animal Ecology, 71 (6), 937-945.

Stromberg, B.E. (1997). Environmental factors influencing transmission. Veterinary Parasitology, 72 (3-4), 247-264.

Sucher, R., Schroecksnadel, K., Weiss, G., Margreiter, R., Fuchs, D. \& Brandacher, G. (2010). Neopterin, a prognostic marker in human malignancies. Cancer Letters, 287 (1), 13-22.

Sykes, A.R. \& Coop, R.L. (1976). Intake and utilization of food by growing lambs with parasitic damage to the small intestine caused by daily dosing with Trichostrongylus colubriformis larvae. The Journal of Agricultural Science, 86 (3), 507-515.

Szathmáry, E. \& Smith, J.M. (1995). The major evolutionary transitions. Nature, 374 (6519), $227-$ 232.

Szyszka, O. \& Kyriazakis, I. (2013). What is the relationship between level of infection and 'sickness behaviour'in cattle? Applied Animal Behaviour Science, 147 (1), 1-10.

Telfer, S., Lambin, X., Birtles, R., Beldomenico, P., Burthe, S., Paterson, S., et al. (2010). Species interactions in a parasite community drive infection risk in a wildlife population. Science, 330 (6001), 243-246.

Terio, K.A., Lonsdorf, E. V., Kinsel, M.J., Raphael, J., Lipende; Iddie, Collins, A., et al. (2016). Oesophagostomiasis in non-human primates of Gombe National Park, Tanzania. American Journal of Primatology, 80 (1), e22572.

Thierry, B. (2007). Unity in diversity: Lessons from macaque societies. Evolutionary Anthropology: Issues, News, and Reviews, 16 (6), 224-238.

Thierry, B. (2013). Identifying constraints in the evolution of primate societies. Philosophical Transactions of the Royal Society B, 368(1618), 20120342.

Thierry, B., Iwaniuk, A.N. \& Pellis, S.M. (1999). The infuence of phylogeny on the social behaviour of macaques (Primates: Cercopithecidae, genus Macaca). Ethology, 106 (8), 602-617. 
Thoits, P.A. (2011). Mechanisms linking social ties and support to physical and mental health. Journal of Health and Social Behavior, 52 (2), 145-161.

Thompson, N.A. \& Cords, M. (2018). Stronger social bonds do not always predict greater longevity in a gregarious primate. Ecology and Evolution, 8, 1604-1614

Tiddi, B., Aureli, F., Polizzi Di Sorrentino, E., Janson, C.H. \& Schino, G. (2011). Grooming for tolerance? Two mechanisms of exchange in wild tufted capuchin monkeys. Behavioral Ecology (3), 22, 663-669.

Tiddi, B., Aureli, F. \& Schino, G. (2012). Grooming up the hierarchy: the exchange of grooming and rank-related benefits in a new world primate. PLoS One, 7, e36641.

Tompkins, D.M. \& Begon, M. (1999). Parasites can regulate wildlife populations. Parasitology Today, 15 (8), 311-313.

Tompkins, D.M., Dunn, A.M., Smith, M.J. \& Telfer, S. (2011). Wildlife diseases: From individuals to ecosystems. Journal of Animal Ecology, 80 (1), 19-38.

Tsai, E.B., Sherry, N.A., Palmer, J.P., Herold, K.C. \& Group, D.-1 S. (2006). The rise and fall of insulin secretion in type 1 diabetes mellitus. Diabetologia, 49 (2), 261-270.

Tung, J., Barreiro, L.B., Burns, M.B., Grenier, J.C., Lynch, J., Grieneisen, L.E., et al. (2015). Social networks predict gut microbiome composition in wild baboons. Elife, 4, 1-18.

Tung, J. \& Gilad, Y. (2013). Social environmental effects on gene regulation. Cellular and Molecular Life Sciences, 70 (22), 4323-4339.

de Turckheim, G. \& Merz, E. (1984). Breeding Barbary macaques in outdoor open enclosures. The Barbary Macaque: A Case study in Conservation. Plenum Press, New York and London, pp. 241-261.

Uchino, B.N. (2006). Social support and health: a review of physiological processes potentially underlying links to disease outcomes. Journal of Behavioral Medicine, 29 (4), 377-387.

Uchino, B.N., Cacioppo, J.T. \& Kiecolt-Glaser, J.K. (1996). The relationship between social support and physiological processes: a review with emphasis on underlying mechanisms and implications for health. Psychological Bulletin, 119 (3), 488-531.

Uhlír, J. \& Volf, P. (1992). Ivermectin: its effect on the immune system of rabbits and rats infested with ectoparasites. Veterinary Immunology and Immunopathology, 34 (3-4), 325-336.

Unal, B., Kocer, B., Altun, B., Surmeli, S., Aksaray, S., Balci, M., et al. (2009). Serum neopterin as a prognostic indicator in patients with gastric carcinoma. Journal of Investigative Surgery, 22(6), 419425.

Urban, J.F., Madden, K.B., Svetic, A., Cheever, A., Trotta, P.P., Gause, W.C., et al. (1992). The importance of Th2 cytokines in protective immunity to nematodes. Immunological Reviews, 127 (1), 205-220.

Uvnäs-Moberg, K. (1998). Oxytocoin may mediate the benefits of positive social interactions and emotions. Psychoneuroendocrinology, 23 (8), 819-835.

Vandeleest, J.J., Beisner, B.A., Hannibal, D.L., Nathman, A.C., Capitanio, J.P., Hsieh, F., et al. (2016). Decoupling social status and status certainty effects on health in macaques: a network approach. PeerJ, 4, e2394.

VanderWaal, K.L., Atwill, E.R., Hooper, S., Buckle, K. \& McCowan, B. (2013). Network structure and prevalence of Cryptosporidium in Belding's ground squirrels. Behavioral Ecology and Sociobiology, 67 (12), 1951-1959.

VanderWaal, K.L., Atwill, E.R., Isbell, L.A. \& McCowan, B. (2014). Linking social and pathogen transmission networks using microbial genetics in giraffe (Giraffa camelopardalis). Journal of Animal Ecology, 83 (2), 406-414. 
Vanderwaal, K.L. \& Ezenwa, V.O. (2016). Heterogeneity in pathogen transmission: mechanisms and methodology. Functional Ecology, 30 (10), 1606-1622.

VanderWaal, K.L., Mosser, A. \& Packer, C. (2009). Optimal group size, dispersal decisions and postdispersal relationships in female African lions. Animal Behaviour, 77 (4), 949-954.

van Lavieren, E. \& Wich, S.A. (2010). Decline of the endangered Barbary macaque Macaca sylvanus in the cedar forest of the Middle Atlas Mountains, Morocco. Oryx, 44 (1), 133-138.

Vaumourin, E., Vourc'h, G., Gasqui, P. \& Vayssier-Taussat, M. (2015). The importance of multiparasitism: examining the consequences of co-infections for human and animal health. Parasites and Vectors, 8 (1), 545-557.

Vicente, J., Delahay, R.J., Walker, N.J. \& Cheeseman, C.L. (2007). Social organization and movement influence the incidence of bovine tuberculosis in an undisturbed high-density badger Meles meles population. Journal of Animal Ecology, 76 (2), 348-360.

Viney, M. (2017). Strongyloides. Parasitology, 144 (3), 259-262.

Wang, G.C. \& Casolaro, V. (2014). Immunologic changes in frail older adults. Translational Medicine (a) UniSa, 9, 1-6.

Watson, R.L., McNeilly, T.N., Watt, K.A., Pemberton, J.M., Pilkington, J.G., Waterfall, M., et al. (2016). Cellular and humoral immunity in a wild mammal: Variation with age \& sex and association with overwinter survival. Ecology and Evolution, 6 (24), 8695-8705.

Weber, N., Carter, S.P., Dall, S.R.X., Delahay, R.J., McDonald, J.L., Bearhop, S., et al. (2013). Badger social networks correlate with tuberculosis infection. Current Biology, 23 (20), 915-916.

Weinstein, S.B., Moura, C.W., Mendez, J.F. \& Lafferty, K.D. (2018). Fear of feces? Tradeoffs between disease risk and foraging drive animal activity around raccoon latrines. Oikos, doi:10.1111/oik.04866

Weng, N. ping. (2006). Aging of the immune system: how much can the adaptive immune system adapt? Immunity, 24 (5), 495-499.

Werner, E.R., Bichler, A., Daxenbichler, G., Fuchs, D., Fuith, L.C., Hausen, A., et al. (1987). Determination of neopterin in serum and urine. Clinical Chemistry, 33 (1), 62-66.

Wey, T.W., Blumstein, D.T., Shen, W. \& Jordán, F. (2008). Social network analysis of animal behaviour: a promising tool for the study of sociality. Animal Behaviour, 75 (2), 333-344.

White, L.A., Forester, J.D. \& Craft, M.E. (2017a). Covariation between the physiological and behavioral components of pathogen transmission: host heterogeneity determines epidemic outcomes. Oikos 127(4), 538-552

White, L.A., Forester, J.D. \& Craft, M.E. (2017b). Using contact networks to explore mechanisms of parasite transmission in wildlife. Biological Reviews, 92 (1), 389-409.

Widdig, A., Streich, W.J. \& Tembrock, G. (2000). Coalition formation among male Barbary macaques (Macaca sylvanus). American Journal of Primatology, 50 (1), 37-51.

Widner, B., Murr, C., Wirleitner, B., Mayr, C., Spöttl, N., Baier-Bitterlich, G., et al. (1999). The importance of neopterin as a laboratory diagnostic marker of immune activation. Pteridines, 10 (3), 101-111.

Willette, A.A., Lubach, G.R. \& Coe, C.L. (2007). Environmental context differentially affects behavioral, leukocyte, cortisol, and interleukin- 6 responses to low doses of endotoxin in the rhesus monkey. Brain, Behaviour and Immunity, 21 (6), 807-815.

Wilson, K., Bjørnstad, O.N., Dobson, A.P., Merler, S., Poglayen, G., Randolph, S.E., et al. (2002). Heterogeneities in macroparasite infections: patterns and processes. The Ecology of Wildlife Diseases. Oxford University Press, New York, pp. 6-44. 
Witt, D.M., Winslow, J.T. \& Insel, T.R. (1992). Enhanced social interactions in rats following chronic, centrally infused oxytocin. Pharmacology Biochemistry and Behavior, 43 (3), 855-861.

Wittig, R.M., Crockford, C., Lehmann, J., Whitten, P.L., Seyfarth, R.M. \& Cheney, D.L. (2008). Focused grooming networks and stress alleviation in wild female baboons. Hormones and Behavior, 54 (1), 170-177.

Wittig, R.M., Crockford, C., Weltring, A., Langergraber, K.E., Deschner, T. \& Zuberbühler, K. (2016). Social support reduces stress hormone levels in wild chimpanzees across stressful events and everyday affiliations. Nature Communications, 7, 13361.

Woolhouse, M.E.J., Dye, C., Etard, J.F., Smith, T., Charlwood, J.D., Garnett, G.P., et al. (1997). Heterogeneities in the transmission of infectious agents. Proceedings of the National Academy of Sciences, 94 (1), 338-342.

Wrangham, R.W. (1980). An ecological model of female-bonded primate groups. Behaviour, 75 (3), 262-300.

Wren, B.T., Remis, M.J., Camp, J.W. \& Gillespie, T.R. (2016). Number of grooming partners is associated with hookworm infection in wild vervet monkeys (Chlorocebus aethiops). Folia Primatologica. 87 (3), 168-179.

Wright, V.J., Ame, S.M., Haji, H.S., Weir, R.E., Goodman, D., Pritchard, D.I., et al. (2009). Early exposure of infants to GI nematodes induces Th2 dominant immune responses which are unaffected by periodic anthelminthic treatment. Plos Neglected Tropical Diseases, 3 (5), e433.

Yang, E. V. \& Glaser, R. (2002). Stress-induced immunomodulation and the implications for health. International Immunopharmacology, 2 (2-3), 315-324.

Yazdanbakhsh, M., Kremsner, P.G. \& Van Ree, R. (2002). Parasites and the hygiene hypothesis. Science, 296 (5567), 490-494.

Young, C., Hähndel, S., Majolo, B., Schülke, O. \& Ostner, J. (2013). Male coalitions and female behaviour affect male mating success independent of dominance rank and female receptive synchrony in wild Barbary macaques. Behavioral Ecology and Sociobiology, 67 (10), 1665-1677.

Young, C., Majolo, B., Heistermann, M., Schülke, O. \& Ostner, J. (2014a). Responses to social and environmental stress are attenuated by strong male bonds in wild macaques. Proceedings of the National Academy of Sciences, 111 (51), 18195-18200.

Young, C., Majolo, B., Schülke, O. \& Ostner, J. (2014b). Male social bonds and rank predict supporter selection in cooperative aggression in wild Barbary macaques. Animal Behaviour, 95, 23-32. 


\section{Acknowledgements}

There are famously no beginnings and no ends in life, but this is an end, and a beginning. Looking back, it has been a wild ride, wonderful, thrilling, challenging, stressful, sometimes hard, always exciting - I would not have missed it for the world!

There are of course many people without whom this thesis would not have been possible and there is so much I am grateful for and not enough space to adequately thank everyone who deserves my gratitude. I still want to give my heartfelt thanks to everyone for making these last years what they were: A wonderful, great time, one of most trying and still one of the best times of my life! And for helping me become a happier, more confident version of myself than I ever imagined. I want to thank you all, from the bottom of my heart, for the suitcase of memories you helped me pack, all the experiences, support, time, and everything you did for me, knowingly or unknowingly. I would be nothing without you guys!

First and foremost, I of course want to thank my supervisors, Prof. Julia Ostner and Dr. Oliver Schülke: For the supervision and many important lessons they shared with me about behavioural ecology, research and surviving in academia, and for the constant support and encouragement to help me live up to my full potential all the way from the Masters until the end of the Ph.D. project. Thank you for setting me back on track when I doubted myself, for the positive feedback and more than useful criticism, which was at least as valuable as all the things science I learned during my Ph.D. journey. And of course my deepest, heartfelt thanks for giving me the opportunity to work on this amazing project and spend these fantastic months in the field, the office and in various other locations, trying to make sense of what is going on between the Barbary macaques and those nastily complicated parasites! It was the greatest experience I could have wished for, different and harder, but so much more rewarding, and none if it would have been possible without you!

I would further like to thank the third member of my thesis committee, Prof. Lars Penke for the fresh ideas and new perspective he added to the project in the discussions. It was helpful to have someone looking at our questions from a different angle and the discussion substantially improved my approach on and overview over the topic.

I also thank Prof. Peter Kappeler, Prof. Eckhart W. Heymann and Dr. Christian Roos for agreeing to be my defence committee, and the helpful discussions, comments and criticism they gave during the thesis within the Sociality and Health in Primates (SoHaPi) Research Unit.

My deep thanks also go to all of collaborators without whom this project would not have been possible. First of all, I want to thank Dr. Ellen Merz for allowing me to conduct the study at Affenberg Salem, and Dr. Berhard Stark, who supervised the antiparasite treatment. I want to thank Dr. Michael Heistermann for the support with the hormone analyses and the very pleasant collaboration. And of course to Andrea Heistermann, whose support in the analyses was invaluable. It was always a pleasure to come over to the Endocrinology Lab and I greatly appreciate 
the effort you put into the project and how much it helped me. It was great working with you and I hope I'll get the opportunity to do so in the future! I also want to thank Prof. Christina Strube and her team at the Institute for Parasitology and the University of Veterinary Medicine, Hannover for the collaboration on the parasitological part of the project. I am grateful for the very warm welcome I received in the Institute and the amazing support from the lab team, especially Elisabeth Janecek, Sandra Buschbaum, Sabine Händel and, last but not least, Daniela Jordan. My heartfelt thanks also go to Dr. Mathias Franz from the Institute for Zoo- and Wildlife Research in Berlin for contributing the modelling approaches and offering solutions to problems that had been vexing me for ages. You were always there immediately when I got stuck on the statistics, which was more than I could have asked for! I also want to thank my HiWis, Salina Kadal, Birte Ehrhart and Jenny Hofmann, for the support with labwork and analyses.

I want to extend a heartfelt thanks to Dr. Roland Hilgartner and Mamisolo Hilgartner for the warm welcome and wonderful support on site at Affenberg Salem. Whenever we ran into problems or needed anything, you were right there to help, which was so much more than I could have asked for and just amazing. Mamisolo, you brought so much positive energy to the field every single day, so whatever the weather, if you showed up in the forest, it felt like the sun was rising right there! I want to thank both of you so, so, so much for everything, and as always: see you soon, because I will be back! Whenever I can manage, and that's a promise!

I thank all the Affenberg staff for the support and all those little moments and stories we exchanged. Special thanks go to Jochen Dammbacher, Sylvia Altheimer and Martina Buhrmester, for the friendship and the countless little things you did to help and make my life easier every single day. In more than one way, you made the Affenberg feel like home, and I am immensely grateful for it and wish all of you the very, very best for the times to come!

Of course, there is another group of people without whom I could never (never, never, NEVER!) have completed the project: My "army" of field assistants and my wonderful Master students!

Nicole Paschek: You were amazing, hardworking, dedicated, calm, and you had a way to pay attention to the details of the project as well as the monkeys from which I learned a lot. Having you around was an asset, not only for data collection, but also for the team, and me personally.

Zina Morbach: You were the best right hand woman I could have wished for, extremely professional, strong and hardworking, and a wonderful ally to have - you stepped up and had my back when I needed support the most, and I cannot tell you how glad I am that I had you around!

Navina Lilie: You brought a lot of fun into the field season, even when times got rough, offering new perspectives and focussing on the bright side, creating islands of positivity. I hope I will be able to take some of these lessons into the future.

Thanks also go my field assistants for joining this project and adventure, sharing work and life and all the pains and pleasures of fieldwork! Alice Bouchard, my wonderful "angry French woman": Thank you for everything! You are a friend even more than you were an amazing assistant, you poured your heart and soul into the project, and your encouragement and understanding helped me 
push through when I was struggling. I miss you, and I am so, so glad you were part of my team! Georg Messerer: Thank you so much for bringing your very own perspective to the project, and even more for your positive and calm influence on the atmosphere and your gift to find solutions. Stay wild, my friend! Frauke Gärtner: You were right about so many things I would not have believed... Good things, too! Thank you for all those wonderful moments of friendship and the conversations, the understanding and the challenges, and all the big and small lessons I learned from you!

I also want to thank Fabrizio del'Anna, Graciela Sanguino and Andrea Schick for the contribution in data collection, for the fun evenings outside of the field, and Louise Wilson for all the things I learned from working with you, which helped me grow as a person.

To my second season field team, Rachel Voyt, Natalie Weil, Lola Rivoal, and Juliane Schindler: Ladies, you were simply amazing! Working with you was not perfect, but near enough to make no matter! I hope I managed to tell you all how great it was to work with you and all those things I don't feel I have space to write here. You were an amazing team, and it was a pleasure to work with you for these amazing three months!!! And of course to Cassy Gaylor, Breanne Boughan and Aaron Skinner, who I want to thank for taking up the baton in the second season and continuing the amazing work with Natalie. It was a wonderful summer and a golden autumn, and you brought a lot of fun, friendship and opportunity for shared experience. Thank you for the great work, the laugther and the shared moments!

I want to thank all the members of the Behavioural Ecology department, past, present and future, for the warm welcome to the "research family", for all the scientific and personal lessons you taught me, and all the shared Ph.D. moments inside and outside the office. Miranda Swagemaker, Sally MacDonald, Marlies Heesen, Christin Richter, Christin Minge and most of all Chris Young - my "senior Ph.D. student" and instructor in Endnote, $\mathrm{R}$ and all things Barbary macaque for the endless answering of questions, the support and the wonderful time! Josi Kalbitz, Christine Haunhorst and Andreas Berghänel, for the statistical and personal support, sharing experiences, understanding and encouragement and creating a wonderful climate to work in, and of course Markus Port for being a great office mate! Thanks also to the "next generation", Sonia Touitou, Sofia Vilela and Simone Anza, James Stranks and Niels Kil for the brief but fun time we shared in the department!

And of course my fellow Ph.D. students and Post-Docs who shared a part of journey: Daria Gutleb, the most hardworking, single-minded and organized fellow Ph.D. I could imagine, who never failed to build me back up when I was struggling. Anja Ebenau, who will just be there if you need a hand without you even having to ask for it. Alan Rincon, course the greatest cat sitter I ever had, who saved me countless hours of work by just sharing his R knowledge, and who endured all my ranting and need for discussion and chatting patiently. And Delphine de Moor, who is wise beyond her years (although I think she'd say it's not true) and always ready to share wisdom, kindness and a good deep conversation when you need it the most. Thanks to Adeelia Goffe, Katja Brodmann, Barbora Kubenova, Pascal Marty, Cedric Girard-Buttoz, Lauren Cassidy, Laurianne Faraut, Anna Sperber, Klara Kittler, Lisa Danish, Sara Placi, Vanessa Wilson, and 
Laura di Paolo for the companionship and the many fun hours inside and outside of the office, making Göttingen a home and a place to enjoy staying in. And for those nights I laughed so hard with you I had sore muscles in my cheeks! Special thanks go to Federica Dal Pesco and Matthis Drolet, for the many conversations, the understanding, constantly encouraging me to join in social activities, for introducing me to podcasts (Matthis, you changed my life with that, probably to everyone else's annoyance $(;)$ )... I am just glad I met the two of you!

And of course a huge thank you from the heart and hug to Eva Maria Rathke, who changed my life in several, positive ways. Thank you for helping me focus more on the things I tend to neglect in the busy race of (Ph.D.) life. And for your openness and honesty, and living the change I want to see. It was more helpful to me than you can imagine to have those conversations, and I am incredibly glad to have had you around to share these lessons, and some of the greatest pleasures in life: Swimming, tea and pizza!!!

I want to thank all the members of the SoHaPi group, Antje Engelhard, Dietmar Zinner, Sascha Knauf, Conelia Kraus, Claudia Fichtel, Fabian Leendertz, Sèbastien CalvignacSpencer, Verena Behringer, Tobias Deschner, Roman Wittig and Cathy Crockford for the insights, discussions, ideas, and all the shared wisdom concerning not only science, but also surviving in the academic world. I especially want to thank my fellow SoHaPi students and PostDocs, Andrea Springer, Doris Wu, Filipa Paciência, Therese Löhrich, Katja Rudolph and Celine Bret, for working as a team, sharing the journey, rocking conferences and workshops, exchanging ideas, learning and growing together. A huge hug goes to Charlotte Defolie, and of course her family! Thank you for the friendship, the strolls in the sun and conversation about what our primates actually do and what it means for their health, the precious moments seeing the little one grow, and learning first hand that science and family are not mutually exclusive, which is incredibly reassuring. All the best!

And last but not least from the work-part of life, those who helped me navigate the complex ways of administration and organization and made sure I didn't forget filling in forms and handing in stuff in time: Clarissa Licht, Martina Plaettner, Rebecca Jürgens, and Christian Schloegl. Thank you for your reminders, patience and keeping me out of administrative troubles, always!

I also want to thank all the friends, fellows and companions who shared at least a part of the way with me and made my life so much more interesting, enjoyable, exciting and colourful, and ensured not only my imagination and sometimes sanity, but also made sure that I never got completely lost in my Ph.D. thesis and kept at least one foot in the real world - or various imaginary ones: Jan and Steffi Hoeber, for making every hour spent together feel like a minute, but at the same time like two weeks of holidays, and their kids for being just the most amazing, fascinating little humans. Jochen Pausch and Janina Shhadeh for sharing my craziness and nerdism, food, laughter, sunshine and deep conversations. The members of the Book Club in Marburg for widening my horizon every time we meet and making me love books more (which I didn't think was possible), everyone from Herbstwind and the Björnar-Sippe for the absolutely fantastic holidays from the presence each year, and my Pen and Paper Groups, who I shared the most crazy, fun and intense adventures with, both in Aventurien and Myranor. Special thanks also go to my hiking companions 
for those wonderful days of just being in the moment in the grandiose landscape of the mountains, particular Andreas Schneider for the continued friendship and staying in touch, never mind the distance, and Eiko Woesner, who made me search for answers to questions I never asked myself, taught me that making others happy is a way to save the world and managed to build me up when I felt I hit the bottom. Every. Single. Time!

I also want to thank, from the bottom of my heart, soul and being, those amazing friends who I have known for years, sometimes even for longer than I can remember, who showed me that friendship is not limited by time and space, but that social bonds can bridge any distance: Sabine Stanik, Jasmin Müller, Susanne Nusser, Brandon Morrell, Christian Kliemann, Verena Baumgart, Emma Geiser, and Sandra Pfeifer: You are amazing people and rock-solid foundation of support, confidence, security, building me up when I am. Knowing you is that piece of home that I can always return to and that allows me to go out into the world and seek new horizons. I don't have words to adequately express what you have done for me throughout all these years, but looking back, I am sure I would not be alive today if it wasn't for you, honestly and literally. You are how I know about the power of friendship - now I just need to figure out the "why" of it, in an evolutionary sense $\odot$.

And of course I want to thank the people without whom I wouldn't even be here: my family, who has been a constant resource of reassurance, back up and support. Undoubtedly I would not have made it to where I am today without them. My grandmother Marianne Breuer, who was always unconditionally supportive, kind, caring (unconditionally as in sometimes she doesn't even care if you WANT support (:), and taught me to never be held back by others' opinions (well, she tried (:) and instead go my own way.

My father, Reiner Müller, for his quick wit and sense of humour, his unrelenting positive view on the world, for always showing up, literally and metaphorically, to support me if I needed a helping hand, for the unconditional faith in my capability to manoeuvre this crazy, wonderful thing called life.

My sisters, Nicole Spies and Ann-Kathrin Müller, for sticking together when it matters, for being the amazing, admirable women you are. Nicky, you manage your life in a way I feel I never could, as you always know exactly what you want (I feel I hardly ever do), and I admire your singlemindedness, your dedication, your incredibly big heart and your readiness to always be right there for others, and to back me up despite all the differences between us. Kathrinchen, you remind me so much of who I was when I was young, but you are stronger, smarter and more creative than I ever felt I was. I am glad you are my little sister, and although I never reacted appropriately, I never forgot you said you were proud of what I am doing, and how much it meant to me and helped me going on when I was doubting myself - I am proud of you too, little one!

And of course, my mother, Monika Müller: because my mum is a f***ing hero, and I never say or express it enough! If for my own family I will manage to do half as well a job of keeping everyone together in face of difficult times, if I can muster half the strength, dedication, ingenuity to 
find solutions and capability to see the positive side of things rather than complaining, I will be glad. Thank you for everything! I will try to live up to your example, just a little, every day!

Family is not only two legged household members, but of course also the four legged kind, as a constant source of cuddles, emotional support and reasons to smile. So honourable mentions to Momo, Sando, Lucky, Arya, Findus and most of all my M\&Ms, Morrigan and Matatabi, because taking those two into my home was the best decision since - I don't even know when! Of course, it's not like they will care, they just love, either way!

And last but not least, Marcel Klein, for everything! Someone else said it better than I ever could, I thought I wouldn't even try to say more here, I will just leave it to the professionals:

Ich kann maximal betrübt sein, oder maximal beschwingt; ich bin der, der endlos schweigt und der, der laute Lieder singt;

ich kann maximal verletzen und bin maximal verletzt, meine Ängste sind gewaltig, doch meine Hoffnung stirbt zuletzt.

Meine Geduld, die ist unendlich, doch ich halte es nicht aus, wenn man in 1000 Worten sagt, Wofür es gerade mal 3 braucht... Ich bin ein riesengroßer Eisberg, schmelz' genau so schnell dahin;

Ich brauch' grenzenlose Freiheit, solange ich nicht einsam bin!

Ich stehe felsenfest im Leben, treibe ziellos auf dem Meer, mach's mir gerne kompliziert, wo es doch oftmals einfach wär';

ich bin ein hoffnungsloser Träumer, und knallharter Realist ganz sicher nehm ich jede Hürde, wenn nur du an meiner Seite bist!

Ich verlier' mich in Gedanken, du holst mich wieder zurück, denn als die eiserne Konstante habe ich Dich, mein grösstes Glück; mein Leben ist wie eine Strasse, die führt mich immer wieder Heim Denn auch in allergrösster Ferne möchte ich - an Deiner Seite sein...

An deiner Seite, (C) Schandmaul (aka the best band in the world - thanks to the band for allowing me to use their lyrics here!)

Thank you - for believing in me when I do not believe in myself, for loving me when I hate myself, for understanding when I cannot not understand myself, for sticking with me when I can be so difficult... For teaching me maybe the most important lesson I learned in life, which I am still trying to implement: To appreciate the wonderful things we have and be grateful rather than fearful, for no one can take away the wonderful moments you already experienced, unless you do it yourself. Aim high, dream higher, and then the sky is the limit. To all those wonderful days, and all the ones still to come! 


\section{Curriculum Vitae}

Name: Nadine Erika Müller

Date of birth: $26^{\text {th }}$ of September 1987

Place of birth: Roth, German

Nationality: German

\section{Education}

06/14 - 08/18 Ph.D. program "Behaviour and Cognition"; University of Göttingen, Germany Thesis title: The costs and benefits of sociality in semi-free ranging Barbary macaques (Macaca sylvanus)

Supervisors: Dr. Julia Ostner, Dr. Oliver Schülke

Dept. of Behavioural Ecology, University of Göttingen, Germany

10/10 - 01/13 M. Sc. program "Master of Developmental, Neural and Behavioural Biology" University of Göttingen, Germany

Focus: Neuro- and behavioural biology, graduation with honours, grade 1.0

Master thesis: Analysis of wild Assamese macaque MHC-DRB

10/07 - 06/10 B. Sc. program "Biomedical Science (Humanbiologie)"

Philipps-University Marburg, Germany

Focus: Neurobiology, graduation grade 1.7

Bachelor thesis: Regulation of hTRPV4 by intracellular calcium concentration

\section{Employment and research experience}

02/13 - 05/14 Dept. of Behavioural Ecology, University of Göttingen, Germany:

Teaching assistant: Course "social behaviour and communication"

Research assistant: Literature research and grant writing for DFG Research Unit

SoHaPi (FOR 2136)

\section{Peer reviewed articles}

2019 N. Müller, M. Heistermann, C. Strube, M. Franz, O. Schülke, J. Ostner. Exposure and susceptibility drive reinfection with gastrointestinal parasites in a social primate. Function Ecology, doi: 10.1111/1365-2435.13313

2018 N. Paschek, N. Müller, M. Heistermann, J. Ostner, O. Schülke. Subtypes of aggression and their relation to anxiety in Barbary macaques. Aggressive Behavior, 45(2), 120-128

N. Müller, M. Heistermann, C. Strube, Z. Morbach, N. Lilie, M. Franz, O. Schülke, J. Ostner. Physiological and social consequences of gastrointestinal nematode infection in a nonhuman primate. Behavioral Ecology, doi:10.1093/beheco/ary168

N. Müller, M. Heistermann, C. Strube, O. Schülke, J. Ostner. Age, but not anthelmintic treatment, is associated with urinary neopterin levels in semi-free ranging Barbary macaques. Scientific Reports, doi:10.1038/srep41973 


\section{Conference contributions}

Symposium organization: "Host-pathogen interactions: from sociality to susceptibility"; 35th International Ethological Conference \& Summer Meeting of the Association for the Study of Animal Behaviour, Estoril, Portugal

N. Müller et al. Macaques, sociality and parasites - (How) do social interactions predict parasite infection? (oral presentation)

7th European Federation for Primatology Meeting, Strasbourg, France

N. Müller et al. Macaques, sociality and parasites - (How) do social interactions predict parasite infection? (invited talk)

Meeting of the German Veterinary Medicine Society, Hannover, Germany

N. Müller et al. The connection between health, age, and parasite infection in semifree ranging Barbary macaques at Affenberg Salem. (oral presentation)

15th Conference of the Primatological Society (Gesellschaft für Primatologie), Zürich, Switzerland

N. Müller et al. Physiological and social consequences of gastrointestinal parasite infection in semi-free ranging Barbary macaques. (oral presentation)

2016 26th Meeting of the International Primatological Society, Chicago, USA

$\mathbf{N}$. Müller et al. Effect of experimental anthelmintic treatment on urinary C-peptides in semi-free ranging Barbary macaques (Macaca sylvanus) at Affenberg Salem. (oral presentation)

14th Conference of the Primatological Society (Gesellschaft für Primatologie), Leipzig, Germany

N. Müller et al. Comparing social networks before and after experimental deworming in Barbary macaques at Affenberg Salem. (poster)

2013 IX. Göttinger Freilandtage: The Sociality-Health-Fitness Link, Göttingen, Germany N. Müller et al. Towards the non-invasive assessment of MHC genotype in wild primates - Analysis of wild Assamese macaque MHC-DRB from fecal samples. (poster)

9th International Conference on Behaviour, Physiology and Genetics of Wildlife, Berlin, Germany

N. Müller et al. Towards the non-invasive assessment of MHC genotype in wild primates - Analysis of wild Assamese macaque MHC-DRB from fecal samples. (poster)

\section{Grants}

2018

Robert-Glaser-Conference Grant (awarded by the Gesellschaft für Primatologie)

2014 - 2016 Ph.D. Scholarship of the German Academic Scholarship Foundation for excellent students

Actively contributed to grant writing for DFG-Research Unit Sociality and Health in Primates (SoHaPi); PI Julia Ostner

Research scholarship of the Gerhard-Mazurczak Foundation, Schwabach, Germany 


\section{Fieldwork}

2014 - 2015 Affenberg Salem, Southwest Germany, 12 months

Behavioural data and non-invasive faecal and urine sample collection in semi-free ranging Barbary macaques (Macaca sylvanus)

Laboratory work: Preparation of larval cultures, faecal egg counts (McMaster flotation)

Supervisors: Dr. Julia Ostner, Dr. Oliver Schülke, Dept. of Behavioural Ecology, University of Göttingen, Germany

2011 Ifrane National Park, Morocco, 1.5 months

Behavioural data collection on wild Barbary macaques (Macaca sylvanus)

Supervisors: Dr. Julia Ostner, Dr. Oliver Schülke, Dept. of Behavioural Ecology, University of Göttingen, Germany

Estacion Biologia Quebrada Blanco, Peru, 1 month

Behavioural data collection on wild Saddleback tamarins (Sanguinus fuscicollis)

Supervisor: Dr. Eckhard W. Heymann, Dept. of Sociobiology and Anthropology, University of Göttingen, Germany

\section{Laboratory experience}

2016 - 2017 Genetic parasite analyses, 3 months

Polymerase chain reaction, gel electrophoresis, Sanger sequencing

Supervisor: Dr. Christina Strube, Institute for Parasitology, University of Veterinary Medicine, Hannover, Germany

2016 Field endocrinology workshop, supervised by Dr. Tobias Deschner, Dept. of Primatology, Max Planck Institute for Evolutionary Anthropology, Leipzig, Germany,

Molecular genetics and epidemiology workshop, supervised by Dr. Fabian Leendertz, Epidemiology of Highly Pathogenic Microorganisms Group, Robert Koch Institute, German National Institute of Health, Berlin, Germany

2015 - 2016 Microscopic parasite analyses, 7 months

McMaster flotation, morphological identification of L3 larvae from larval cultures Supervisor: Dr. Christina Strube, Institute for Parasitology, University of Veterinary Medicine, Hannover, Germany

MHC-DRB genotyping of Assamese macaques (Macaca assamensis), 6 months Polymerase chain reaction, gel electrophoresis, microsatellite analysis, Sanger sequencing

Supervisors: Dr. Lutz Walter, Dr. Christian Roos, Primate Genetics Laboratory, German Primate Centre, Göttingen, Germany

2009 - $2010 \quad$ Electrophysiology, 6 months

Cell culture, transfection, patch clamp

Supervisors: Dr. Timothy Plant, Dr. Frauke Kepura, Pharmacological Institute, Philipps-University Marburg, Germany 


\section{Data analysis skills}

$\mathrm{R}$

Advanced: Data processing and visualization, linear mixed modelling, social network analysis

Basic: Patch occupancy modelling \& information theory based model selection (collaboration with Dr. Mathias Franz, Dept. of Wildlife Diseases, Institute for Zoo and Wildlife Research, Berlin, Germany),

\section{Teaching}

2014 - 2015 Training and supervision of master students and international field assistants

2013

Teaching assistant "social behaviour and communication" course

\section{Further qualifications}

Organization Coordination of team of 6 field assistants (Ph.D. project), 2014 - 2015

\& Organization of "SoHaPi" meetings, retreats and student workshops, $2014-2017$

administration Organization of the CRC Evolution of Social Behaviour Ph.D. workshop, 2014

Languages German, native

English, fluent (Cambridge Certificate in Advanced English Level C1)

Latin, advanced (5 years)

\section{Memberships}

Primatological Society (Gesellschaft für Primatologie)

International Primatological Society

Ethological Society (Ethologische Gesellschaft)

Göttingen, $2^{\text {nd }}$ of July 2018

Nadine Müller 


\section{Declaration}

I hereby declare that all parts of my thesis titled "The costs and benefits of sociality in semi-free ranging Barbary macaques (Macaca sylvanus)" were written by myself. Assistance of third parties was only accepted if scientifically justifiable and acceptable in regards to the examination regulations. Assistance or contributions to the individual chapters are indicated and all sources have been quoted.

Göttingen, $2^{\text {nd }}$ of July 2018

Nadine Müller 